\title{
Notes on Craspedophorus (Coleoptera: Carabidae: Panagaeini) from Vietnam, with description of new species and subspecies
}

\section{Заметки о роде Craspedophorus (Coleoptera: Carabidae: Panagaeini) из Въетнама с описанием новых видов и подвидов}

\author{
D.N. Fedorenko \\ A.H. Федоренко
}

\begin{abstract}
A.N. Severtsov Institute of Ecology and Evolution, Leninsky pr. 33, Moscow 119071, Russia.
Институт проблем экологии и эволюции им. А.Н. Северцова, Российская Академия Наук, Ленинский пр-т, Москва 119071, Россия, dmitri-fedorenko@yandex.ru
\end{abstract}

KEY WORDS: Coleoptera, Carabidae, Craspedophorus, new species, new synonym, key for identification, Vietnam.

КЛЮЧЕВЫЕ СЛОВА: Coleoptera, Carabidae, Craspedophorus, новый вид, новый синоним, определительная таблица, Вьетнам.

ABSTRACT. Five new species groups and one new subgroups of Craspedophorus Hope, 1838 are defined and keyed. Ten new species and subspecies, $C$.dalatensis sp.n., C. d. abramovi ssp.n., C. d. kruskopi ssp.n., $C$. breviceps sp.n., C. pallidicornis sp.n., C. kabakovi sp.n., C. sparsepunctatus sp.n., C. expansicollis sp.n., and $C$. crebrepunctatus sp.n., all from Vietnam, and $C$. affinis sp.n. from Laos, are described. Craspedophorus basifasciatus (Chaudoir, 1869) is downgraded to a subspecies of $C$. saundersii (Chaudoir, 1869). The following new synonyms are proposed: $C$. saundersii basifasciatus (Chaudoir, 1869), stat.n. $=C$. neglectus Kirschenhofer, 2000, syn.n., =C. yalaensis Kirschenhofer, 2010, syn.n., = C. khaoyai Häckel et Kirschenhofer, 2014, syn.n.; C. mandarinellus (Bates, 1892) $=C$. vietnamensis Kirschenhofer, 2000, syn.n., =C. freudeellus Häckel et Kirschenhofer, 2014, syn.n.; C. alaticollis (Bates, 1892), comb.n. = Dischissus baehri Kirschenhofer, 2000, syn.n.; C. chaudoiri (Andrewes, 1919), comb.n. = Dischissus formaster (Andrewes, 1936), syn.n.; C. cereus (MacLeay, 1825) $=C$. buruensis Häckel et Kirschenhofer, 2014, syn.n.; C. formosanus Jedlička, 1939, syn.n., = C. chinensis Jedlička, 1965, syn.n., = C. saddlepeakensis Kirschenhofer, 2011, syn.n., $=C$. laosensis Kirschenhofer, 2012, syn.n., $=C$. punensis Häckel et Kirschenhofer, 2014, syn.n., $=C$. batesi Häckel, 2016, syn.n.

РЕЗЮМЕ. В роде Craspedophorus Норе, 1838 выделены 5 новых видовых групп и 1 новая подгруппа, составлена таблица для их определения. Описаны 10 следующих новых видов и подвидов: $C$. dalatensis sp.n., C. d. abramovi ssp.n., C. d. kruskopi ssp.n., $C$. breviceps sp.n., $C$. pallidicornis sp.n., $C$. kabakovi sp.n., C. sparsepunctatus sp.n., $C$. expansicollis sp.n., и C. crebrepunctatus sp.n. из Вьет- нама и $C$. affinis sp.n. из Лаоса. C. basifasciatus (Chaudoir, 1869) понижен в ранге до подвида $C$. saundersii (Chaudoir, 1869). Установлена сдедующая синонимия: C. saundersii basifasciatus (Chaudoir, 1869), stat.n. = C. neglectus Kirschenhofer, 2000, syn.n., $=C$. yalaensis Kirschenhofer, 2010, syn.n., $=C$. khaoyai Ндсkel et Kirschenhofer, 2014, syn.n.; $C$. mandarinellus (Bates, 1892) $=C$. vietnamensis Kirschenhofer, 2000, syn.n., = C. freudeellus Ндckel et Kirschenhofer, 2014, syn.n.; C. alaticollis (Bates, 1892), comb. n. = Dischissus baehri Kirschenhofer, 2000, syn.n.; C. chaudoiri (Andrewes, 1919), comb.n. = Dischissus formaster (Andrewes, 1936), syn.n.; $C$. cereus (MacLeay, 1825) $=$ C. buruensis Häckel et Kirschenhofer, 2014, syn.n.; C. formosanus Jedlička, 1939, syn.n., $=C$. chinensis Jedlička, 1965, syn.n., $=C$. saddlepeakensis Kirschenhofer, 2011, syn.n., $=C$. laosensis Kirschenhofer, 2012, syn.n., = C. punensis Häckel et Kirschenhofer, 2014, syn.n., = C. batesi Häckel, 2016, syn.n.

\section{Introduction}

Craspedophorus Hope, 1838 is a speciose genus widespread from Africa to Australia yet especially species-rich in the Paleotropical realm. The Oriental Region has over 80 species, including numerous recently described [Kirschenhofer, 1996, 2000, 2004, 2010, 2011a,b, 2012a,b; Pang, Tian, 2012; Häckel, Kirschenhofer, 2014b; Häckel, Anichtchenko, 2015]. Many species and species groups included in Craspedophorus are very distinctive in appearance, as well as in those structural characters that are used to define genus-group taxa in many other carabid tribes, including shape of the labrum and mandibles, shape and chaetotaxy of the 
maxillary and labial palps, length ratio of basal antennomeres, length of metepisterna, etc. However, the species groups were defined based mostly on external characters of little importance. A treatment that stands out is that of Chaudoir [1879], who based his classification of Panagéides upon a variety of characters, including details of the mouthparts, length of the metepisterna, sculpture of the abdominal sterna, etc.

The most recent taxonomic developments are as follows. Lorenz [1998] synonymized Brachyonychus Chaudoir, 1879 under Craspedophorus and downgraded six species of the former to subspecies of a single species. Häckel \& Farkač [2012] adopted that treatment, even though Kirschenhofer [2000] had disregarded it. He also outlined the polytypic microspilotusgroup and the oligotypic nepalensis-group by merely listing species rather than providing detailed diagnoses. Quite recently, Häckel \& Kirschenhofer [2014a, b] transferred the sapaensis-group from Dischissus to Craspedophorus and introduced further nine species groups in the latter. Fedorenko [2015] transferred the elegans-group from Craspedophorus to Microcosmodes Strand, 1936 and the guttiferus-group from Dischissus Bates, 1873 to the microspilotus-group of Craspedophorus. As a result, Craspedophorus is currently subdivided into 12 species groups in total.

In this paper we describe new species from the Oriental Region, chiefly Vietnam, and clarify relationships between some species and species groups.

The vast majority of the material has been collected during a number of expeditions to several areas in Vietnam sponsored by the Joint Russia-Vietnam Tropical Center. Material examined is curated in the following collections: Natural History Museum, London (BMNH); private collection of Martin Häckel, Prague (CH); Museo Civico di Storia Naturale Giacomo Doria, Genova, Italy (MSNG); author's reference collection at A.N. Severtsov Institute of Ecology \& Evolution, Russian Academy of Sciences, Moscow (SIEE); Siberian Zoological Museum of the Institute of Animal Systematics \& Ecology, Siberian Branch of the Russian Academy of Sciences, Novosibirsk (SZMN); Zoological Institute, Russian Academy of Sciences, St. Petersburg (ZISP); Zoological Museum of the Moscow State University (ZMMU).

All the labels are printed, unless marked '[hw]' (= handwritten). Data on labels of type specimens are in quotes, each line separated with a slash.

The following parameters were analyzed: $\mathrm{AnL}$ lengths of antennomeres 1 to $4(\mathbf{n}=1,2,3,4)$; used in the antennal ratio $(\mathrm{AR}=\mathrm{A} 1 \mathrm{~L} / \mathrm{A} 3 \mathrm{~L}: \mathrm{A} 2 \mathrm{~L} / \mathrm{A} 3 \mathrm{~L}: \mathrm{A} 4 \mathrm{~L} /$ A3L); BL - maximum body length measured between apices of closed mandibles and elytra; EL — maximum length of elytron; ES3L - length of metepisternum along outer margin; ES3W - width of metepisternum along anterior margin; EW - maximum width of elytra; HW - maximum width of head across eyes; OL length of eye tubercle (eye and gena combined) measured from middle of preocular concavity to the neck in dorsal view; PL - length of pronotum along mid-line;
PLw - distance between level of maximum width and apex of pronotum, measured along mid-line; PW maximum width of pronotum; PWa - width of pronotum at apex (between apical angles); PWb - width of pronotum at base (between basal angles); LL - length of greater apical lobe of respective tarsomere 4 in proportion to $\mathrm{nT} 4 \mathrm{~L}$ - lengths of pro- or metatarsomere 4 ( $\mathbf{n}=1$ and 3 , respectively).

Measurements were taken using an eyepiece micrometer, to two decimal places. Unless otherwise indicated, the number of specimens measured (n) is only given for the first ratio in the description.

\section{Results}

\section{Craspedophorus Hope, 1838}

Häckel \& Kirschenhofer [2014b] treated Craspedophorus as the genus subdivided into 13 species groups in the Oriental fauna, all defined mainly based on coloration, size and shape of the body, pronotum, elytra and elytral maculae, with no consideration of many important characters, such as shape of the labrum, chaetotaxy of the labrum and labials, shape of the mandibles and terminal labial palpomere, shape and structure of the male genitalia, etc.

A wider comparative analysis across the genus (mainly the Oriental fauna) using these characters has led me to slightly different results, so the species groups I recognize within the genus not always match those established by earlier workers.

Also, many Oriental species share a conspicuous microsculpture of the forebody dorsum including the labrum and the exposed parts of closed mandibles, the neck being either rugose or coarsely punctate and the penultimate labial palpomere subtriangular and plurisetose at inner margin, i.e., with three or more setae arranged in a subtransverse row. Parameres of the aedeagus have been found to vary considerably in shape, and the right paramere also in how much its apical pubescence is developed. Most large- to small-sized species have the paramere indistinctly ciliate to glabrous, whereas a few medium-sized species have the paramere clearly pubescent with long and dense (Figs 54, 56) to short and sparse (Figs 60, 98) setae. Sometimes, e.g., in C. saundersii (Chaudoir, 1869), this character varies between populations and probably also between individuals, so that the parameres are generally glabrous (Figs 95-97), but clearly, albeit sparsely and shortly, pubescent in some males from several local populations (as in Fig. 99). Because a sparsely pubescent right paramere has also been found in some Microcosmodes [Fedorenko, 2015], clarifying the taxonomical significance of this character would require a comparative analysis across the Panagaeini.

A key to species groups recorded in Vietnam is proposed below. The brackets mark the groups/subgroups that are present in the Oriental Region yet have not been recorded in Vietnam.

KeY to SPECIES GROUPS OF CRASPEDOPHORUS FROM VIETNAM

1(14) Apterous, with metepisterna clearly wider than long. Head, labrum and exposed parts of mandibles with a conspicuous isodiametric microsculpture. Neck rugose or coarsely punctate, or both. Labrum deeply emarginate, with medial pair of setae equidistant from base and apex. Body usually large to very large. Elytra with setigerous pores in interval 3 and often also in intervals 5 and 7. 
2(7) Head attenuate, mostly more than twice as narrow as pronotum, with at least frontoclypeal area convex between frontal foveae. Penultimate labial palpomere at inner margin with a triangular preapical dilatation bearing 3 or more long setae. Terminal labial and maxillary palpomeres with inner margin much shorter than apex. Protibia with 4-7 spines at apex of posterolateral edge. Pronotum with posterolateral seta in basal angles and several anterolateral setae in basal two thirds, often combined with long yet sparse setae in anterior half of disc. Parameres glabrous apically.

3(4) Scape slightly shorter than eye, A1L/OL ca. 0.8. Neck constriction deep, very convex forward, its apex at the level of eye mid-length. Clypeus, frons and vertex very convex between frontal foveae. Pronotum small and very convex. Dorsal pubescence dense and very long. Abdominal sterna crenate along extreme bases. Elytral maculae short, transversely semifasciate ................... [the angulatus-group]

4(3) Scape slightly longer than eye, A1L/OL ca. 1.2. Neck constriction behind eyes, straight to barely convex forward, moderately deep to missing. Only frontoclypeal area moderately convex between frontal foveae. Pronotum large and rather flat. Dorsal pubescence shorter, dense to almost absent. Abdominal sterna neither crenate nor punctate along bases. Elytral maculae longer and less transverse .................................. 2. the sublaevis-group

5(6) Tarsi short and fairly wide; tarsomere 4 deeply emarginate, LL/3T41 $\sim 0.5$. Body very large, $23.5-30 \mathrm{~mm}$ in length, densely pubescent to almost glabrous. Neck constriction moderately deep to missing. Abdominal sternites IV-VI with 2-3 pairs of ambulatory setae

the sublaevis-subgroup

6(5) Tarsi of normal length and width; tarsomere 4 slightly emarginate, LL/3T41 $\sim 0.25$. Body smaller, $18.5 \mathrm{~mm}$ in length, densely pubescent. Neck constriction missing. Abdominal sternites IV-VI with one pair of ambulatory setae .......................... [the brevisternis-subgroup nov.]

7(2) Head short, wide to very wide, and flattened. Penultimate labial palpomere subcylindrical (more or less parallelsided in lateral view), with two subequally long setae at inner margin (by way of exception, slightly dilated apicad and with 4 setae at most). Abdominal sterna neither crenate nor punctate along bases.

8(13) Antennae long, scape 1.30-2.15 times as long as eye tubercle. Head moderately large, eyes small and protruding. Genae subtransverse, short to very short, meeting neck at acute to right angle, glabrous in dorsal view. Labrum subconvex, without impressions. Body smaller, 12-23 mm. Penultimate labial palpomere cylindrical, usually bisetose at inner margin. Aedeagus median lobe with apical lamella very short and truncate in dorsal view; internal sac with a moderately large apical sclerite; parameres pubescent or at least setulose apically.

9(12) Neck constriction conspicuously convex forward and moderately deep; neck rugose to rugose-punctate (Figs 24 $25,29)$. Antennae long to very long, with scape $1^{2 / 3}$ to more than twice as long as eye. Pronotum cordate to subcordate and long, less than $1^{1 / 3}$ as wide as long, with lateral margins widely explanate and usually strongly reflexed. Parameres finely and rather sparsely setulose at apex.

10(11) Pronotal basal flange thick in posterodorsal view. Antennomere 3 with numerous long and sparse erect setae proximal to verticellate ones. Scape slightly concave in basal third to half of anterior margin; antennomere 4 about a half as long as 3. Last labial palpomere with apex as long as or longer than inner margin in male while shorter in female. Basal orifice of aedeagus median lobe extended into a long and wide dorsal slot. Anterior elytral macula reaching epipleuron. Protibia with 2-4 spines irregularly set at apex of posterolateral edge... 4. the lykaon-group.

11(10) Pronotal basal flange thin in posterodorsal view. Antennomere 3 without long and sparse erect setae other than verticellate ones. Scape subconvex at base of anterior margin; antennomere 4 more than two thirds as long as 3 . Last labial palpomere with apex shorter than inner margin in both sexes. Anterior elytral macula inside stria 9. Protibia with three spines at apex of posterolateral edge. Basal orifice of penis with very small, short and narrow dorsal slot .............. 7. the crebrepunctatus-group nov.

12(9) Neck constriction convex to subconvex forward and very deep; neck mostly rugulose to almost smooth (Figs 26-27). Antennae shorter, scape 1.30-1.55 (rarely up to 1.71) times as long as eye tubercle. Pronotum mostly subhexagonal and shorter in general, $1^{1 / 3}-1^{1 / 1} / 2$ as wide as long, with lateral margins widely explanate yet only slightly reflexed. Anterior elytral macula reaching epipleuron. Posterolateral edge of protibia with three apical spines and one preapical spine. Parameres with long and dense pubescence at apex (Figs 54, 56) ......................... 5. the pallidicornis-group nov.

13(8) Antennae rather short, scape less than $1 \frac{1}{4}$ as long as eye tubercle. Head very large, with eyes small and flattened (Figs 28-29). Genae oblique and long, 0.35-1.43 times as long as eye, meeting neck at very obtuse angle, clearly pubescent in dorsal view. Labrum with a pair of wide and round paramedian impressions. Anterior elytral macula inside stria 9. Body large, 23-28 mm in length; elytral intervals sparsely and irregularly pubescent. Penultimate labial palpomere slightly dilated apicad, bi- to plurisetose at inner margin. Protibia with 2-4 spines at apex of posterolateral edge. Apical lamella of aedeagus median lobe large and triangular in ventral view; internal sac with a very large apical sclerite ........... 6. the sparsepunctatus-group nov.

14(1) Metepisterna as long as or longer than wide. Abdominal sterna crenate along bases.

15(18) Penultimate labial palpomere broadened apicad; a preapical subtriangular dilation of its inner margin with three or more stronger setae and often also with a few additional shorter setae proximal to them. Head, labrum and exposed parts of mandibles with a conspicuous isodiametric microsculpture. Labrum subconvex, deeply emarginate at apical margin, with medial pair of setae equidistant from base and apex. Pronotal chetotaxy as in couplet 2. Elytral intervals 3,5 and 7 with setigerous pores. Entire dorsum very densely pubescent. Scape barely shorter than eye tubercle, A1L/OL 0.78-0.95. Protibia with 6-8 spines at apex of posterolateral edge. Body large, $15.5-21 \mathrm{~mm}$.

16(17) Head attenuate, with clypeus to vertex strongly raised between frontal foveae; neck mostly rugose. Mandibles with outer margin strongly rounded at apex, much less rounded at base and nearly straight in between. Dorsal pubescence long, combined with sparse yet very long setae over pronotum and elytral base. Metepisterna long, about 1.4 times as long as wide. Elytral maculae semifasciate. Macropterous .............. 1. the mandarinus-group

17(16) Head short and wide, flat to subconvex, coarsely and closely to confluently punctate except on clypeus. Mandibles at outer margin evenly rounded, much more rounded at base of lower scrobal ridge. Elytral pubescence fairly short. Metepisterna less than $1 \frac{1 / 4}{4}$ as long as wide .......... .. 3. the mouhotii-group nov. 
18(15) Penultimate labial palpomere parallel-sided or almost so and generally bisetose at inner margin. Labrum subconvex to flat, with extreme apical margin strongly deflexed medially, vertical; medial pair of setae situated close to apex. Protibia with 2-3 spines at apex of posterolateral edge. Pronotum generally bisetose each side. Elytral mostly with two setigerous pores in the middle third of interval 3. Body smaller, $8.5-16.3 \mathrm{~mm}$.

19(20) Labrum flat and nearly truncate apically (Fig. 30). Mandibles flat and evenly rounded at outer margin. Neck either rugose to rugulose or coarsely and sparsely punctate in anterior half. Scape barely shorter to indistinctly longer than eye tubercle. Head and mandibles otherwise as in couplet 15. Tarsomere 4 slightly emarginate. Metepisterna barely wider than long, ES3L/W 0.80-0.96. Apterous

8. the basifasciatus-group

20(19) Labrum subconvex, clearly emarginate to bilobed apically. Mandibles strongly curved inwards at tip, subangulate at base, with outer margin barely convex to concave. Scape 1.09-1.30 times as long as eye tubercle. Clypeus and neck glossy from microsculpture absent to indistinct, sometimes slightly rugulose in anterior half or with several coarse punctures. Tarsomere 4 slightly emarginate to bilobed. Metepisterna 1-1.4 (or more) times as long as wide. Usually macropterous .......... 9. the microspilotus-group

21(22) Tarsomere 4 slightly emarginate. Body slender to fairly wide. Metepisterna as long as to clearly longer than wide. Head narrow to moderately wide.

the microspilotus-subgroup

22(21)Tarsomere 4 deeply emarginate to bilobed. Body slender. Metepisterna clearly longer than wide. Head moderately wide .............................. the sapaensis-subgroup

\section{The mandarinus species group}

COMMENTS. This group has been established by Häckel \& Kirschenhofer [2014b] for nine species, including four described by the authors.

The nominate species of the group, C. mandarinus (Schaum, 1853), is similar to and shares many characters with $C$. angulatus (Fabricius, 1781) from India, a sole member of its group. The body is wide and very convex in both, the pronotum small and hardly explanate laterally, the head attenuate, the pubescence very long and dense, the elytral maculae are semifasciate, wide and short, the posterior one extending posterad along sides (more clearly in C. angulatus, slightly in $C$. mandarinus). The main difference is that the adults are apterous in $C$. angulatus vs. macropterous in $C$. mandarinus, resulting in short or long metepisterna, respectively. This may suggest a closer relationship between the two species than between each of them and any other Oriental species. The mandarinus-group is thus likely a subgroup of the angulatus-group.

Furthermore, $C$. mandarinus has for a long time been recognized as a widespread species ranging west to Myanmar and east to Japan. Häckel \& Kirschenhofer [2014b] described three new species, $C$. huensis, $C$. jakli, and $C$. horaki, from within the species range of $C$. mandarinus, restricting the latter to the area east of (and including) Vietnam. Diagnoses of these four species were used in the key showing only slight differences between them in shape of the pronotum and sometimes also of the anterior elytral macula.

Yet these characters vary considerably between local populations of $C$. mandarinus (sensu lato). Specifically, the pronotum tends to become narrower relative to both the elytra and the head both westward and eastward within the species range, resulting in EW/PW 1.68-1.70 in Thailand and Myan- mar, 1.50-1.63 in Laos and Vietnam, and 1.62-1.68 in Japan; the populations from Thailand and Myanmar also show sides of the pronotum increasingly straight in apical half — said to be a distinctive feature of $C$. horaki. Finally, the length and shape of elytral maculae of $C$. huensis are within $C$. mandarinus variation; I have a specimen from Chiang Mai, Thailand, in which the anterior macula is fairly long, with very straight anterior margin.

A comparison between properly prepared male genitalia would show whether the taxa in question are species, subspecies, or just local forms. However, no such comparison was provided, even though the paratype of $C$. horaki and the holotypes of $C$. huensis and C. jakli are male. I believe that the differences between these three or, at least, two forms merely reflect geographic variability of $C$. mandarinus and better be interpreted as infra- rather than interspecific. Hence I recognize $C$. horaki as a subspecies and $C$. huensis as a local form of $C$. mandarinus, i.e., $C$. horaki $=C$. mandarinus horaki, stat.n.; C. mandarinus $=C$. huensis, syn.n. The status of $C$. jakli needs further clarification because of the combination of smaller body size (BL just under $15 \mathrm{~mm}$ ) and fairly wide pronotum (PW/PL 1.44).

Some other species placed by Häckel \& Kirschenhofer [2014] in this group need comments, too. First, C. bifasciatus (Laporte de Castelnau, 1835) and its junior homonym $C$. bifasciatus (Chaudoir, 1861) require no extensive discussion, since nothing was added to what had been said by Andrewes [1919] long ago.

C. pubiger (Chaudoir, 1861) was provisionally placed in this group based chiefly on a wide macula getting longer 'from $4^{\text {th }}$ stria to $1^{\text {st }}$ stria' - certainly based on the misinterpreted re-description of the species [Chaudoir,1879: 122], defined [Chaudoir, 1869, 1878] by the head only a half narrower than the pronotum and by the anterior macula spanning the elytron laterad of stria 3, with the inner four component strips (on intervals 4-7) getting increasingly longer. This character combination excludes this species from the mandarinus-group whose members share a much narrower head (about twice narrower than pronotum) and the anterior macula shaped as a uniformly wide transverse band extending inwards as far as stria 1 or 2 .

C. transversalis (Laporte de Castelnau, 1835). - Häckel \& Kirschenhofer [2014b] positively stated that (1) Chaudoir [1879] synonymized Panagaeus versutus (Laporte de Castelnau, 1835) with Craspedophorus cereus from W-Africa and supposed C. transversalis to originate from W-Africa, and (2) Andrewes [1919] "confirmed Chaudoir's opinion in the case of versutus/cereus".

This second statement is false. First, C. cereus (MacLeay, 1825) was described from Java, not West Africa. Second, neither $C$. versutus nor W-Africa is mentioned in Andrewes [1919]. He examined the type of Panagaeus cereus MacLeay, 1825, and demonstrated that it belongs in Craspedophorus, not Dischissus, contrary to Chaudoir [1879]. Andrewes gave an excellent redescription of C. cereus (MacLeay, 1825) and introduced the name Dischissus chaudoiri Andrewes, 1919 to replace Chaudoir's name (Panagaeus cereus: Chaudoir, $1869=$ Dischissus cereus Chaudoir, 1879). To sum up, MacLeay's species was unknown to Chaudoir who [Chaudoir, 1879] suspected Dischissus cereus (Chaudoir, 1869) to be synomymous with Panagaeus versutus Laporte de Castelnau, 1835. That was subsequently proven not to be the case, and the synonymy Craspedophorus cereus (MacLeay, 1825) $=C$. versutus (Laporte de Castelnau, 1835) [Häckel \& Farkac, 2012] is thus erroneous, too. 


\section{The sublaevis species group}

This group has long been treated as the genus Brachyonychus Chaudoir, 1879 [Andrewes, 1924; Csiki, 1929; Darlington, 1952]. Lorenz [1998] placed that name among junior synonyms of Craspedophorus and downgraded the six species of Brachyonychus to subspecies of C. sublaevis (Chaudoir, 1869). Häckel \& Farkač [2012] shared his viewpoint; Kirschenhofer [2000] has not accepted this change, and also omitted B. s. medius Darlington, 1952 in the list.

I agree with Lorenz's [1998] treatment, further supported by the fact that at least one species, $C$. brevisternis (Bates, 1892), shows traits intermediate between the sublaevis-group and the other Craspedophorus. This obscure species shows all the main characters of the sublaevis-group, except for smaller body and the fourth tarsomere only gently emarginate. I place C. brevisternis in a subgroup of itself. This subroup appears to be the same as the kubani-group [Häckel, Kirschenhofer, 2014] that includes C. kubani Kirschenhofer, 2011 and C. hovorkai Häckel et Kirschenhofer, 2014 (the two may be conspecific).

The status of, and relationships between the subspecies of C. sublaevis need clarification. They are all similar in appearance and differ in elytral pubescence and some other subtle details. In particular, the elytra are impunctate and glabrous on the disc in more western subspecies, but entirely punctatepubescent in the eastern ones, C. s. sublaevis, C. s. punctipennis (Gestro, 1883), and C. s. perraudieri (Bates, 1889). A transitional form, C. s. medius (Darlington, 1952), was described from southern Thailand, and I saw a similar specimen from near the coast of the Gulf of Siam in Cambodia.

Several male specimens examined from various localities in Thailand, Malaysia, Cambodia, and Vietnam show some differences in shape of the internal sac of aedeagus. This makes me inclined to recognizing C. sublaevis and C. laevipennis as separate species, the former apparently eastern while the latter generally western in distribution. Kirschenhofer [1996] recorded both in Saraburi, Thailand, but Häckel \& Kirschenhofer [2014a, b] treated the two taxa as subspecies, with no comment on this partial sympatry.

Craspedophorus sublaevis (Chaudoir, 1869)

Chaudoir, 1869: 67 (Epicosmus; 'Cochinchine'); 1879: 89 (Brachyonychus); Andrewes, 1924: 588; Csiki, 1929: 354; Kirschenhofer, 2000: 323; Darlington, 1952: 126 (s. sublaevis); Lorenz, 1998: 300 (Craspedophorus s. sublaevis); Häckel, Farkač, 2012 : 78; Häckel, Kirschenhofer, 2014b: 362. - ? ssp. humeratus Chaudoir, 1869: 69 (Epicosmus; 'Cochinchine'); 1879: 89 (Brachyonychus); Andrewes, 1924: 588 (= B. sublaevis); Kirschenhofer, 2000 323; Darlington, 1952: 126 (= B. s. sublaevis); Lorenz, 1998: 300 (= Craspedophorus s. sublaevis); Häckel, Farkač, 2012: 78; Häckel, Kirschenhofer, 2014b: 362.

MATERIAL. C. s. humeratus: 2 ex. (ZISP): Saigon, Cochinchine, coll. Le Moult; 2 ex. (ZISP), Vietnam, Dong Nai Prov., Vinh Cuu Distr., Vinh Cuu Nat. Res. (= Ma Da forest), $11^{\circ} 22^{\prime} 51^{\prime \prime N}$, $107^{\circ} 03^{\prime} 44^{\prime \prime} \mathrm{E}, 75 \mathrm{~m}, 18-27 . V I .2011$, L. Anisyutkin \& A. Anichkin leg.; 1 ex. (ZISP), same locality, 11.05.1995, T. Sergeeva leg.; 우 (SIEE), Nam Cat Tien Natn. Park, 16.IV.2004, A. Anichkin leg.; same locality: + (SIEE), 28-29.XI.2004, D. Fedorenko leg.; 웅 V.2003, M. Kalyakin leg.; $\mathrm{O}^{7}$ (MPSU), $\sim 120 \mathrm{~km} \mathrm{NE}$ of Ho Chi Minh, env. Cat Tien, 2-8.IV.1994, D. Volkov leg.; + , (MPSU), Tay Ninh Prov., lowland Dipterocarpus-forest, 19.X.2001, A. Borisenko leg.

C. s. sublaevis: 3 우 (SIEE), Cambodia, Kep Prov., env. Kep, $10^{\circ} 29^{\prime} 25^{\prime \prime} \mathrm{N} / 104^{\circ} 18^{\prime} 09^{\prime \prime} \mathrm{E}, \mathrm{h}=70 \mathrm{~m}, 13$.VI.2014, I. Melnik leg.

COMMENTS. Two closely related species, C. sublaevis from Cambodia and C. humeratus from Cochinchina (southern Vietnam), were described in the same paper [Chaudoir, 1869]; the former species was later recorded in Cochinchina
[Chaudoir, 1879]. Andrewes [1924] synonymized the two without comment, and later workers, including Darlington [1952], agreed.

All populations of $C$. sublaevis from Vietnam are monomorphic and confined to southern provinces of the country. It seems justifiable to refer to them as $C$. s. humeratus. The examined specimens of the latter show subtle yet constant differences from the five female specimens I have from a locality in southern Cambodia west of the Mekong River. Out of those five, two are probably $C$. perraudieri while the rest are $C$. sublaevis. This suggests that $C$. humeratus is the easternmost subspecies of $C$. sublaevis inhabiting Indochina west of the Mekong River.

DIAGNOSIS. BL $23.4-26.6 \mathrm{~mm}$. Pronotum only slightly and evenly convex in lateral view, with maximum convexity at or just in front of the middle; base about 1.46-1.59 (1.52, $\mathrm{n}=5$ ) times as wide as apex, broadest just behind middle (0.52-0.56, mean 0.53, from apex). Elytral striae becoming very shallow and very finely punctate towards suture, striae 1-3 with punctures hardly larger than punctures of elytral pubescence. All intervals more or less evenly punctate-pubescent, intervals 3 and 4 each with 4-5 irregular punctate rows on disc. Abdominal sterna entirely punctulate-pubescent, except for in basal 1/4-1/5 at most.

For comparison, populations of C. s. sublaevis from southern Cambodia: BL 25.3-28.2 mm. Pronotum in lateral view conspicuously convex, most convex $1 / 3-2 / 5$ from apex. Elytral striae deeper and moderately coarsely punctate, becoming shallower towards suture, with punctures in striae 1 to 3 clearly larger than setigerous punctures on intervals. Intervals slightly more densely punctate-pubescent, each with 5-7 irregular rows of punctures.

DISTRIBUTION. Vietnam: Tay Ninh and Dong Nai provinces. Population from 'Saigon' is sure to have become extinct. Given the apterous condition of the species, the Mekong River seems to be a natural barrier that separates $C$. s. humeratus from C. s. sublaevis.

HABITATS AND HABITS. The subspecies inhabits lowland semideciduous monsoon forests.

\section{The mouhotii species group, nov.}

DESCRIPTION. Body large, winged or wingless, very densely punctate-pubescent. Head short, wide and somewhat flattened, with distinct isodiametric microsculpture over entire dorsal surface, including labrum and exposed parts of mandibles; neck constriction transverse and moderately deep to shallow; neck coarsely punctate. Penultimate labial palpomere dilated before apex of inner margin, with three or more close and strong setae across the dilation. Antennae rather short, scape barely longer than eye tubercle, slightly longer than antennomere 3. Labrum deeply emarginate between widely rounded lateral lobes, medial setae subequidistant from basal and apical margins. Terminal labial and maxillary palpomere strongly securiform, apex about twice wider than inner margin in male. Pronotum subhexagonal, with lateral margins hardly explanate/reflexed. Protibia with 5-7 close spines at apex of outer margin.

COMMENTS. This group is established to include three species from Indochina: C. mouhotii (Chaudoir, 1869), C. laticollis (Chaudoir, 1869), and C. feae (Bates, 1890), all formerly placed in the hexagonus-group [Häckel, Kirschenhofer, 2014]. The hexagonus-group is further restricted to include the nominate species and $C$. chiangmaiensis Häckel et Kirschenhofer, 2014. I place the remaining two species, $C$. brevisternis and $C$. latigenis, in the sublaevis-group and the microspilotus-group, respectively. 
Chaudoir [1869, 1879], having noted a great similarity between $C$. mouhotii and C. laticollis, diagnosed the latter as follows: pronotum wider, more so behind, broadest clearly behind middle; basal angles rounded, with no emargination in front of them; elytral intervals absolutely flat (vs. flat), especially so on disc; anterior macula narrower [wider ?], spanning intervals 3 to 9 (vs. interval 2 to lateral margin), its anterior and posterior margins less dentate than in C. mouhotii; posterior macula on intervals 5-8 (vs. 4-8). Häckel \& Kirschenhofer [2014b] treated these two species the other way around.

C. feae (Bates, 1890) need a brief note because the caption to Figure 39 in Häckel \& Kirschenhofer [2014b] says the photographed female specimen is the holotype - apparently, a mistake, as the species was originally described based on several specimens.

\section{KEY TO SPECIES OF THE MOUHOTII SPECIES GROUP}

1(2) Elytral maculae with even anterior and posterior margins; anterior macula between outer part of interval 2 or 3 and stria 9. Intervals convex. Pronotum transverse, $\mathrm{PW} /$ PL 1.47 and nearly twice as wide as head (PW/HW 1.94), with sides evenly rounded. BL $19.4 \mathrm{~mm}$. - Myanmar ..

C. feae (Bates, 1890)

2(1) Elytral maculae more or less dentate at anterior and posterior margins, anterior macula with component strips on even intervals much longer than those on odd intervals. Pronotum less transverse, PW/PL under 1.44, PW/HW 1.80 at most.

3(4) Metepisterna short, as long as wide. Elytral intervals flat nearly throughout. Body wingless and stout; elytra more rounded at sides and slightly shorter, EL/EW 1.37-1.47 (1.43). Pronotum larger, with sides straight to subconvex in front of less distinct, very obtuse to rounded, basal angles; base 1.28-1.37 (1.34) times as wide as apex. Elytral maculae mostly less dentate before and behind, anterior macula spanning intervals $2-$ or $3-9$, or extended also onto outer part of epipleuron, while leaving the extreme lateral edge infuscate. Pronotal pubescence grey and fairly short. BL 18.2-20.2 mm. - Thailand, Laos, Cambodia, southern Vietnam ........................ C. laticollis (Chaudoir, 1869)

4(3) Metepisterna $1 \frac{1 / 4}{4}$ as long as wide. Elytral intervals convex to flat on disc. Body winged and slenderer; elytra less rounded at sides and barely longer, EL/EW 1.50. Pronotum smaller, with sides straight to very gently sinuate in front of obtuse yet distinct basal angles; base 1.47 times as wide as apex. Elytral maculae with anterior and posterior margin strongly dentate; anterior macula extended from stria 1 to outer part of epipleuron. Pronotal pubescence yellowish and fairly long ................ C. mouhotii (Chaudoir, 1869)

a(b) Elytral intervals flat on disc between maculae. BL 19.4 $20 \mathrm{~mm}$ C. mouhotii, forma typica

b(a) Elytral intervals convex. BL 18.5-19.4 mm C. mouhotii, forma subcostata

\section{Craspedophorus mouhotii Chaudoir, 1869} Figs 5, 9.

Chaudoir, 1869: 69 (Epicosmus; Laos). - mouhoti Chaudoir, 1879: 124; Kirschenhofer, 2000: 361, Fig. 15; Häckel, Farkač, 2012: 79. — laticollis: Häckel, Kirschenhofer, 2014b: 330, Fig. 32.

MATERIAL. O (SZMN), Thailand, Nakhon Ratchasima (Korat), Nong Bun Nak, 15-19.12.2008, Korshunov leg.; forma subcostata: 3 OO(SIEE): South Vietnam, Dongnai Province, Nam Cat Tien National Park, at light HQL450, 6-11.VI.2005, leg. D.Fedorenko.

REDESCRIPTION unnecessary, except for the following features.
BL 19.4-20 mm. Body black. Elytral maculae yellow and strongly dentate at anterior and posterior margins. Anterior macula very wide, between stria 1 and lateral margin while extended onto outer part of epipleuron, with component strips on odd intervals much longer than on even; pale colour in interval 9 anteriorly level with or just behind that in interval 8. Posterior macula spanning intervals 4-8 (or 5-8, as the original description indicates), its component strips subequally long, strips on odd intervals shifted forward relative to strips on even intervals. Dorsum with a distinct isodiametric microsculpture.

Dorsal pubescence yellowish on pronotum (better seen in dorsolateral view), yellow within pale elytral maculae while greyish semitransparent and thence seemingly black over black parts of dorsum. This pubescence is sparse to moderately dense on frons and vertex while very dense and moderately long over pronotum and elytra, elytral intervals each with 8-9 irregular rows of fine setigerous punctures (traceable across interval); pubescence on pronotum and elytra binary because of admixture of scattered sparse longer setae. Venter and legs with a fairly long yellow pubescence. Antennae: A1L/OL 0.88-0.92 (0.90, n=3) and AR 0.77-0.79 (0.78) : $0.36-0.38$ (0.37) : 0.60-0.61 (0.60).

Head: neck constriction indistinctly convex forward, almost straight, moderately deep to very shallow; frons and vertex coarsely and very closely to confluently punctate, neck less densely punctate, with several short wrinkles of confluent punctures. Terminal labial palpomere securiform (in females), with inner margin more than half longer than apex; outer margin concave in basal $2 / 3$, thence convex, inner margin straight apex gently convex. Terminal maxillary palpomere similar but slightly slenderer.

Pronotum hexagonal, 1.39-1.44 (1.42, n=4) times as wide as long, 1.73-1.76 (1.75) times as wide as head, broadest slightly behind middle, PLw/PL $0.54-0.59$ (0.57); sides well rounded at middle, less so in apical half, straight to very gently sinuate in basal third. Base and apex truncate, base 1.43-1.52 (1.47) times as wide as apex; basal angles obtuse, yet distinct, with a subtle emargination just in front; apical angles obtuse, rounded apically, somewhat removed from neck, barely to indistinctly projecting forward. Lateral margin finely beaded in apical $3 / 5$. One posterolateral seta in basal angles, anterolateral setae 4-5 in apical half.

Elytra oblong-oval, 1.49-1.52 (1.50) times as wide as long, 1.29-1.34 (1.32) times as wide as pronotum, broadest behind middle; sides rounded, slightly diverging apicad while straight to indistinctly sinuate in basal half, well rounded behind; humeri rounded yet distinct. Striae deep, rather finely punctate at bottom; intervals slightly convex only within pale elytral maculae and before apex, otherwise flat.

Wings full, metepisterna long, 1.18-1.24 (1.21) times as long as wide.

DISTRIBUTION. Thailand, Laos, Vietnam.

HABITATS AND HABITS. All specimens of C. mouhotii forma subcostata have been collected at light, at the edge of a semideciduous monsoon forest near the bank of the Dong Nai River.

COMMENTS. According to the original description, the species has flat elytral intervals, though less flat than those of C. laticollis. Of four examined specimens of C. mouhotii, only one (from Thailand) matches the species description well, whereas the remaining three (all from Vietnam) have intervals conspicuosly convex. In northeastern Thailand [Kirschenhofer, 2000], southeastern Thailand and Laos [Häckel, Kirschenhofer, 2014b] populations, the intervals are more or less convex as well. In the closest realtive of $C$. mouhotii, $C$. 
laticollis, this character shows no variation across the spesies range.

The available material is too scarce to decide whether the flat intervals reflect individual or geographical variability of $C$. mouhotii, or are aberrant, so I designate such specimens as $C$. mouhotii forma subcostata instead of introducing a new subspecific name: With characters of $C$. mouhotii, except as follows. BL 18.5-19.4 mm. Pronotum: PW/PL 1.39-1.44 (1.41, n=3), PLw/PL 0.57-0.59 (0.58), PWb/PWa 1.43-1.49 (1.45). Elytra: 1.49-1.52 (1.51). Elytral intervals conspicuously convex throughout, subcostate between posterior maculae.

Craspedophorus laticollis Chaudoir, 1869

Figs 1-4, 6-8, 10-13.

Chaudoir, 1869: 114 (Epicosmus; without indicated type locality); 1879: 125 ('Laos; Camboje'); Häckel, Farkač, 2012: 79. mouhoti: Häckel, Kirschenhofer, 2014b: 331, Fig. 43.

MATERIAL. $\sigma^{7}$ (SIEE), S Vietnam, N[orthern part of] Dongnai $\operatorname{Pr}[$ ovince]., Nam Cat Tien National Park, Exped. Russ.-Vietnamese Tropical Centre, at light HQL450, 10.X.2004, D. Fedorenko leg.; $2 \sigma^{\top} \sigma^{\top}$ (SIEE), Binh Phuoc Prov., Bu Gia Map Natn. Park, $12^{\circ} 11^{\prime} 37^{\prime \prime} \mathrm{N} / 107^{\circ} 12^{\prime} 21^{\prime \prime} \mathrm{E}, \mathrm{h}=350-540 \mathrm{~m}, 13 . \mathrm{IV} .2009$ and 26.IV4.V.2013, D. Fedorenko leg.; 2 +⿱ (SIEE), Lam Dong Prov., 25 km NW of Bao Loc, Loc Bao env., h=800 m, 11 ${ }^{\circ} 44^{\prime} 18^{\prime \prime} \mathrm{N} / 107^{\circ} 42^{\prime} 08^{\prime \prime} \mathrm{E}$ 5-20.IV.2013, D. Fedorenko leg.; $\sigma^{7}$ (SIEE), Thailand, Prov. Nakhon Ratchasima (Korat), Saeng Sang, Lam Sae Dam, Natn. Park
Tha Plan, h=250 m, 14 $16^{\prime} 40^{\prime \prime} \mathrm{N} / 102^{\circ} 25^{\prime} 28.5^{\prime \prime} \mathrm{E}, 24-30.07 .2012$, A.V. Korshunov leg.; 7 ex., $\sigma^{\top} \sigma^{\top}$,,++ (SZMN, SIEE), Prov. Buriram, Hevea brasiliensis plantations, 13-14.07.2013, A.V. Korshunov leg. - Aedeagus examined in five $\sigma^{\top} \sigma^{\prime}$.

REDESCRIPTION. As compared with C. mouhotii: BL 18.2-20.2 mm. Elytral maculae vary in shape and size, mostly width (Figs 1-4, 6-8), usually not reaching beyond interval 9. Dorsal pubescence on pronotum semitransparent grey and mostly shorter. Terminal labial palpomere with inner margin slightly less than half (ca. 1.43 times) longer than apex in female while more than twice (ca. 2.15 times) in male. Antennae barely longer: A1L/OL 0.92-0.96 (0.95, $\mathrm{n}=3)$ and AR 0.85-0.92 (0.87) : 0.40-0.41 (0.40) : 0.66-0.71 (0.69).

Pronotum similar in shape, but larger, 1.39-1.50 (1.44, $\mathrm{n}=10)$ times as wide as long, $1.72-1.84(1.79)$ times as wide as head, broadest slightly behind middle. Base narrower, 1.28-1.37 (1.34) times as wide as apex; basal angles more obtuse and more rounded; pronotal sides in front of them barely, if at all, emarginate; apical angles hardly more projecting forward in general.

Elytra oval and shorter, 1.37-1.47 (1.43) times as wide as long, 1.26-1.38 (1.30) times as wide as pronotum; sides well rounded in front of preapical sinuation; base slightly more oblique, humeri more rounded and less prominent. Striae moderately deep and moderately coarsely punctate; intervals
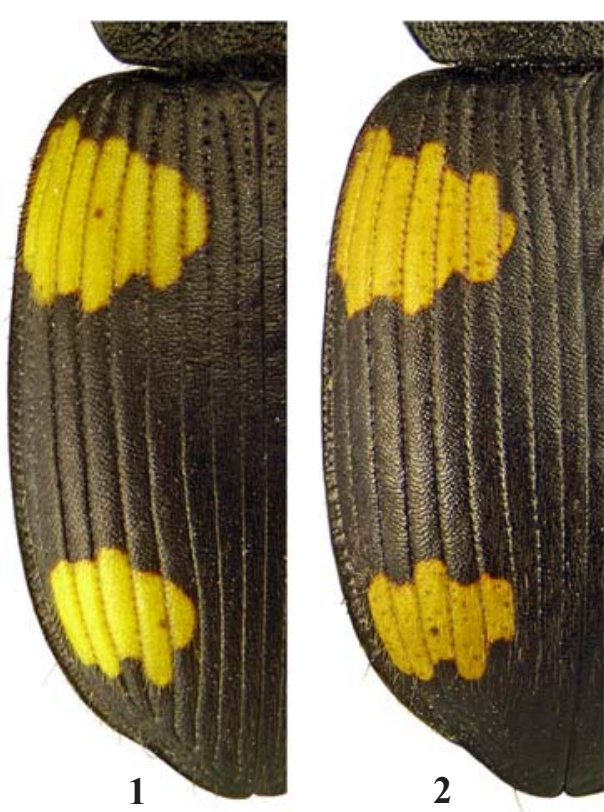

6

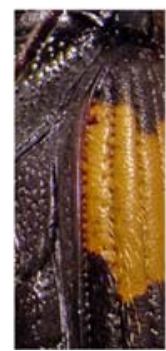

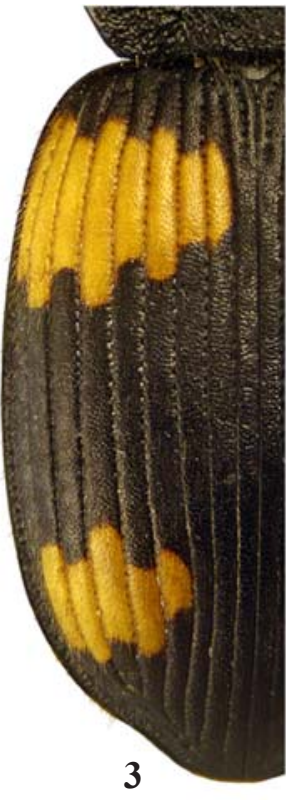

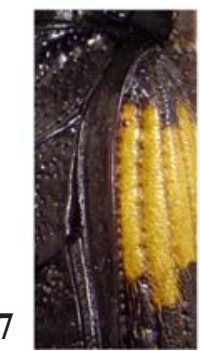

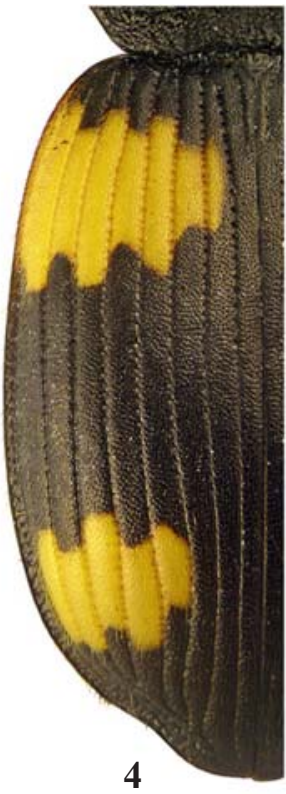

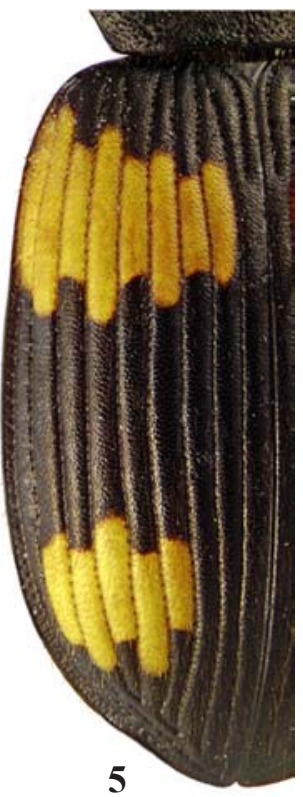

8

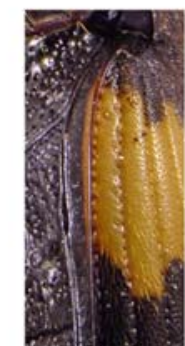

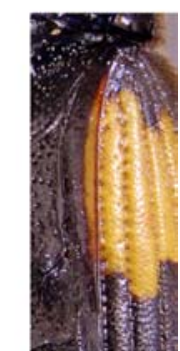

Figs 1-9. Craspedophorus, left elytron, variation in pale pattern: 1-4, 6-8 - C. laticollis (1-2, 6 - specimens from Cat Tien, S-Vietnam; 3-4, 7-8 - specimens from Buriram, Thailand); 5, 9-C. mouhotii forma subcostata; 1-5 — dorsal and slightly lateral aspect; 6-9 - left lateral view.

Рис. 1-9. Craspedophorus, изменчивость рисунка левого надкрылья: 1-4, 6-8 - C. laticollis (1, 2, 6 - экз. из Кат-Тьен, Ю. Вьетнам; 3-4, 7-8 - экз. из Бирирамб Таиланд); 5, 9-C. mouhotii forma subcostata; 1-5 — вид сверху и немного сбоку; 6-9 - вид слева. 
flat throughout or slightly convex within anterior maculae only.

Wings reduced to very short scales, metepisterna about as long as wide, ES3L/W 0.97-1.03 $(1.0, \mathrm{n}=5)$.

Aedeagus (Figs 10-13): basal bulb with no dorsal slot; apical lamella in ventral view rather wide, truncate, with apical margin very gently concave. Internal sac with moderately large apical sclerites. Left paramere fusiform, with apex narrowly rounded and very sparsely ciliate.

VARIABILITY. The species shows considerable, mostly geographic, variability in shape of the elytral maculae (Figs $1-4,6-8)$. In eastern populations, the pattern is typical: the anterior macula narrower, on intervals 3 to 9 , with anterior and posterior margins sinuous rather than dentate (Figs 1-2). In western populations (from Thailand) the maculae are as wide and exactly of the same shape as those in C. mouhotii (Figs 3-4). The only difference is that the anterior macula extends beyond the lateral edge of the elytron only occasionally, in which case the extreme lateral edge remains infuscate and the epipleuron just very narrowly edged with yellow.

DISTRIBUTION. Indochina east to southern Vietnam.

HABITATS AND HABITS. Prefers natural habitats, ocurring in monsoon broadleaf forests or along their edges. Probably also not uncommon on Hevea brasiliensis plantations.

\section{The lykaon species group}

REDESCRIPTION. Body large, black, antennomeres 13 , mandibles, labrum and tibiae at apex black to piceous, maxillae, mandibular apices, labrum at apical angles and often also along apical margin, tarsi, antennomeres 4-11, as well as bases and apices of antennomeres $1-3$, paler in general, brown rather pale, antennomere 4 often intermediate in color between 3 and 5.

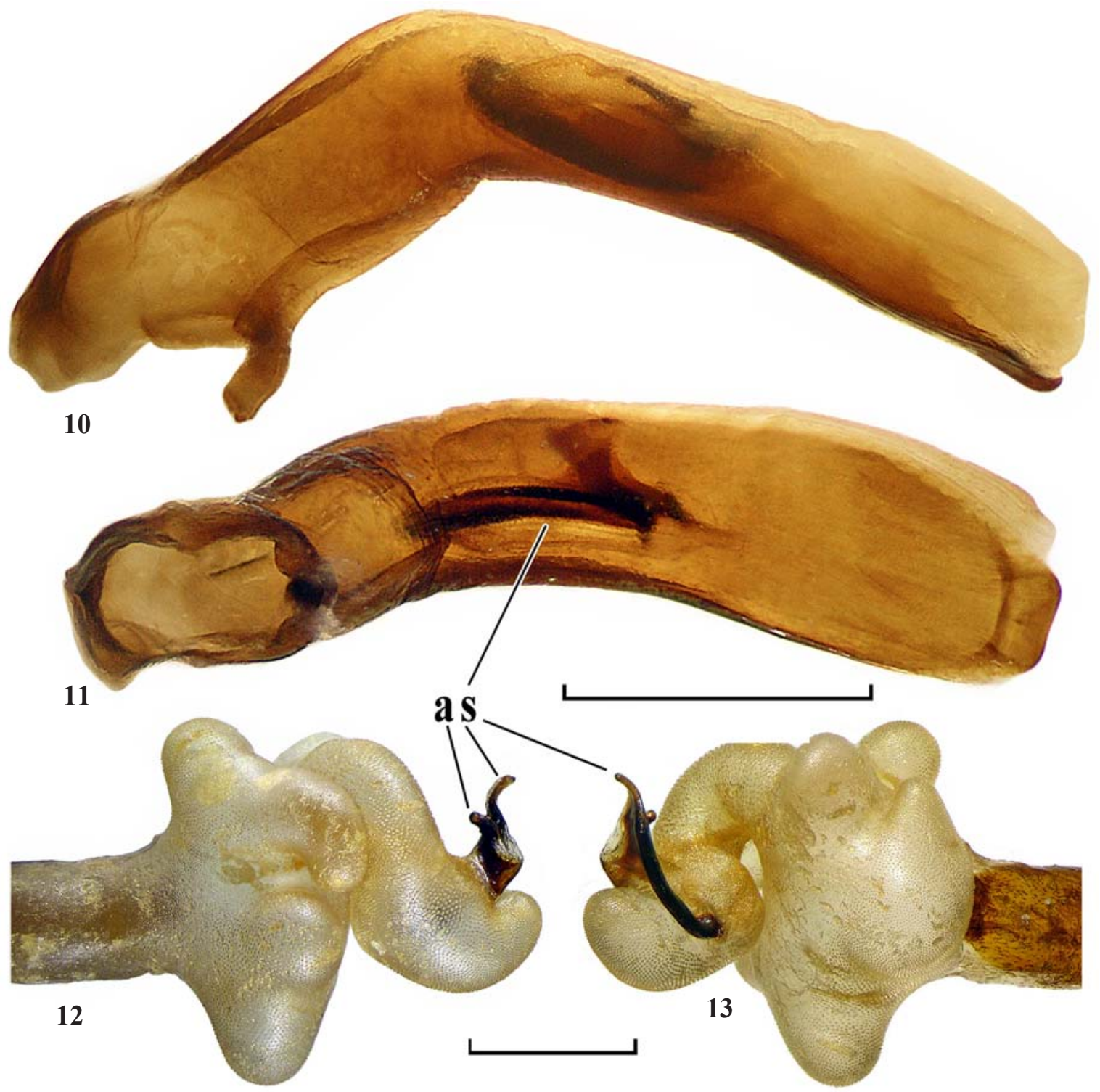

Figs 10-13. Craspedophorus laticollis, aedeagus; $10-11$ - median lobe; $12-13$ - everted and inflated internal sac; 10 - left lateral aspect; 11,13 - ventral aspect; 12 - dorsal aspect; as - apical sclerites. Scale bars $-1 \mathrm{~mm}$.

Рис. 10-13. Craspedophorus laticollis, эдеагус; 10-11 - средняя доля; 12-13 - вывернутый и надутый внутренний мешок; $10-$ слева; 11, 13 - снизу; 12 - сверху; as - апикальные склериты. Масштаб - $1 \mathrm{~mm}$. 
Head (Figs 24-25) wide, with eyes small yet protruding; genae short and subtransverse, glabrous to indistinctly pubescent in dorsal view. Last labial palpomere and last two maxillary palpomeres pubescent, sometimes (C. dalatensis) scarce pubescence present also on maxillary palpomere 3 . Labrum deeply emarginate, quadrisetose, with inner setae subequidistant from base and apex; penultimate labial palpomere cylindrical, bisetose at inner margin (but with 3-5, mostly four, setae in C. dalatensis). Mandibles wide and flat, evenly rounded at outer margins. Labrum, clypeus and exposed parts of closed mandibles dull due to a sharp isodiametric microsculpture. Frontoclypeal suture distinct, with a small and deep to very deep pit on each side. Frons moderately densely and moderately coarsely punctate-pubescent. Neck rugose to rugose-punctate.

Antennae very long, going beyond pronotal base by $4.5-$ 6 apical joints, scape long, 1.67-2.15 times as long as eye tubercle, antennomere 3 about as long as or barely longer than scape, about 3 times as long as pedicel and $1^{1 / 2}-1^{2 / 3}$ as long as antennomere 4 ; scape slightly yet distinctly concave at inner margin in basal $1 / 3-1 / 2$, glabrous to pubescent behind, with 1-2 strong dorso-apical setae, antennomere 3 with numerous erect setae as long as and proximal to verticellate ones.

Pronotum cordate to subcordate, rather flat on disc; lateral margins widely explanate and slightly to strongly reflexed, more strongly so in basal half, with 4-8 long setae in apical $1 / 2-3 / 5$. Base only a little wider than apex $(\mathrm{PWb} / \mathrm{PWa} 1.09$ 1.24), maximum width two fifths to half from apex (PLw/PL 0.41-0.49). Apical angles distinct, slightly removed from neck and slightly projecting forward; basal angles right to obtuse, blunt to rounded apically. Basal flange in posterodorsal view thick, flat to convex. Lateral bead fading basad to missing.

Elytra connate, flattened, oval, broadest at the middle, with base narrow, slightly oblique, shoulders widely rounded, a slight preapical sinuation, apices rounded combined and a slight to indistinct depression at bases of intervals 3 to 6 ; striae deep, finely to coarsely punctate, intervals flat to very convex. Metepisterna much shorter than long. Discal setigerous pores on elytra vary in number, mostly two in interval 3 , sometimes serial in intervals 3,5 and 7 . bases.

Abdominal sterna neither punctate nor crenate along

Aedeagus: median lobe with apical lamella short, wide and truncate in dorsal view, as usual in panagaeines. Parameres (Figs 48-51) glabrous and, when compared dissected, subequally long; right paramere long and narrow, tapering apicad and rounded at tip.

External sexual differences: last labial and maxillary palpomere wider in males than in females, as usual in the genus.

DIAGNOSIS. The group is well-defined by the combination of the following characters: body rather large; anterior elytral macula reaching lateral margin; head wide and flattened, with small yet protruding eyes; penultimate labial palpomere mostly bisetose at inner margin; last labial palpomere at apex as long as or longer than its inner margin in male, shorter in female; antennae very long, with scape concave at inner (anterior) margin and antennomere 3 bearing long and sparse erect setae; pronotum with widely explanate lateral margins and thick basal flange; abdominal sterna without row of punctures at bases.

HABITATS AND HABITS. The members of the group inhabit montane semideciduous monsoon broadleaf forests. Adults are nocturnal, as usual in carabids, but in daytime they stay in various covered places, mostly larger fallen trees on soil surface. $C$. dalatensis sp.n., $C$. breviceps sp.n., and $C$. (s.) sparsepunctatus sp.n. are largely sympatric. The latter two species live syntopically and prefer altitudes of 1,600$1,900 \mathrm{~m}$ (sometimes down to $1,400 \mathrm{~m}$ ), whereas $C$. dalatensis sp.n. is confined chiefly to the $900-1,500 \mathrm{~m}$ zone (occasionally up to $1,800 \mathrm{~m}$ ).

DISTRIBUTION. Three species described here are distributed along the Truong Son ridge in Laos and Vietnam south to the Dalat Plateau. The nominal species, C. lykaon Kirschenhofer, 2012, was described from Myanmar and later recorded in Laos [Häckel, Kirschenhofer, 2014].

COMMENTS. This group has been established for four species, based on their similarity in several characters, such as distinctive body shape (no details provided), long legs and very small pale elytral maculae [Häckel, Kirschenhofer, 2014]. Three of these species, C. kerberos Häckel et Kirschenhofer, 2014, C. facchinii Häckel et Kirschenhofer, 2014, and C. assamensis Häckel et Kirschenhofer, 2014 do not fit the group as described above: either their antennae are significantly shorter or the scape shorter relative to the eyes, combined with different antennal ratio. Based on these differences, I transfer C. kerberos to the sparsepunctatus-group nov.; tentatively place $C$. facchinii in the pallidicornis-group (see below); and move C. assamensis to incertae sedis species. As a result, the group is restricted here to the nominate species plus two species described below.

\section{KEY TO SPECIES OF THE LYKAON-GROUP}

1(6) Neck constriction very convex forward and angulate, reaching about the level of eye mid-length (Fig. 24). Head fairly narrow. Elytra longer, 1.43-1.57 times as long as wide, usually densely punctate-pubescent, so that interval 3 or 4 at the middle with 5-6 irregular rows of fine setigerous punctures. Body larger, 18.7-22.5 mm.

2(3) Pronotum more transverse, PW/PL 1.24-1.38, and wider relative to eyes, $\mathrm{PW} / \mathrm{HW} 1.85-1.99$.

C. lykaon Kirschenhofer, 2012

3(2) Pronotum less transverse, PW/PL 1.12-1.22, and narrower relative to eyes, PW/HW 1.50-1.76.

2(5) Pronotum subcordate, broadest just in front of the middle, with disc flat to gently convex, combined with strongly reflexed lateral margins (Fig. 14).

3(4) Elytral striae moderately deep, finely and sparsely punctate at bottom; intervals moderately convex to nearly flat. Scape two or more times as long as eye tubercle. Body larger, 19.6-22 mm .......................... C. dalatensis sp.n.

a(b) Elytral intervals densely punctate-pubescent, those 3 and 4 each with 5-6 irregular rows of punctures

C. d. dalatensis ssp.n.

b(a) Elytral intervals irregularly and sparsely punctate-pubescent at middle of disc, those 3 and 4 each with 1-2 irregular rows of punctures along striae and very few punctures along middle ............. C. d. abramovi ssp.n.

4(3) Elytral striae deep, coarsely to moderately punctate; intervals convex. Scape slightly less than twice (1.811.89 times) longer than eye tubercle. Body a little smaller, 18.7-19.2 mm .............................. C. C. kruskopi ssp.n.

5(2) Pronotum disc-shaped, broadest at the middle, with disc convex and lateral margins much less reflexed (Fig. 15). BL $20.1 \mathrm{~mm}$...................................... C. affinis sp.n.

6(1) Neck constriction evenly convex forward, not or barely reaching beyond the level of posterior margin of eye (Fig. 25 ). Head wide. Elytra sparsely punctate-pubescent, interval 3 or 4 at the middle with 2-3, rarely 3-4, irregular rows of fine setigerous punctures .............. C. breviceps sp.n. 
Craspedophorus dalatensis Fedorenko, sp.n.

Figs 24, 32, 36, 48-49, 66-67.

MATERIAL. Holotype $\sigma^{7}$ (ZMMU) labelled: 'S[outh] Vietnam, Lam Dong Prov[ince]./ Bi Doup - Nui Ba [Nature] Reserve env. Long Lanh, / $12^{\circ} 10^{\prime} 44^{\prime \prime} \mathrm{N}, 108^{\circ} 40^{\prime} 44^{\prime \prime} \mathrm{E} / \mathrm{h}=1400-1600 \mathrm{~m} 9$ 11./ leg. D. Fedorenko IV.2008'. Paratypes (ZMMU, ZIN, SIEE): 10 $\sigma^{7} O^{7}, 11$ ofㅇ, same locality, various dates between 26.III. and 18.IV.2008, as well as between 30.IV. and 1-2.V.2009; $30^{7} 0^{7}$,,+ Dak Lak province, Chu Yang Sin Natn. Park, $12^{\circ} 23^{\prime} 48^{\prime \prime} \mathrm{N}$ $108^{\circ} 20^{\prime} 59^{\prime \prime} \mathrm{E}$, upper flow of Krong Kmar river, $\mathrm{h}=970 \mathrm{~m}$, 30.III14.IV.2012, D. Fedorenko leg.; $2 \sigma^{7} \sigma^{7}, 3$ +o, same data, but $12^{\circ} 25^{\prime} 25^{\prime \prime} \mathrm{N} / 108^{\circ} 21^{\prime} 53^{\prime \prime} \mathrm{E}, 15-30 . \mathrm{V} .2014 ; 4 \mathrm{O}^{7} \mathrm{O}^{7}$, , , same data, ecept for $12^{\circ} 22^{\prime} 40^{\prime \prime} \mathrm{N} / 108^{\circ} 21^{\prime} 11^{\prime \prime} \mathrm{E}, 1.5 \mathrm{~km}$ W [of ] Chu Pan Phan $\mathrm{Mt}, \mathrm{h}=1650 \mathrm{~m}, 30 . \mathrm{III}-11$. IV.2012 and 23-25.III.2013.

DESCRIPTION. Slender, BL 19.6-22 mm. Black, tarsi brown, palps dark brown, elytral maculae almost invariable, rounded, anterior macula between stria 4 or mid-width of interval 5 and mid-width of epipleuron, sometimes reaching inward beyond stria 4, posterior macula on intervals 5 to 8 , mostly with apical margin slightly emarginate in interval 6 . Microsculpture moderately sharp, isodiametric in general, with very wide transverse meshes here and there on pronotum and elytra. Dorsal pubescence rather short, sparse on frons and vertex, dense, greyish over pronotum and elytra, elytral intervals each with 5-6 irregular rows of fine setigerous punctures.

Head (Fig. 24) slightly dilated before eyes, genae glabrous to indistinctly pubescent in dorsal view, meeting neck at nearly right angle; clypeus glabrous and smooth, without impressions; frontal sulci wide, moderately deep, slightly converging posterad and almost reaching neck, with a conspicuously raised area in between; vertex very short, flat to subconvex, with a small and shallow impression in the middle; neck constriction deep and angulate, its tip angular and blunted, reaching about the level of eye mid-length; neck coarsely and densely transversely rugose in front, combined with irregular, fine and denser rugosities behind. Scape $2.0-2.15(2.07, \mathrm{n}=6)$ times as long as eye tubercle, antennomere 3 twice as long as antennomere 4, AR 0.88-0.94
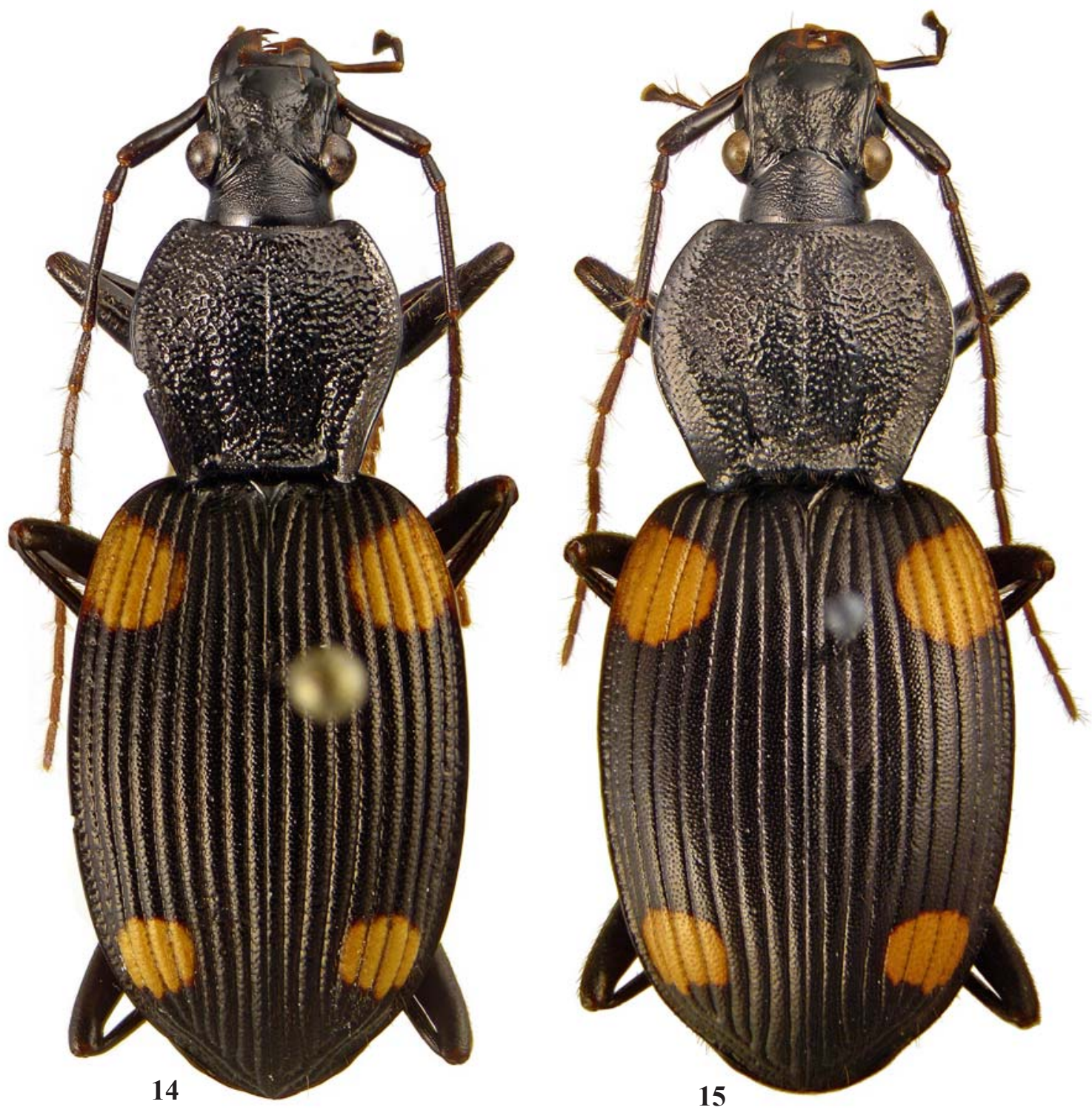

Figs 14-15. Craspedophorus, dorsal habitus: $14-$ C. dalatensis kruskopi ssp.n.; $15-$ C. affinis sp.n.

Рис. 14-15. Craspedophorus, габитус сверху: $14-$ C. dalatensis kruskopi ssp.n.; $15-$ C. affinis sp.n. 
(0.91) : 0.29-0.33 (0.31) : 0.44-0.49 (0.47). Labrum with a few cilia in the middle of apical emargination. Basal maxillary palpomere with a sparse and short pubescence on dorsal side, penultimate labial palpomere with 3 to 5 (mostly 4 ) setae at inner margin. Terminal labial palpomere strongly securiform in male, less so in female, with inner margin two thirds as long as apex or barely (about 1.1 times) longer than apex, respectively; in male, outer margin concave, inner margin very gently concave, apex very convex, running parallel to outer margin in basal 1/3-2/5. Terminal maxillary palpomere similar yet slightly slenderer.

Pronotum subcordate, $1.12-1.21(1.15, \mathrm{n}=8)$ times as wide as long, 1.68-1.75 (1.72) times as wide as head, broadest just in front of the middle, PLw/PL 0.43-0.46 (0.45); sides subsinuate to nearly straight in basal half. Base 1.10-1.24 (1.19) times as wide as apex, base straight, apex straight to very slightly concave; basal angles rectangular, rounded apically, protruding behind pronotal base as small yet distinct lobes, each with a minute, blunt to sharp, denticle and a subtle lateral emargination in front of it; apical angles small, apically rounded, gently projecting forward. Explanate lateral margin flat, moderately wide, slightly more so in basal half, increasingly reflexed basad, from slightly reflexed in apical third to very strongly reflexed behind; lateral bead missing. Median line moderately deep, fading towards base and apex; apical impression absent, basal transverse impression more than one sixth from base, straight to slightly convex forward, well-defined at least at sides; basal foveae sulcate and very deep, subparallel to very slightly diverging on each side of basal transverse impression, not quite reaching base and fading $2 / 5-1 / 2$ from base. Disc slightly convex along the middle, flat to feebly concave laterally, densely and moderately coarsely, somewhat confluently punctate in addition to fine and dense aciculate setigerous punctures; explanate lateral margin moderately densely punctate-pubescent, with setigerous punctures deeper than those on disc and no coarse punctures.

Elytra 1.43-1.57 (1.51) times as wide as long, 1.40-1.59 (1.49) times as wide as pronotum, with a distinct basal depression. Striae finely and sparsely punctate at bottom, intervals moderately convex (sometimes nearly flat) on disc, more convex at bases and still more so before apex.

Prosternum except middle, pleura, sides of metasternum and abdominal sternite II coarsely and moderately densely punctate, abdominal sterna III and IV with several coarse punctures along sides, venter otherwise minutely and rather densely punctate-pubescent, with abdominal sterna III and IV inwardly, and the other sterna at bases, smooth and glabrous.

Tarsi rather stout, 4th metatarsomere 1.67-1.88 (1.8, $\mathrm{n}=5$ ) times as long as wide, its greater apical lobe long, a third as wide as the tarsomere, LL/LT4 $=0.3-0.38(0.34)$.

Aedeagus (Figs 32, 36, 48-49, 66-67). Apical lamella very short, truncate apically in ventral view. Internal sac (Figs 66-67) with fairly short (apical) sclerites (Fig. 36); right lateral bulb long and apically rounded.

DIAGNOSIS. Easily distinguishable from C. lykaon by the pronotum less transverse and narrower relative to head, i.e., $1.50-1.76$ vs. $1.85-1.99$ times as wide as head.

DISTRIBUTION. The Dalat Plateau within Lam Dong and Dak Lak provinces, south Vietnam.

NAME. Refers to the type locality, the Dalat Plateau.

\section{Craspedophorus dalatensis abramovi Fedorenko, ssp.n.}

MATERIAL. Holotype $\sigma^{7}$ (ZMMU) and paratype + (SIEE) labelled: 'Vietnam, Kon Tum Prov[ince]./ Kon Plong Distr. / $14^{\circ} 45^{\prime} \mathrm{N}$, $108^{\circ} 18^{\prime} 10^{\prime \prime} \mathrm{E} / \mathrm{env}$. Ngoc Boc I Mt./ h=1200-1300 m 8-23.IV./ leg. D. Fedorenko 2015'.
DESCRIPTION. As for the nominate subspecies, except as follows: BL 21.9-22.9 mm. Elytral pubescence sparse on disc; intervals $1-7$, mostly $2-5$ and, especially, 3 and 4 , at middle of disc each with 1-2 irregular rows of punctures close to striae, while very sparsely and unevenly punctate along the middle, with 3-4 (rarely 5) punctures traceable across the interval. Pronotum with lateral margin a little more widely explanate and slightly more reflexed; lateral lobes of base a little farther produced behind. PW/PL 1.62-1.65, PW/ HW 1.12-1.13. Elytra each with a deeper and larger basal depression on bases of intervals 3-5; EL/EW 1.47-1.57, EW/ PW 1.44-1.54.

Aedeagus as described for $C . d$. dalatensis sp.n.

DIAGNOSIS. Different from the other two subspecies chiefly in the elytral intervals very unevenly punctate-pubescent on disc, densely along striae while very sparsely along the middle. A slightly larger body seems to be further difference from $C$. d. kruskopi ssp.n. For the other details see 'Description' under C. dalatensis sp.n.

DISTRIBUTION. Kon Tum Province, central Vietnam.

NAME. Given after the mammalogist Alexey V. Abramov (ZISP), my good friend and colleague, who has provided me with many specimens of carabids taken by him during our expeditions to Vietnam.

\section{Craspedophorus dalatensis kruskopi Fedorenko, ssp.n.}

Figs 14, 68-69.

MATERIAL. Holotype $\sigma^{7}$ (ZMMU) and paratype $\sigma^{7}$ (SIEE), with label: 'Vietnam, C[entral] Annam/ prov[ince]. Quan[g] Binh/ Minh Hoa distr.,/ env. Yen Hop/ 7-12.IV.1999 / leg. S. Kruskop'.

DESCRIPTION. Hardly different from C. dalatensis sp.n. in the following characters: Smaller, BL 18.7-19.2 $\mathrm{mm}$. Anterior elytral macula between stria 4 or 5 and midwidth of epipleuron, posterior macula on intervals 5 to 8 . Scape slightly shorter, 1.81-1.89 times as long as eye tubercle, AR 0.87-0.91:0.29-0.30:0.47-0.48. Pronotum slightly narrower, PW/PL $1.12(\mathrm{n}=2), \mathrm{PW} / \mathrm{HW} 1.5-1.6$, its sides straight behind. Elytral striae coarsely (holotype) to moderately coarsely (paratype) punctate; intervals convex to very convex, interval 3 with 2-4 large discal pores.

Aedeagus of the same structure, but everted and inflated internal sac is slightly different in shape, due mainly to the right lateral bulb being shorter, wider and bifid (Figs 68-69).

DIAGNOSIS. See Description above.

DISTRIBUTION. Known from type locality only.

NAME. Named after the mammalogist Sergei V. Kruskop, my friend and colleague who collected the specimens.

\section{Craspedophorus affinis Fedorenko, sp.n.} Fig. 15.

MATERIAL. Holotype + (ZISP): 'Laos, N Vientiane / Nam Ngum 400 m / 20 X 1994 [O.N.] Kabakov' [hw].

DESCRIPTION. As $C$. dalatensis sp.n., except as follows: BL $20.1 \mathrm{~mm}$. Anterior elytral macula between stria 5 and mid-width of epipleuron, posterior macula on intervals 5 to 8 .

Head: genae convex, with a subtle concavity traceable between eye and gena, and angle between gena and neck slightly acute; neck constriction narrowly rounded at tip. Scape slightly yet clearly shorter relative to eye, 1.82 times as long as eye tubercle; AR $0.90: 0.27: 0.44$.

Pronotum round, 1.22 times as wide as long, 1.76 times as wide as head, broadest at middle; sides subevenly rounded in apical three quarters, with only a hint of sinuation behind. Explanate lateral margin very slightly reflexed in apical half 
and just a little more so at base. Median line fine but deep, deeper in apical two thirds; basal transverse impression traceable only at basal foveae. Disc clearly more convex along the middle than in $C$. dalatensis sp.n.

Elytra 1.47 times as wide as long, 1.37 times as wide as pronotum, with intervals flat on disc, subconvex basally and towards lateral margin, and convex behind apex.

DIAGNOSIS. Very similar to $C$. dalatensis sp.n., but distinguishable by the shape of the pronotum and the shorter scape.

DISTRIBUTION. Known from the type locality only, Nam Ngum [River] north of Vientiane, Laos.

COMMENTS. Strongly resembles $C$. dalatensis sp.n. in appearance as well as in many details of external morphology, and may prove to be its subspecies.

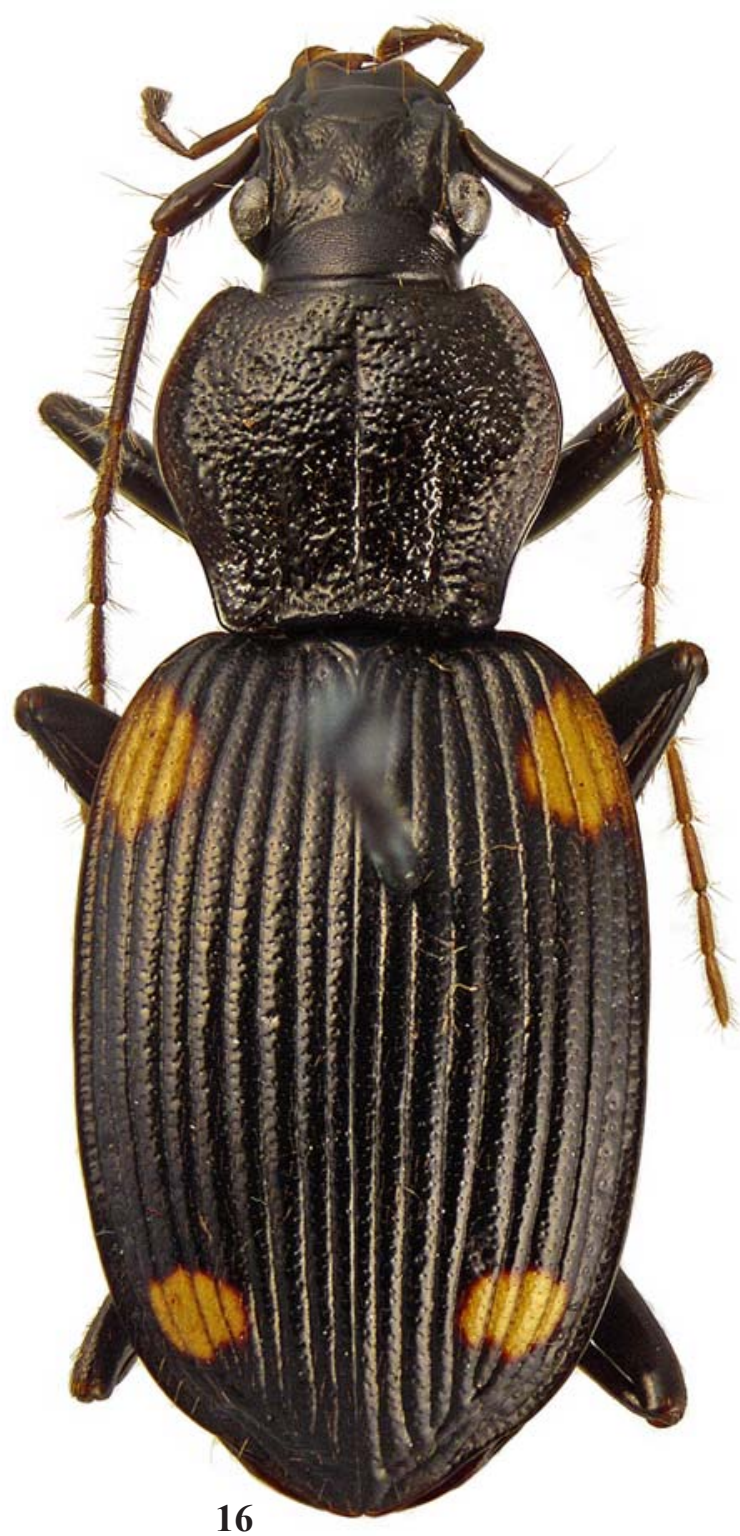

Craspedophorus breviceps Fedorenko, sp.n.

Figs 16, 25, 33, 37, 50-51, 70-71.

MATERIAL. Holotype $\sigma^{7}$ (ZMMU) labelled: 'S[outh] Vietnam, Lam Dong Prov[ince]./ Bi Doup - Nui Ba [Nature] Res[erve]/ $12^{\circ} 07^{\prime} \mathrm{N}, 108^{\circ} 39^{\prime} 20^{\prime \prime} \mathrm{E} / \mathrm{Bi}$ Doup Mt., N[orthern] slope, $\mathrm{h}=1700$ 1900 m 15-16./ leg. D. Fedorenko .IV.2008'. Paratypes (ZMMU, SIEE, ZISP): $50^{7} \sigma^{7}, 7$ 우, same data, as well as additional dates 1922.IV.2008, 6.V. and 21.V.2009; + , same data, but $12^{\circ} 10^{\prime} 44^{\prime \prime} \mathrm{N}$, $108^{\circ} 40^{\prime} 44^{\prime \prime} \mathrm{E}$, env. Long Lanh, $\mathrm{h}=1400-1600 \mathrm{~m}, 3-6 . I V .2008 ; 2$ $0^{\top} \sigma^{\top}$, + , same data, but $12^{\circ} 11^{\prime} \mathrm{N} / 108^{\circ} 42^{\prime} \mathrm{E}, \sim 4 \mathrm{~km}$ SSE of Hon Giao Mt., h=1500-1800 m, 2-3.IV.2008; $0^{7}$, o, same data, but $\mathrm{h}=1500$ 1700 m, 5.V.2009; 9 O $^{7} \sigma^{7}, 12$ 어, Dak Lak province, Chu Yang Sin Natn. Park, $12^{\circ} 22^{\prime} 40^{\prime \prime} \mathrm{N} / 108^{\circ} 21^{\prime} 11^{\prime \prime}$ E, $1.5 \mathrm{~km}$ W [of ] Chu Pan Phan Mt, $\mathrm{h}=1650 \mathrm{~m}, 30 . \mathrm{III}-11 . \mathrm{IV} .2012$ and 21.III-1.IV.2013, D. Fedorenko leg.

Additional material: $\sigma^{7}$ (SIEE): Khanh Hoa province, Hon Ba Mts, 1400 m a.s.1., IV.2003, A. Borisenko leg.; +, Central Vietnam,

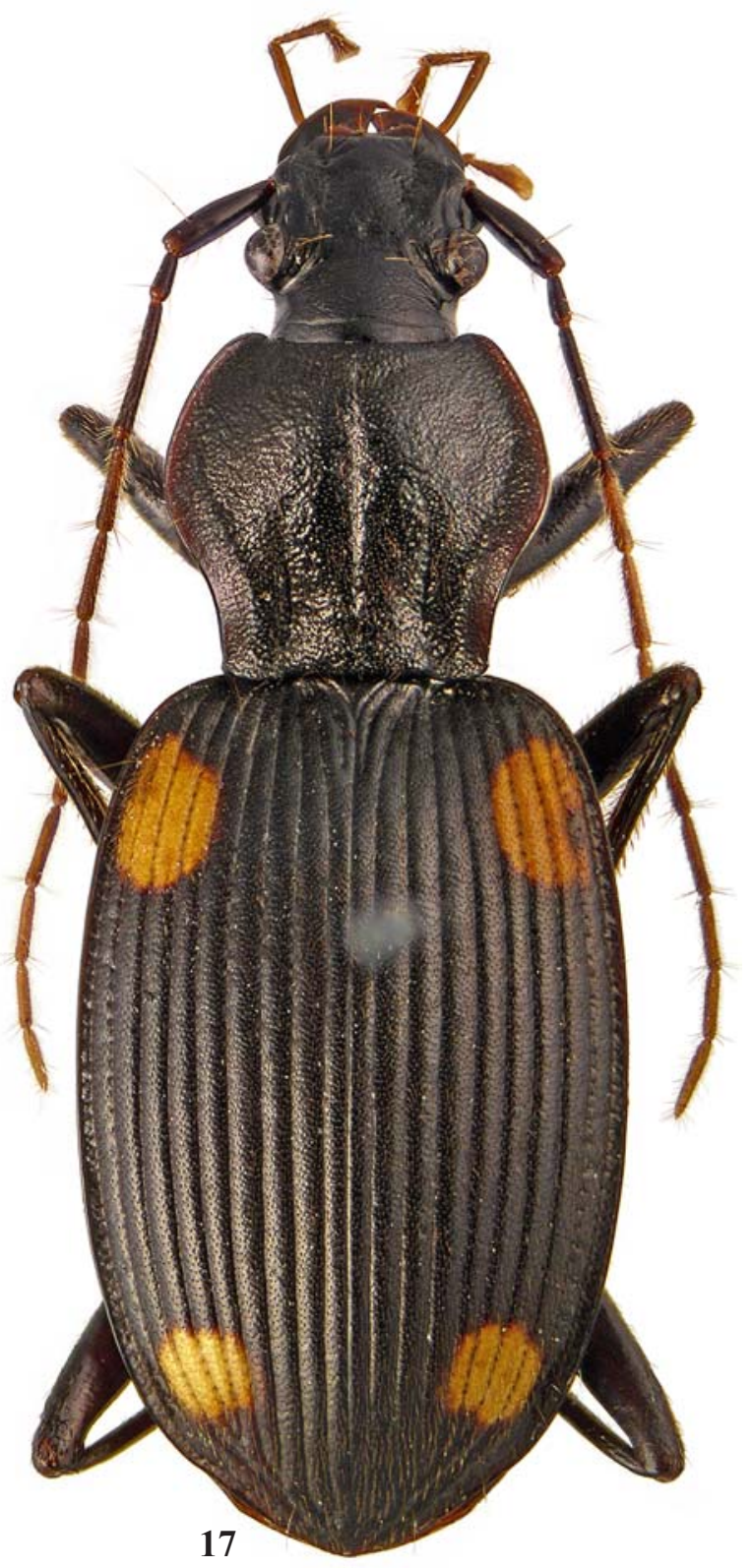

Figs 16-17. Craspedophorus, dorsal habitus: $16-$ C. breviceps sp.n.; $17-$ C. crebrepunctatus sp.n. Pис. 16-17. Craspedophorus, габитус сверху: $16-$ C. breviceps sp.n.; $17-$ C. crebrepunctatus sp.n. 
Kon Tum Prov., N. part, Ngoc Linh Nat[ural] Reserve, Ngoc Linh env., pitfall trap, V.2006, A. Anichkin leg.

DESCRIPTION. As compared with $C$. dalatensis sp.n.: Body (Fig. 16) stouter and smaller, BL 14.6-17.5 mm. Tarsi dark red, palps brown, both elytral maculae smaller, anterior macula between mid-width of interval 5-6 and lateral edge, extending to epipleuron and varying there in width, posterior macula subquadrate, on intervals 5-8. Microsculpture obliterate to very superficial and hardly traceable on pronotal disc. Dorsal pubescence greyish and short, dense on pronotum, sparse on head and elytra, elytral intervals each with 2-3, rarely 3-4, irregular rows of fine setigerous punctures.

Head (Fig. 25) wide and short, parallel-sided in front. Genae slightly longer and meeting neck at obtuse blunt angle. Neck constriction moderately deep, evenly convex forward, reaching the level of eye's posterior margin or just beyond. Frontal sulci deep, triangular, wide anteriorly, each with inner and outer sides converging posterad and meeting at or slightly behind anterior supraorbital seta; a rounded convexity between sulci with a wide central depression. Frons and vertex moderately coarsely punctate, densely in central depression, a little less so in frontal foveae, with several finer punctures at sides and before neck constriction. Neck less coarsely and more regularly sculpted in general, with transverse wrinkles in front, becoming somewhat irregular rugosities towards base. Scape $1.67-1.86(1.74, n=7)$ times as long as eye tubercle, AR 0.88-1.01 (0.97) : 0.31-0.35 (0.33) : $0.50-0.56(0.53)$. Terminal labial and maxillary palpomeres narrower; terminal labial palpomere at inner margin ca. 0.75 $\left(O^{T}\right)$ or slightly less than $1.4(+)$ times as long as apex; outer margin straight, inner margin concave, apex convex.

Pronotum cordate to subcordate, 1.16-1.27 (1.22) times as wide as long, $1.54-1.60(1.57, \mathrm{n}=8)$ times as wide as head, with broadest point ranging between at and clearly in front of the middle. Sides rounded in apical two thirds, sinuate to nearly straight behind; base and apex straight; apical angles a little more strongly protruding in general, hind angles subrectangular, blunt to narrowly rounded, reaching just beyond base level, with or without a subtle lateral emargination. Explanate lateral margin anteriorly from narrow to moderately wide and from very slightly to conspicuously reflexed, posteriorly wide and slightly to strongly reflexed; very fine lateral bead hinted in apical half. Disc rather convex across the apical half, with no flat area inside explanate margin.

Elytra 1.38-1.44 (1.41) times as wide as pronotum, 1.491.56 (1.51) times as wide as long; basal depressions often shallow and short; intervals (sub)convex.

Venter slightly to much more sparsely punctate, often with sterna III and IV smooth and glabrous laterally.

Tarsi long, metatarsomere 4 about twice (1.84-2.10, mean 2.0 , times, $\mathrm{n}=5$ ) as long as wide, with greater apical lobe short, only a fourth as long as tarsomere, LL/LT4 $=0.24-0.29(0.26)$.

Aedeagus (Figs 33, 37, 50-51): penis similar in shape and structure, but apical lamella in ventral view more rounded at sides and internal sac quite differently shaped (Figs 70-71).

VARIABILITY. A male from Hon $\mathrm{Ba} \mathrm{Mt}$ is larger, 18.2 $\mathrm{mm}$, with longer pronotum $(\mathrm{PW} / \mathrm{PL}=1.12)$ and elytral intervals rather densely punctate-pubescent, as densely as those in some specimens from Hon Giao Mt. In a female from Ngoc Linh, the pronotum is wider relative to both head and elytra $(\mathrm{PW} / \mathrm{HW}=1.69, \mathrm{EW} / \mathrm{PW}=1.36)$, and pronotal microsculpture is conspicuous.

DIAGNOSIS. Differs from other species of the group in having a rather wide head, neck constriction evenly convex forward, pronotum (sub)cordate and elytral intervals sparsely punctate-pubescent.
DISTRIBUTION. Mountain massifs of the Lam Dong, Khanh Hoa and Dak Lak provinces, southern Vietnam, north to at least Kon Tum Province, central Vietnam.

NAME. Refers to the wide head.

\section{The pallidicornis species group, nov.}

DIAGNOSIS. This group differs from the lykaon-group in the following: Body smaller and stouter. Head rather short, with a very deep neck constriction (Figs 18-20, 26-27) and a small yet deep median impression adjoining it anteriorly. Penultimate labial palpomere bisetose at inner margin. Pronotum wide, subhexagonal, with lateral margin widely explanate yet little reflexed. Antennomere 3 with no or (rarely) very few long erect setae proximal to verticellate ones. Elytra with two discal setigerous pores in middle third of interval 3 . Aedeagus with internal sac peculiar in shape. Right paramere poorly sclerotized apically, with fairly dense and long apical setae (Figs 54, 56).

COMMENTS. This group includes at least four species from northern Vietnam and Laos (two of which described below as new) plus C. tamdaoensis Häckel et Kirschenhofer, 2014 (formerly placed in the hexagonus-group) and C. phoupanensis Häckel et Kirschenhofer, 2014 (formerly placed in the obscurus-group). Two more potential members of the pallidicornis-group are C. soppongensis Kirschenhofer, 2011 and C. facchinii Häckel et Kirschenhofer, 2014, formerly placed in the kubani-group or the lykaon-group, respectively. Besides, I failed to see any difference between the illustrated holotypes of the two species, other than $C$. soppongensis being slightly larger, with elytral maculae perhaps a tad smaller.

The obscurus-group that has been diagnosed and called homogeneous based mainly on external similarity between its five species [Häckel, Kirschenhofer, 2014] seems to be closest or identical to to the qiongensis-group. My comparing the illustrated species of the latter group suggest that only $C$. obscurus Xie et $\mathrm{Yu}, 1991$ and C. qiongensis Pang et Tian, 2012 certainly belong there, whereas $C$. cenwanglao Häckel et Kirschenhofer, 2014 and $C$. sikkimensis Häckel et Kirschenhofer, 2014 might belong in the crebrepunctatus- and nepalensis-groups, respectively.

\section{Craspedophorus pallidicornis Fedorenko, sp.n.} Figs 18, 26, 34, 38, 54-55, 72-73.

MATERIAL. Holotype $\sigma^{7}$ (ZISP) labelled: 'VIETNAM, mountains $50 \mathrm{~km} / \mathrm{NO}$ [NE of] Thai Nguen, $300 \mathrm{~m} / 9.5 .1963$, [O.N.] Kabakov' [micrograh, in Russian]. Paratypes: 2 ㅇ (ZISP), same data, but 15.5.1963 and 10.4.1963; $0^{7}, 6$ OP (SIEE), N-Vietnam, Phu Tho Prov., $\sim 90 \mathrm{~km}$ W of Hanoi, Xuan Son National Park, $21^{\circ} 07^{\prime} 52^{\prime \prime} \mathrm{N} / 104^{\circ} 57^{\prime} 07^{\prime \prime} \mathrm{E}, \mathrm{h}=400-470 \mathrm{~m}, 6-15 . V I .2014$, D. Fedorenko leg.; $\sigma^{7}$ (SIEE), same data, but $21^{\circ} 08^{\prime} 12^{\prime \prime} \mathrm{N} / 104^{\circ} 57^{\prime} 04^{\prime \prime}$ $\mathrm{E}, \mathrm{h}=450 \mathrm{~m}, 27 . \mathrm{VI}-7 . \mathrm{VII} .2014$, A. Abramov \& A. Shchinov leg.

DESCRIPTION. Body (Fig. 18) stout, BL 12-13.9 mm. Black, with lateral pronotal margin vaguely narrowly brownish; mandibles, palps, labrum, antennae, femoral apices, tibiae and tarsi pale reddish-brown; antennomeres $1-3$, or 2 and 3 , or 3 only slightly infuscate except for at both ends; terminal palpomere often infuscate just before apex. Elytral maculae fairly small, anterior one very slightly tapering inwards, extended from stria 5, rarely 4 , to mid-width of epipleuron, posterior macula round to subquadrate. Microsculpture isodiametric on head and nearly so on pronotum and elytra, sharp on head, superficial on neck, superficial yet distinct on pronotum and elytra. Head sparsely pubescent on frons and vertex, pronotum and elytra very densely aciculate-pubescent; pubescence yellow on pronotum, as well within elytral maculae, elytra otherwise with greyish pubescence arranged 
into 5-6 irregular rows of fine setigerous punctures in each interval.

Head (Fig. 26) almost parallel-sided, genae short, meeting neck at subacute to right angle; clypeus glabrous and smooth, frontal sulci wide, moderately deep, slightly converging posterad, almost reaching neck; posteromedial impression on vertex indistinct to shallow and separate from neck constriction; the latter deep and convex forward, but not reaching the level of maximum head width; frons and vertex coarsely and closely punctate; neck densely transversely rugulose anterad and more finely irregularly rugulose basad. Scape 1.30-1.47 $(1.39, \mathrm{n}=8)$ times as long as eye tubercle, AR 0.85-0.98 (0.91) : 0.38-0.41 (0.40) : 0.59-0.65 (0.62). Terminal labial palpomere in equilateral triangle, with inner and outer margins straight and apex slightly convex, in male, narrower in female, with inner margin about half longer than apex.

Pronotum hexagonal, wide, 1.34-1.45 (1.42) times as wide as long, 1.77-1.91 (1.85) times as wide as head, broadest quite medially, PLw/PL 0.46-0.52 (0.49). Base and apex truncate, base barely to slightly wider than apex, PWb/a 1.02-1.22 (1.08), due mainly to apical angles being rounded yet distinct and far from neck; sides rounded at middle and slightly rounded in apical half, very slightly sinuate, often nearly straight, in basal half, with three to five lateral setae in apical $1 / 2-3 / 5$ and posterolateral seta in basal angles. Basal angles obtuse, rounded apically, protruding just past base, with a minute, blunt, almost indistinct denticle and a subtle lateral emargination in front of it. Median line fine, but well impressed, slightly deeper basad; apical transverse impression reduced, basal transverse impression indistinct; basal foveae sulcate and very deep, shallower at extremities, almost reaching the middle and not quite reaching base, straight to slightly converging forward from base over a short stretch, thence somewhat diverging. Explanate lateral margin moderately wide anteriorly, wider behind, very slightly reflexed, hardly separated from disc; lateral bead very narrow, welldefined in apical half, obliterate at or just behind middle. Disc moderately coarsely and very closely punctate.
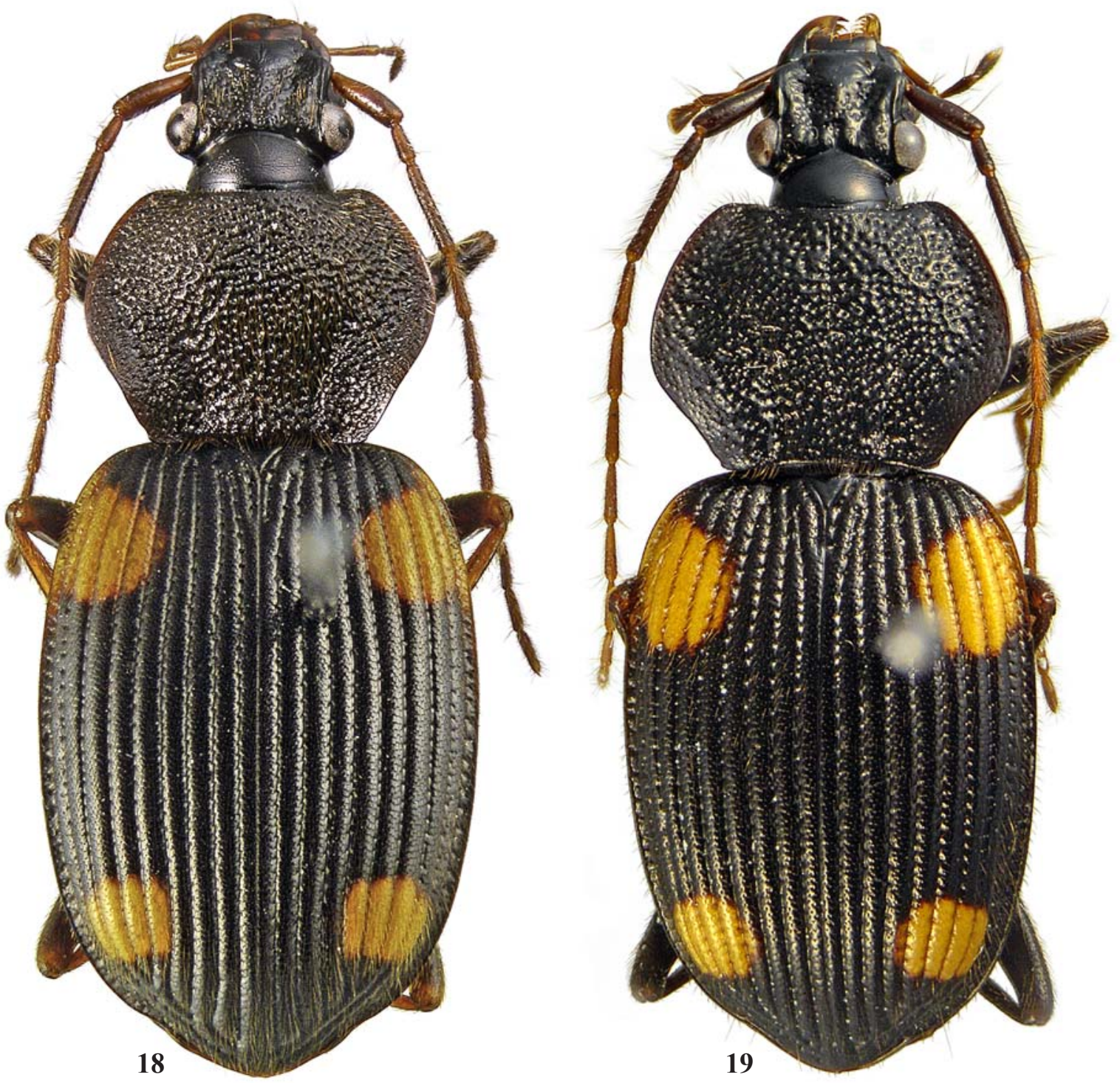

Figs 18-19. Craspedophorus, dorsal habitus: $18-$ C. pallidicornis sp.n.; $19-$ C. kabakovi sp.n.

Рис. 18-19. Craspedophorus, габитус сверху: $18-$ C. pallidicornis sp.n.; $19-$ C. kabakovi sp.n. 
Elytra 1.41-1.50 (1.45) times as wide as long, 1.20-1.30 (1.25) times as wide as pronotum, with basal depressions very slight to indistinct. Striae deep, coarsely punctate; intervals convex on disc, more so at apex, densely punctatepubescent, with 5-6 irregular rows of punctures and long pubescence.

Prosternum, metaventrite in anterior half, pleura and sides of abdominal sterna II-V very coarsely and densely yet somewhat irregularly punctate, venter otherwise finely and densely punctate-pubescent.

Tarsomere 4 but slightly emarginate, $1.63-1.86$ (1.71, $\mathrm{n}=3$ ) times as long as wide in hind legs.

Aedeagus (Figs 34, 38, 72-73): median lobe with apical lamella very short and truncate apically; internal sac with a spiny sclerite in addition to apical one; parameres as in Figs 54-55.

VARIABILITY. The legs and antennae are paler in the holotype and two paratypes from Thai Nguen, with antennae being entirely pale and femora barely infuscate in two of these specimens. Posterolateral pronotal setae are easily abraded: three out of 11 specimens examined have the seta on one side, while the rest have none.

DIAGNOSIS. This species strongly resembles $C$. qiongensis Pang et Tian, 2012, being easily distinguishable in having the pronotum hexagonal and much more transverse, $v s$. subcordate, only a fifth wider than long. Otherwise the two are quite similar; the pale appendages distinguish them from other Oriental congeners. Of the two, at least C. pallidicornis sp.n further differs in having a well-formed sclerite (besides the apical one) in the penile internal sac.

DISTRIBUTION. Phu Tho and Thai Nguen provinces, northern Vietnam.

NAME. Refers to pale antennae.

HABITATS AND HABITS. Occurring in montane semideciduous monsoon broadleaf forests at lower altitudes (below $500 \mathrm{~m}$ ).

\section{Craspedophorus kabakovi Fedorenko, sp.n.} Figs 19, 35, 39, 56-57.

MATERIAL. Holotype $0^{7}$ (ZISP): 'VIETNAM, mountains NO [NE of]/ Cua Rao 500 m / 20.3.1962 Kabakov' [micrograph, in Russian]. Paratypes: O' $^{7}$ (ZISP), 'Vietnam, prov[ince]. Nghe-/ tin, env. Konku-/ ong on r[iver]. Ca. 1.X.[1]994/ Darevsky, Orlov' [hw, in Russian]; O', (BMNH): 'Laos/ Muong Om./ 19.I.1919./ R.V.de Salvaza.' [ts], 'Brit. Mus./ 1921-89.' [ts]; $\sigma^{7}$ (BMNH), same labels, except for 'Laos/ Ban Ban./ 3.I.1919./...' on data label.

DESCRIPTION. Like C. pallidicornis sp.n., except as follows: Body as in Fig. 19, BL 12.3-14.1 mm. Black, tarsomere 1 brown black, mandibular apices pale brown, tarsomeres 2-5 rather pale brown; palps rather dark brown, last palpomere apically margined with yellow; antennae slightly vary in colour, mostly with antennomeres $1-3$ nearly black to brown black and the other antennomeres pale brown, sometimes with antennomeres 4-6 intermediate in colour. Elytron with anterior macula inwardly reaching stria 5 or 4 posterior macula on intervals $4-8$ or $5-8$. Microsculpture more superficial on head, almost obsolete on vertex and neck. Pubescence on pronotum greyish; 4-6 irregular longitudinal rows of punctures traceable in interval 3 or 4 at mid-length.

Head: gena and neck meet at right angle; frontal sulci deeper; neck constriction very deep, adjoining the conspicuous posteromedial impression on vertex; neck almost smooth behind while finely rugulose in front. Scape and antennomere 3 longer, scape $1.42-1.55(1.50, n=5)$ times as long as eye tubercle, AR 0.95-1.01 (0.98) : 0.38-0.45 (0.42): $0.61-0.68(0.64)$.
Pronotum a little longer, $1.28-1.32(1.33, \mathrm{n}=4)$ times as wide as long, 1.74-1.80 (1.87) times as wide as head, broadest just in front of the middle, PLw/PL 0.46-0.50 (0.48, n=5). Base slightly wider than apex, PWb/a 1.08-1.24 (1.16). Sides rounded at middle, a little less so in apical half. Explanate lateral margin moderately wide in apical third, much wider behind, slightly reflexed, but clearly separated from disc; lateral bead very narrow, well defined in apical half, fainting at or just behind middle. Disc very closely, in part confluently punctate, explanate lateral margin impunctate to very sparsely punctate in basal half, except for fine punctures of pubescence.

Elytra $1.49-1.53(1.51, \mathrm{n}=4)$ times as wide as long, 1.22 1.27 (1.23) times as wide as pronotum.

Fourth metatarsomere 1.67-1.82 times as long as wide.

Aedeagus (Figs 35, 39, 56-57) quite similar to that of $C$. pallidicornis sp.n., but internal sac of aedeagus without any sclerite other than apical one. Besides, right paramere, as well as left one at apex, is less desclerotized.

DIAGNOSIS. Very similar to C. pallidicornis sp.n. from which it differs primarily by the dark appendages and no additional sclerite in the internal sac of aedeagus. Besides, the scape is longer relative to both the eye tubercle and antennomere 3.

VARIABILITY. The illustrated paratype (Fig. 19) was originally selected as the holotype. Yet examining further $\mathrm{BMNH}$ material has revealed that this specimen stands out from the remainder. It is stouter, with elytra slightly shorter (EL/EW 1.43) and pronotum wider (PW/PL 1.41), resulting in EW/PW 1.16 and PW/HW 2.0 - differences that seem to reflect individual rather than geographical variability.

DISTRIBUTION. Northern Vietnam (Nghe An Province) and adjacent parts of Laos (Xianghoang and probably also Houaphan Province).

NAME. Given after the late Oleg N. Kabakov, the eminent geologist and coleopterist who collected the holotype.

\section{Craspedophorus phoupanensis} Häckel et Kirschenhofer, 2014 Figs 20, 27.

MATERIAL. Paratype (CH): 'SE ASIA NE-LAOS Hua Phan pr./ Phu Pane Mt. 1200-1900m/ 21 ${ }^{\circ} 12^{\prime} \mathrm{N} 103^{\circ} 59^{\prime} \mathrm{E}$ V - 2012/ lgt. S.Jákl \& Lao collectors', 'Martin Häckel/ collection -/ PRAGUE, Czech Republic', 'PARATYPE:/ Craspedophorus phoupanensis n. sp./ det. Häckel \& Kirschenhofer, 2014'.

Additional material. O (SIEE): 'N-Vietnam, Dien Bien Prov[ince]./ Muong Nhe Nat[ure]. Reserve,/ $22^{\circ} 21^{\prime} 54^{\prime \prime} \mathrm{N}$, $102^{\circ} 14^{\prime} 15^{\prime \prime} \mathrm{E}, / \mathrm{h}=800 \mathrm{~m}$, Exped.Russ.-Vn./ Tropic.C[ente]r, 1120.VI.2014/ A.Abramov, A.Shchinov leg.'; + (BMNH): 'Laos/ La Casade./ 5.I.1918./ R.V.de Salvaza.' [ts], 'Brit. Mus./ 1921-89.' [ts]; + (BMNH): 'Luang Prabang./ Muong You./ R.V.de Salvaza./ 2.XII.1918' [ts], '2208' [hw], 'Brit. Mus./ 1921-89.' [ts].

REDESCRIPTION. As for C. kabakovi sp.n., except as follows: Body (Fig. 20) larger, BL 14.2-15.8 mm. Antennomeres 4-11 brown, gradually paler apicad or antennae almost black, gradually and very slightly paler apicad; tarsi dark brown, hardly paler apicad; palps almost black. Elytron with anterior macula reaching or not quite reaching stria 4 inward and expanding outward onto epipleuron or leaving epipleuron and lateral edge infuscate; posterior elytral macula on intervals 4-8 or 5-8. Microsculpture sharp throughout, making dorsum rather dull. Elytra very densely pubescent, intervals 3 or 4 at mid-length with 7 irregular rows of fine punctures.

Head (Fig. 27): eyes small, teardrop-shaped, with apical margin shifted apicad, so that genae slightly oblique inwards and meeting neck at acute angle; frontal sulci wide, deep to moderately deep, yet short and never reaching anterior su- 
praocular seta or even anterior margin of eye; neck about as rugulose as that of $C$. pallidicornis sp.n. Scape longer, 1.65$1.71(1.68, \mathrm{n}=3)$ times as long as eye tubercle, AR $0.92-0.93$ (0.93) : 0.32-0.38 (0.36) : 0.63-0.68 (0.67).

Pronotum subhexagonal, PW/PL 1.29-1.38 (1.34), PW/ HW 1.80-1.99 (1.87), broadest at mid-length, PLw/PL 0.490.51 (0.50); base truncate, almost $1 \frac{1}{2}$ times as wide as apex, $\mathrm{PWb} / \mathrm{a} 1.40-1.55$ (1.46), owing chiefly to apical angles adjoining neck; apex slightly concave; sides widely rounded at middle and just behind apical angle, a little less rounded in between and straight behind middle. Basal angles obtuse, narrowly rounded apically, with a minute sharp denticle just in front and a minute emargination in front of the latter. Explanate lateral margin narrow in apical two fifths, much wider behind, slightly reflexed in apical half and a little more so in basal two fifths; lateral bead obliterate in basal S!-1/2. Basal foveae fairly shallow yet well-defined, straight and diverging a little forward. Disc moderately coarsely, confluently yet shallowly punctate. Lateral setae two, with an additional shorter setae in front of anterolateral seta.

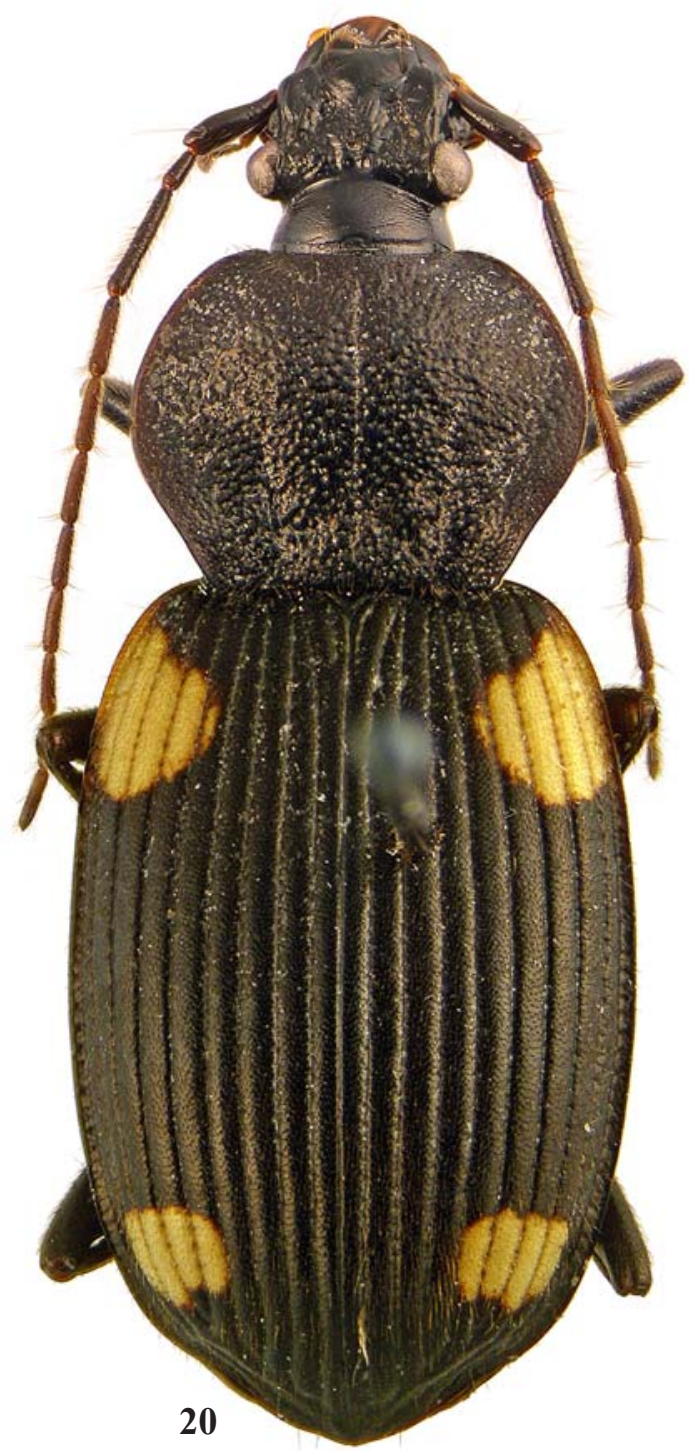

Elytra slightly flattened anteriorly, but without basal depressions, EL/EW 1.48-1.52 (1.50), EW/PW 1.25-1.29 (1.27). Striae rather finely punctate, intervals clearly less convex on disc.

Metatarsomere 41.60 times as long as wide.

COMMENTS. The species is similar to C. kabakovi sp.n., C. pallidicornis sp.n. and C. tamdaoensis, but the apical pronotal angles almost touch the neck, and the eye tubercle meets the neck at a clearly acute (vs. right) angle. C. tamdaoensis further differs from the other species in having the pronotum clearly larger, and thus longer relative to the elytra.

In the original descriptions [Häckel, Kirschenhofer, 2014b], C. phoupanensis and C. tamdaoensis were said to have elytra [sub]parallel-sided, vs. broadly oval in C. chiangmaiensis. The illustrated holotypes of these species [ibid., Figs 12, 40,41] suggest otherwise.

DISTRIBUTION. Northern Laos (Louangphabang and Houaphan provinces) and northern Vietnam (Dien Bien Province).

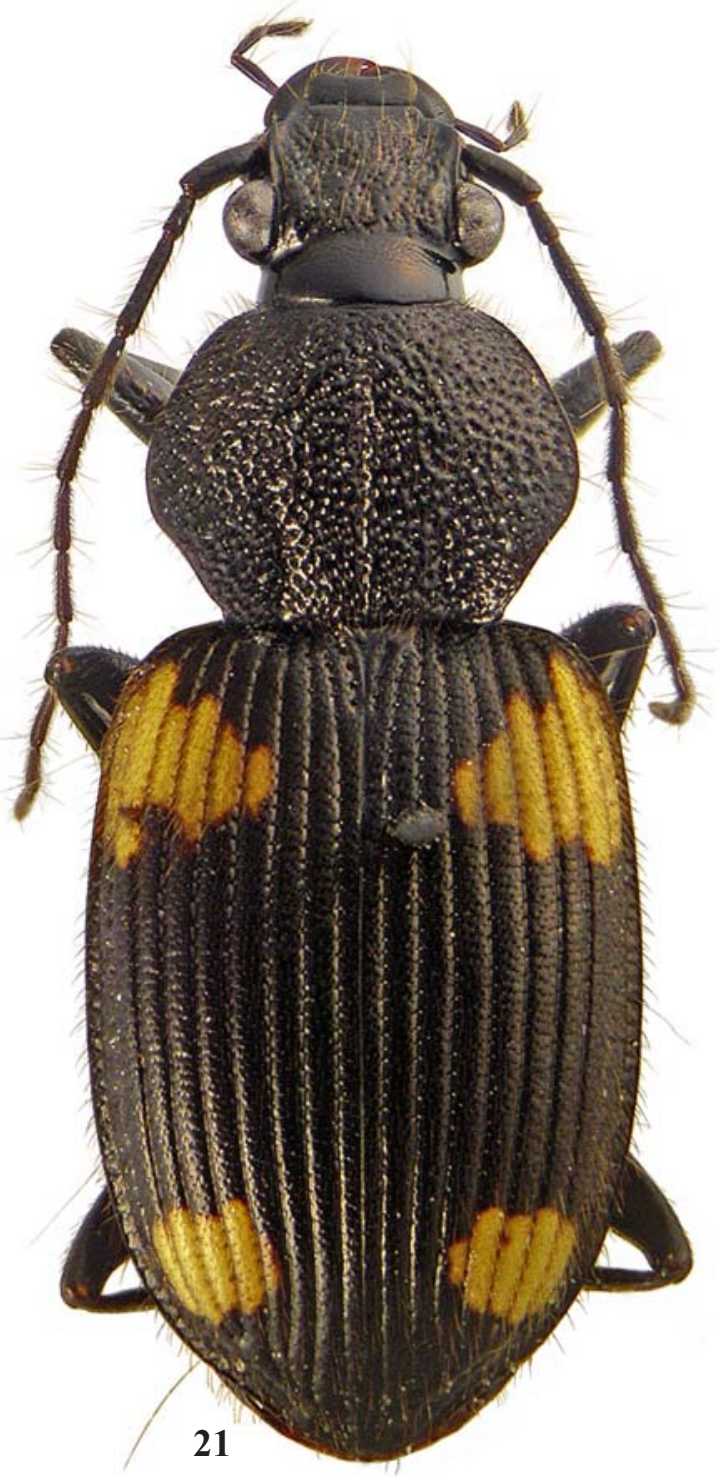

Figs 20-21. Craspedophorus, dorsal habitus: $20-$ C. phoupanensis; $21-$ C. s. saundersii. Pис. 20-21. Craspedophorus, габитус сверху: $20-$ C. phoupanensis; $21-$ C. s. saundersii. 
6. The sparsepunctatus species group nov.

DIAGNOSIS. Similar to the dalatensis-group, except as follows: anterior elytral macula not reaching beyond stria 9; head large, short and very wide (Figs 24, 25); eyes slightly to conspicuously flattened, genae fairly long and clearly pubescent in dorsal view; labrum flat, with a pair of large round impressions.

Median lobe of aedeagus very distinctive: basal bulb very large and not well separated from the remainder, apical lamella flat, large and triangular (Figs 40-41, 44-45), instead of being short and truncate, as in most members of Craspedophorus and allied genera. Internal sac long, tubiform, and rather simple in shape, with no conspicuous bulbs but with very large apical sclerites (Figs 44, 77-78).

Scape clearly to indistinctly concave inside. Antennomere 3 with long and sparse erect setae. Pronotal basal flange thick. Penultimate labial palpomere subtriangular, its inner margin plurisetose or with a shorter lateral seta in addition to two strong setae. Pronotum with a seta at basal angles and 5 to 7 lateral setae in apical 2/3. Parameres glabrous, right paramere clearly shorter than left one. Elytra sparsely punctate-pubescent. Body large to very large.

The group includes three species from Vietnam, two of which are described as new below, and one, C. kerberos Häckel et Kirschenhofer, 2014, is transferred from the lykaon-group.

Craspedophorus sparsepunctatus Fedorenko, sp.n.

Figs 22, 28, 40, 44, 52-53, 77.

MATERIAL. Holotype $\sigma^{7}$ (ZMMU), labelled: 'S[outh] Vietnam, Lam Dong Prov./ Bi Doup — Nui Ba Nat[ure]. Res[erve]/ $12^{\circ} 07^{\prime} \mathrm{N}, 108^{\circ} 39^{\prime} 44^{\prime \prime} \mathrm{E} / \mathrm{Bi}$ Doup Mt., N[orthern] slope/ h=17001900 m, 9./ leg. D. Fedorenko V.2009'. Paratypes (ZMMU, SIEE, ZISP): $9 \sigma^{7} O^{7}, 4$ OPQ, same data, as well as additional dates: 3 and 6.V.2009, 12, 16 and 19-22.IV.2008; + , same data, but $12^{\circ} 10^{\prime} 44^{\prime \prime}$ $\mathrm{N}, 108^{\circ} 40^{\prime} 44^{\prime \prime} \mathrm{E}$, env. Long Lanh, $\mathrm{h}=1400-1600 \mathrm{~m}, 17-18 . I V .2008$; +, same data, but $12^{\circ} 11^{\prime} \mathrm{N} / 108^{\circ} 42^{\prime} \mathrm{E}, \sim 4 \mathrm{~km}$ SSE of Hon Giao Mt.,
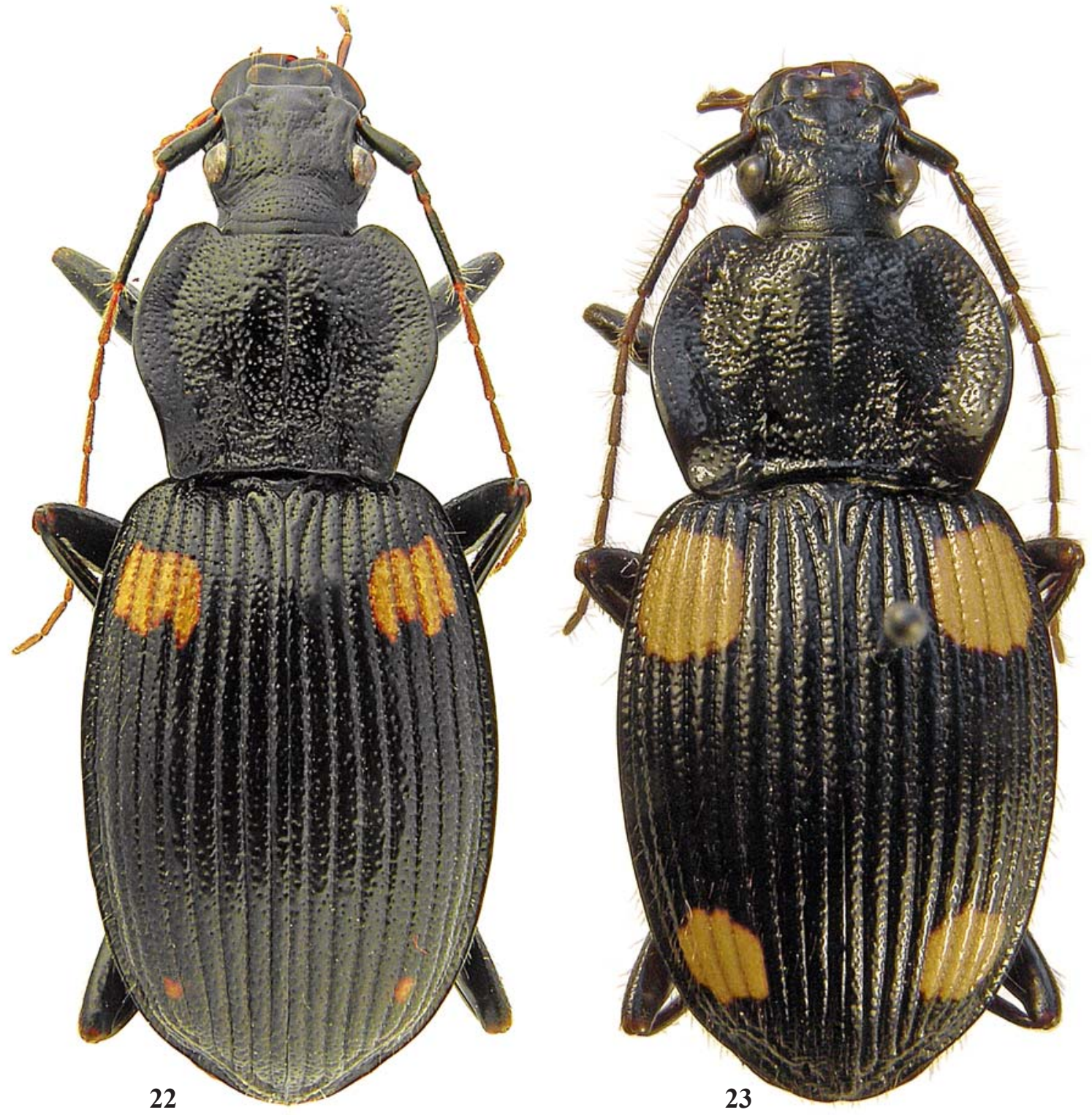

Figs 22-23. Craspedophorus, dorsal habitus: $22-$ C. sparsepunctatus sp.n.; $23-$ C. expansicollis sp.n.

Pис. 22-23. Craspedophorus, габитус сверху: $22-$ C. sparsepunctatus sp.n.; $23-$ C. expansicollis sp.n. 
$\mathrm{h}=1500-1800 \mathrm{~m}, 2-3 . I V .2008 ; \sigma^{\top}$,, , same data, but $\mathrm{h}=1500-1700$ m, 5.V.2009; $\sigma^{\gamma}, 2$ 우, Dak Lak province, Chu Yang Sin Natn. Park, $12^{\circ} 22^{\prime} 40^{\prime \prime} \mathrm{N} / 108^{\circ} 21^{\prime} 11^{\prime \prime} \mathrm{E}, 1.5 \mathrm{~km}$ W [of ] Chu Pan Phan Mt, $\mathrm{h}=1650 \mathrm{~m}, 30 . \mathrm{III}-11 . \mathrm{IV} .2012$, as well as 21 and 29.III.1913, D. Fedorenko leg.

DESCRIPTION. Body (Fig. 22) large, BL 24-27.2 mm. Black, tarsi brown, antennomeres 4-11 red, palps pale brown to reddish-brown, elytral maculae rather small, especially the posterior one, and rounded in individuals with larger maculae; anterior macula on intervals $5-8$ or $5-9$, rarely $6-8$, usually slightly flexuose behind, posterior macula on intervals 5-7, 67 or 6 alone, rarely on 6-8. Microsculpture sharp on forehead, superficial to almost obliterate on vertex and neck except its base, rather sharp on pronotum, very superficial on pronotal disc, superficial yet distinct on elytra. Pubescence greyish, short to long, sparse on head, moderately dense on pronotum, sparse on elytra, intervals $1-7$ each with a row of fine punctures close to striae, combined with larger, sparse and very irregular punctures in between, for a total of 2-4 rows; interval 8 with four rows of punctures due to larger punctures being denser.

Head (Fig. 28) large, its sides slightly diverging forward; eyes rather small; genae oblique and long (0.41-0.43 as long as the eye, $n=2$ ), conspicuously pubescent in dorsal view, meeting neck at very obtuse angle. Frontal sulci deep, wide and short, not or hardly reaching the level of eye's front margin, but extending onto clypeus and converging there, with a raised area in between, limited behind by a shallow V-shaped depression. Vertex flat to subconvex; neck constriction convex forward, moderately deep to shallow, with apex very slightly behind the level of eye's posterior margin. Labrum flat and slightly sinuate at apical margin, with inner pair of dorsal setae just in front of middle and 1-2 minute setae close to the middle of apical margin. Frons and vertex moderately densely and moderately coarsely punctate, sides of frons and often also central part of vertex on each side of the middle impunctate or with few punctures. Clypeus slightly uneven throughout or only basally due to sparse to moderately dense yet rather fine punctures, often combined with fine longitudinal rugulae, sometimes nearly smooth, with punctures confined to lateral impressions. Neck with transverse and coarse, sparse to dense, rugae in front and fine, irregular rugulae with coarse but sparse punctures behind. AR $0.82-0.86(0.83, \mathrm{n}=5): 0.33-0.37(0.35)$ : 0.52-0.57 (0.54), scape 1.03-1.23 (1.11) times as long as eye tubercle. Penultimate labial palpomere bisetose at inner margin; terminal palpomere strongly securiform, with inner margin $3 / 5$ as long as apex in male while slightly less than $4 / 5$ as long as apex in female; outer margin concave while slightly convex at apex, inner margin concave to straight, apex as in C. dalatensis sp.n.

Pronotum subcordate, 1.26-1.37 (1.32) times as wide as long, $1.71-1.76(1.73, \mathrm{n}=8)$ times as wide as head, broadest at the middle, with posterolateral seta and 5-7 setae in apical half. Base straight, apex slightly concave. Sides widely rounded in apical 2/3-3/4, very gently to indistinctly sinuate in basal $1 / 2$. Apical angles porrect and rather widely rounded; basal angles subrectangular, rounded apically, protruding just behind pronotal base. Explanate lateral margin flat, well separated from disc, wide and strongly reflexed throughout, wider towards base, much more so in basal third, engulfing the area lateral to basal fovea; lateral bead missing. Median line moderately deep, fading towards base and apex, basal foveae sulcate, slightly arched inwards, deep to rather shallow, much deeper basally, shallower and wider apically, almost reaching the middle. Disc slightly convex to nearly flat, coarsely and densely yet irregularly punctate, often rather sparsely punctate at each side midway from median line.

Elytra 1.45-1.54 (1.51) times as wide as long, 1.35-1.46 (1.40) times as wide as pronotum, without or with very short and shallow basal depressions. Striae well impressed, moderately coarsely punctate at bottom, intervals flat to slightly convex on disc, more convex at base and still more so before apex.

Venter coarsely yet sparsely punctate at sides, including prothorax, metaventrite, pleura and abdominal sternite II; mesoand metaventrites, as well as abdomen, finely and densely punctate-pubescent along the middle, with sparser punctation on sides of abdominal sterna 5-7, venter otherwise very sparsely punctate-pubescent to smooth and glabrous.

Tarsi fairly short, 4th metatarsomere 1.77-2.12 (1.91, $\mathrm{n}=5$ ) times as long as wide, with greater apical lobe long, a third as long as tarsomere, LL/LT4 $=0.3-0.44(0.35)$.

Aedeagus (Figs 40, 44, 52-53, 77): median lobe in lateral view gently and evenly concave on ventral side. Right paramere long, subtriangular, gently tapering apicad.

DIAGNOSIS. Similar to $C$. kerberos, differs in being more slender, with the elytra $1^{1 / 2}\left(\mathrm{vs} .1^{2} / 5\right)$ as long as wide, and larger, $25-28$ vs. $24 \mathrm{~mm}$ in length.

DISTRIBUTION. The Dalat Plateau within Lam Dong and Dak Lak provinces, south Vietnam.

HABITATS AND HABITS. The species prefers altitudes above $1,600 \mathrm{~m}$, where it lives syntopically with $C$. breviceps sp.n. (see also the respective section under the dalatensisgroup).

\section{Craspedophorus expansicollis Fedorenko, sp.n.} Figs 23, 29, 41, 45, 58-59, 78.

MATERIAL. Holotype $\sigma^{\top}$ (ZISP) labelled [hw]: 'Vietnam, Gia-Lai $\operatorname{Pr}[$ ovince]./ Ankhi distr./ Buoenloy village/ 5-10.XI.1993 Starikov'.

DESCRIPTION. As for C. sparsepunctatus sp.n. except as follows: Robust (Fig. 23), BL $23.2 \mathrm{~mm}$. Black, palps brown, tarsi increasingly brown apicad, antennomeres 4-11 red, anterior and posterior elytral maculae round, spanning intervals 5-9 or 5-8, respectively. Microsculpture sharp on forehead, superficial behind, superficial yet distinct on pronotum and elytra, almost obliterate over pronotal disc, giving it slightly opalescent lustre. On each elytral interval, 2-3 irregular rows of punctures are usually traceable.

Head (Fig. 29): sides diverging forward in front of rather convex eyes; genae slightly shorter ( 0.35 times as long as eye) . Frontal sulci as very shallow foveae, clypeus with a pair of lateral longitudinal impressions. Head flat, with frons barely convex between frontal sulci. Frons and vertex moderately densely punctate. Clypeus minutely and very sparsely punctate. Neck impunctate. AR $0.73: 0.33: 0.52$, scape 1.19 times as long as eye tubercle. Penultimate labial palpomere plurisetose at inner margin; last labial palpomere similar, with inner margin straight, outer margin more convex before apex which is less convex.

Pronotum transverse, 1.51 times as wide as long, 1.91 times as wide as head, broadest at the middle; base wider than apex, very slightly concave; apex concave a little. Sides widely rounded, apical angles porrect, basal angles slightly obtuse, widely rounded apically, protruding a little behind

Figs 24-31. Craspedophorus, head, dorsal aspect: $24-$ C. dalatensis sp.n.; 25 - C. breviceps sp.n.; 26 - C. pallidicornis sp.n.; 27 C. phoupanensis; $28-$ C. sparsepunctatus sp.n.; $29-$ C. expansicollis sp.n.; $30-$ C. s. saundersii; $31-$ C. crebrepunctatus sp.n.

Рис. 24-31. Craspedophorus, голова сверху: $24-$ C. dalatensis sp.n.; $25-$ C. breviceps sp.n.; $26-$ C. pallidicornis sp.n.; 27 C. phoupanensis; $28-$ C. sparsepunctatus sp.n.; $29-$ C. expansicollis sp.n.; $30-$ C. s. saundersii; $31-$ C. crebrepunctatus sp.n. 


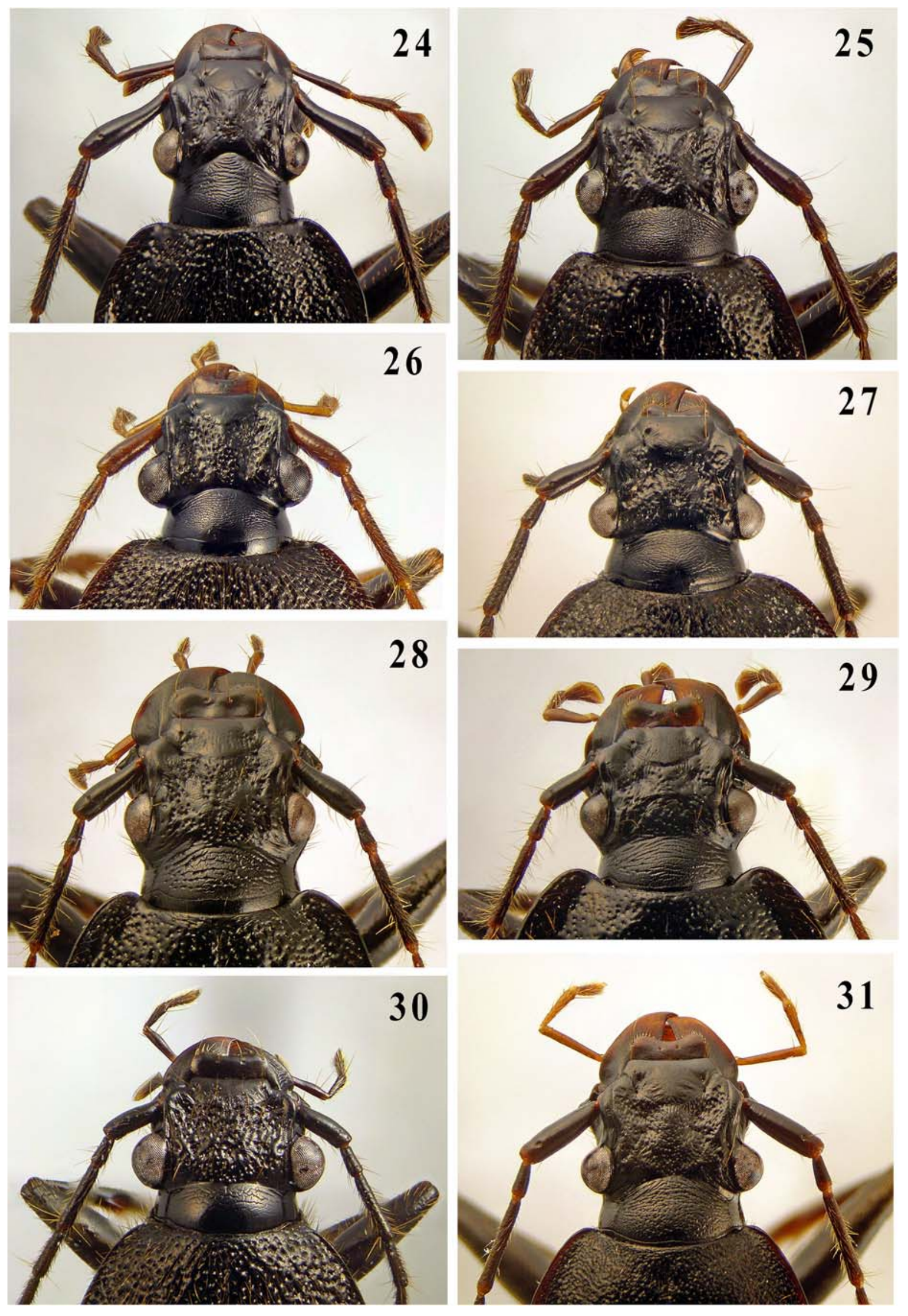


pronotal base. Explanate lateral margin very wide and slightly reflexed in apical third, much wider behind and conspicuously reflexed behind, separated from disc throughout. Basal foveae sulcate and deep, nearly parallel. Disc convex, moderately coarsely and densely punctate.

Elytra 1.41 times as wide as long, 1.21 times as wide as pronotum, with very shallow basal depressions. Striae rather finely punctate at bottom, intervals slightly convex on disc.

Propleura and mesepisterna smooth and glabrous in posterior half.

Metatarsomere 41.82 times as long as wide, its greater apical lobe a third ( 0.34 times) as long as tarsomere.

Aedeagus (Figs 41, 45, 58-59, 78): median lobe in lateral view with ventral side gently convex proximal to apical lamella; apical lamella in dorsal view very gently sinuate on left side. Right paramere wide and widely rounded apically, much wider than in C. sparsepunctatus sp.n.

DIAGNOSIS. Easily distinguishable from C. sparsepunctatus sp.n. by more robust body and smaller size, very shallow frontal foveae, impunctate neck, and differently shaped pronotum with base clearly wider than apex.

DISTRIBUTION. Buonloi, An Khe district, Gia Lai Province, central Vietnam.

HABITATS AND HABITS. No data.
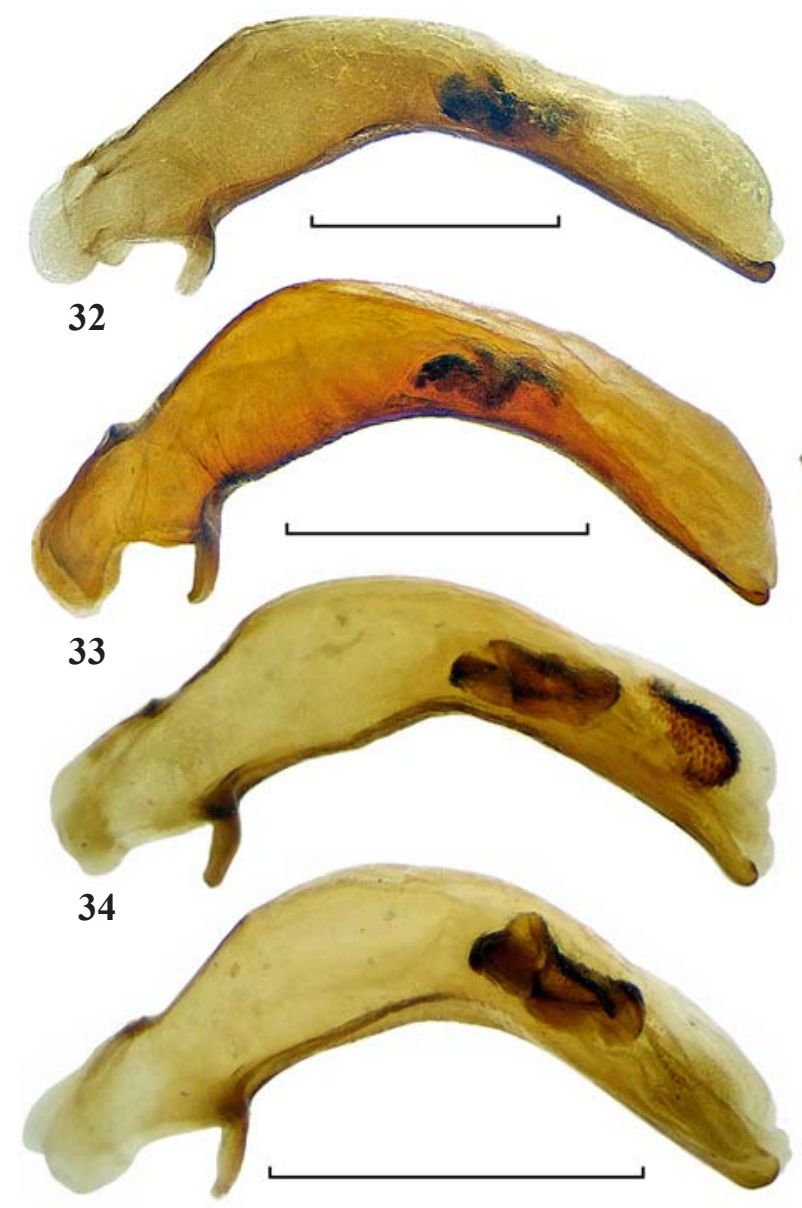

35
7. The crebrepunctatus species group, nov.

DIAGNOSIS. Body shape and proportions as in the dalatensis-group, except as follows: anterior elytral macula reaching stria 9; scape subconvex at inner (anterior) margin; antennomere 3 without long erect setae proximal to verticellate ones; pronotal basal flange thin; eyes small and prominent. Median lobe of aedeagus with a very small dorsal slot of basal orifice, internal sac peculiar in shape; penultimate labial palpomere bisetose at inner margin; terminal labial palpomere with apex clearly shorter than inner margin in both sexes.

This group probably incudes also C. cenwanglao from China and C. luzonensis Häckel et Anichtchenko, 2015 from the Philippines in addition to the nominal species described below.

HABITATS AND HABITS. As for the dalatensis-group.

\section{Craspedophorus crebrepunctatus Fedorenko, sp.n.} Figs 17, 31, 42, 46, 60-61, 74-76.

MATERIAL. Holotype $\sigma^{7}$ (ZMMU) and paratype $\sigma^{7}$ (SIEE) labelled: 'N[orth] Vietnam, Lao Cai Prov[ince]./ Hoang Lien Son Mt. ridge,/ env. Fansipan Mt, Tram Ton/ h=1950-2100[ m a.s.1.], / 15-30. / leg. D. Fedorenko VII.2007'. Paratypes $\bigcirc^{7}$,, (SIEE), same locality: 'N Vietnam, E part of/ prov. Lao Cai,/ env. Sa Pa,/ $\sim 1600$ m a.s.1. / V.2006/ leg. A. Anichkin'.
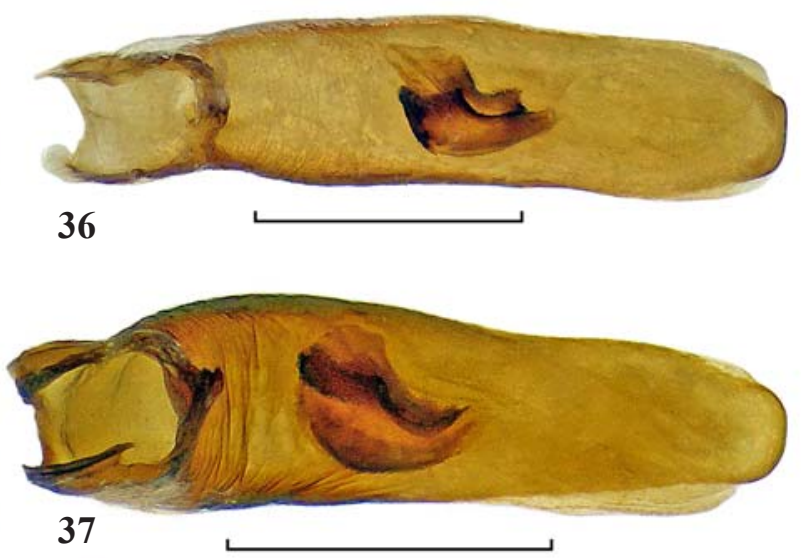

37
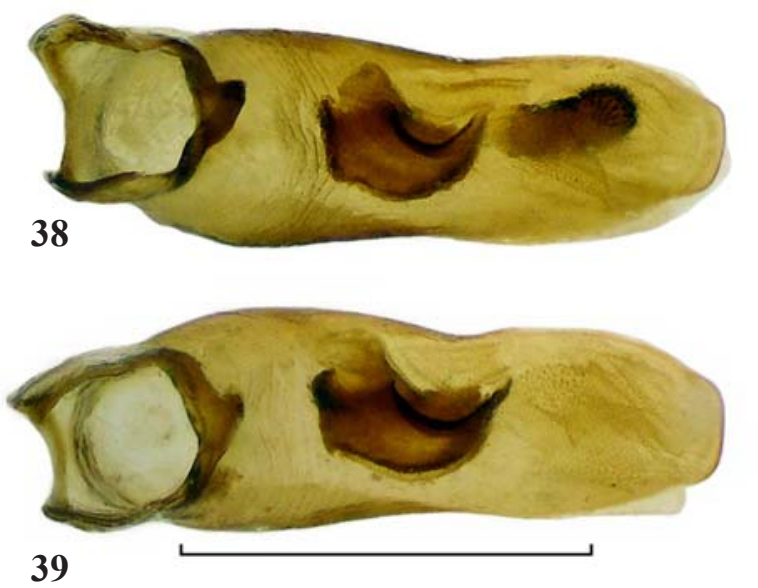

Figs 32-39. Craspedophorus, median lobe of aedeagus: 32, 36 - C. dalatensis sp.n.; 33, 37 - C. breviceps sp.n.; $34,38-C$. pallidicornis sp.n.; 35, 39 - C. kabakovi sp.n.; 32-25 - left lateral aspect; 36-39 — ventral aspect. Scale bars - 1 mm.

Рис. 32-39. Craspedophorus, средняя доля эдеагуса: 32, 36 - C. dalatensis sp.n.; 33, 37 - C. breviceps sp.n.; $34,38-$ C. pallidicornis sp.n.; 35, 39 - C. kabakovi sp.n.; 32-35 - вид слева; 36-39 - вентрально. Масштаб - 1 мм. 
DESCRIPTION. Body slender (Fig. 17), BL 16.7-19 $\mathrm{mm}$. Black, tarsi dark red to brown, palps reddish-brown rather pale, more or less widely yellow along apical margin, antennomeres 4-11 red, elytral maculae rounded, anterior on intervals 6-9, posterior on 5-8. Entire dorsum rather dull due to sharp microsculpture. Pubescence greyish and fairly short, very sparse on head and very dense on pronotum and elytra, intervals each with 7-8 rows of fine setigerous punctures.

Head (Fig. 31): sides diverging forward; genae short, transverse, meeting neck at almost right to slightly obtuse angle, nearly glabrous in dorsal view; frontal sulci short, wide and deep, with a moderate convexity in between; vertex nearly flat to subconvex, with indistinct punctate depression in the middle; neck constriction rather deep, evenly convex forward and almost reaching the level of eye mid-length. Frons and vertex rather finely and closely punctate, a little rugulose to sparsely longitudinally strigose, clypeus posteriorly with rather dense but very shallow punctures; neck densely rugulose-punctate. Scape 1.75-1.84 (mean 1.80) times as long as eye tubercle, with a single dorsoapical seta, without or with a few additional posteroventral setae before apex, antennomere 3 without erect setae. AR 0.94-1.03 $(0.97, \mathrm{n}=4): 0.33-0.38(0.35): 0.67-0.72(0.70)$. Labrum without cilia in the middle of anterior margin. Penultimate labial palpomere bisetose at inner margin. Terminal pal- pomere securiform yet slender in both labials and maxillaries, terminal labial palpomere at inner margin ca. $1.4\left(\sigma^{7}\right)$ or 1.8 (+) times as long as apex; outer margin very gently and evenly concave, inner margin gently concave just before apex; apex very convex.

Pronotum cordate and long, 1.12-1.13 (1.13) times as wide as long, 1.58-1.65 (1.61) times as wide as head, broadest at the middle. Base straight, apical margin slightly and evenly concave. Sides subconvex in front, sinuate behind, almost parallel before base; apical angles a little rounded at tip, hind angles obtuse, rounded apically, hardly protruding behind pronotal base as wide lobes, with a minute, yet distinct, sharp to blunt denticle and a subtle emargination in front of it. Explanate lateral margin narrow and very slightly reflexed in apical third, much wider and strongly reflexed behind; lateral bead fine yet distinct in anterior 3/5. Median line well impressed, fading towards base and apex; basal and apical transverse impressions missing; basal foveae as moderately deep, nearly parallel sulci slightly converging from base to the site of basal transverse impression, almost reaching the middle. Disc slightly convex up to explanate lateral margin anteriorly, and nearly flat behind. Surface uneven, somewhat rugulose due to confluent punctures, shallow and medium-sized, mixed with fine and very dense setigerous ones.
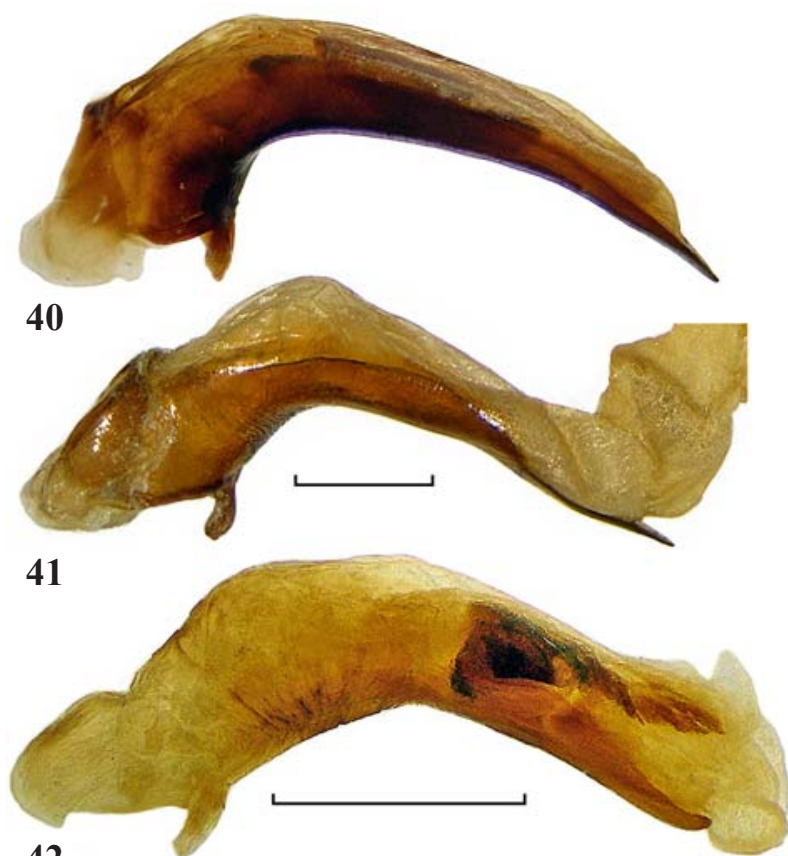

42

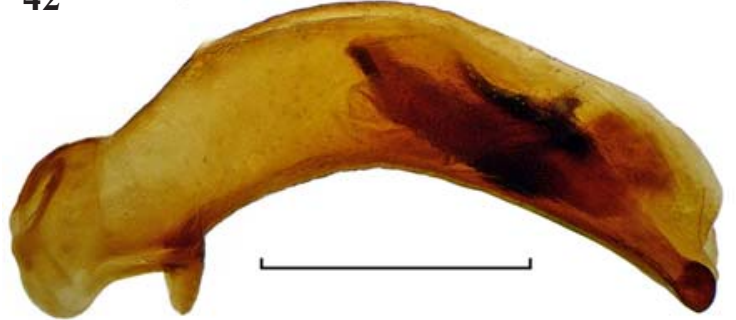

43

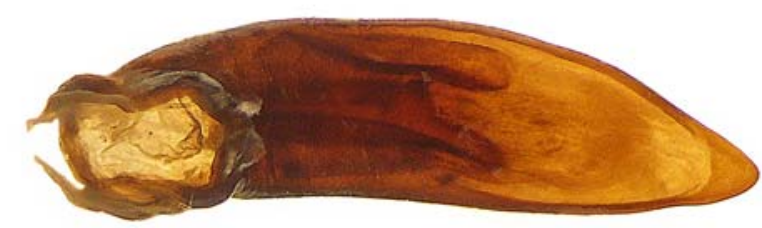

44

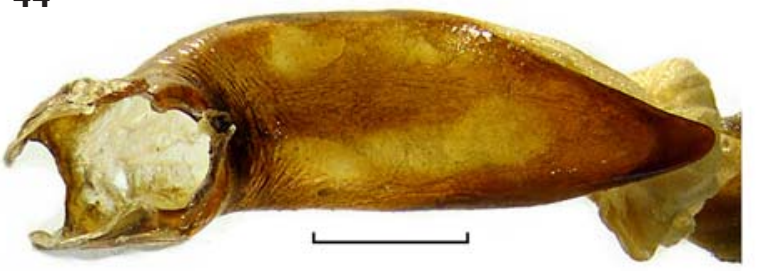

45
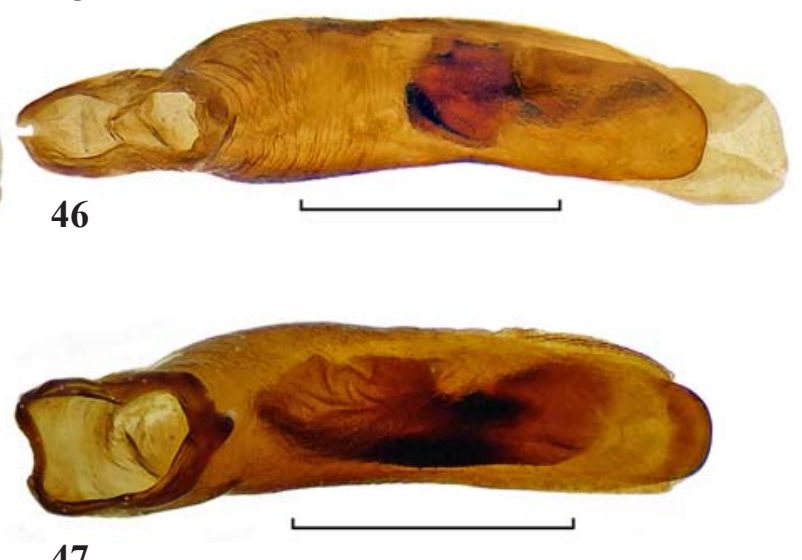

47

Figs 40-47. Craspedophorus, median lobe of aedeagus: 40, 44 - C. sparsepunctatus sp.n.; 41, 45 - C. expansicollis sp.n.; 42, 46 C. crebrepunctatus sp.n.; 43, $47-$ C. alaticollis sp.n.; 40-43 - left lateral aspect; 44-47 — ventral aspect. Scale bars - 1 mm.

Рис. 40-43. Craspedophorus, средняя доля эдеагуса: 40, 44 - C. sparsepunctatus sp.n.; 41, 45 - C. expansicollis sp.n.; 42 , 46 C. crebrepunctatus sp.n.; 43, 47 - C. alaticollis sp.n.; 40-43 - слева; 44-47 - вентрально. Масштаб - 1 мм. 
Elytra 1.40-1.51 (1.44) times as wide as pronotum, 1.50 1.57 (1.54) times as wide as long. Striae minutely to indistinctly punctate at bottom, intervals subconvex on disc, slightly more convex basad, laterad, and apicad.

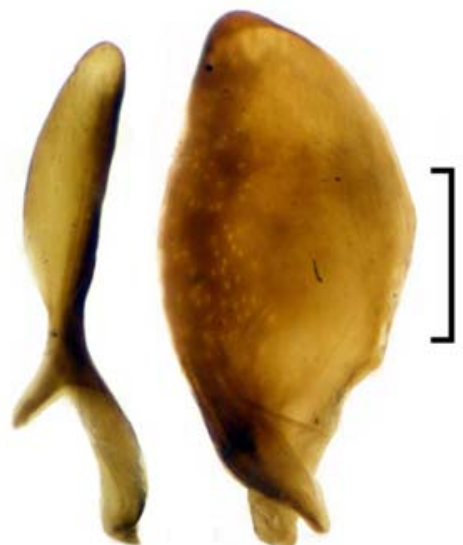

48

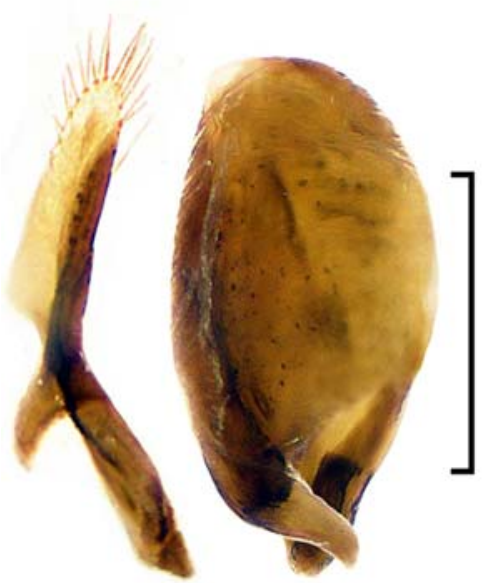

54

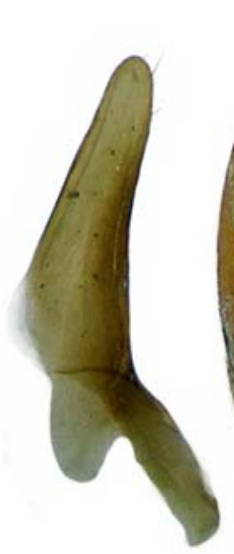

60
55

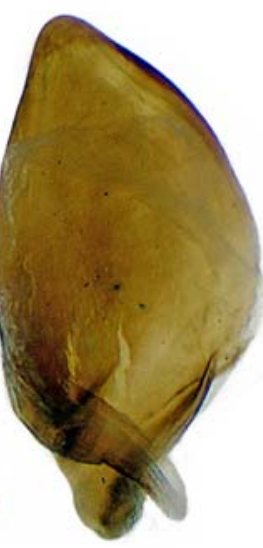

61

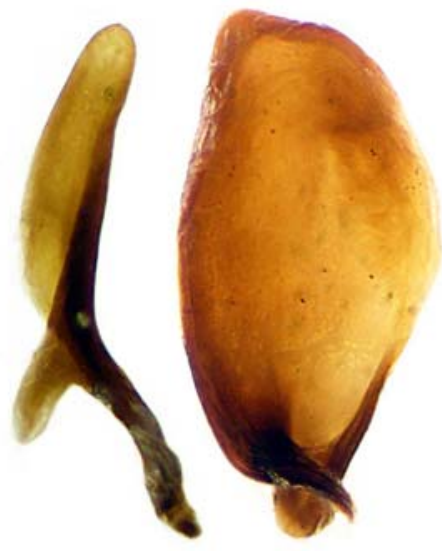

50

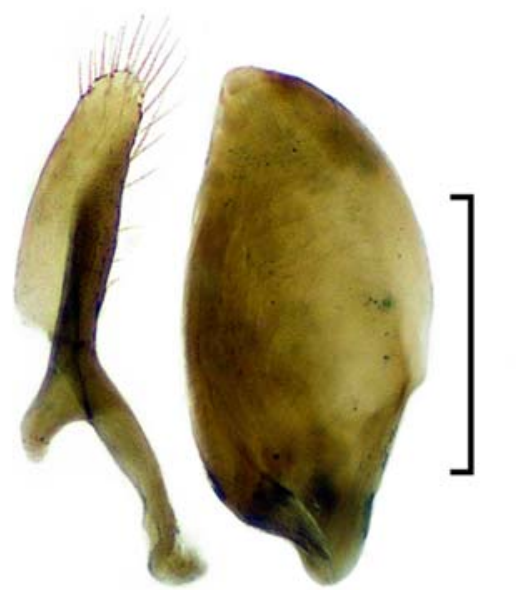

56

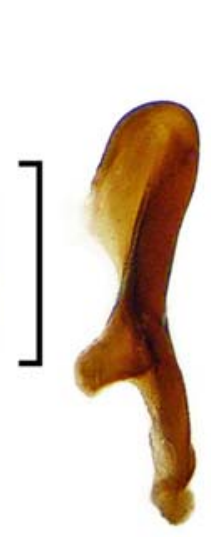

62
57

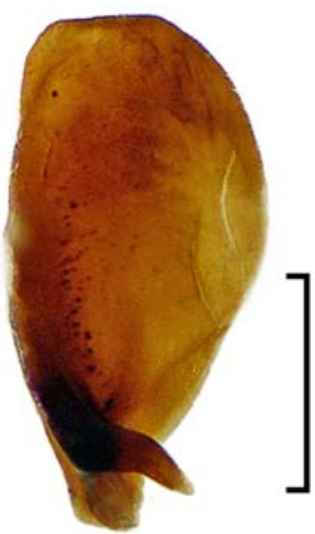

63

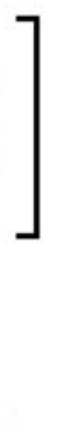

51

58

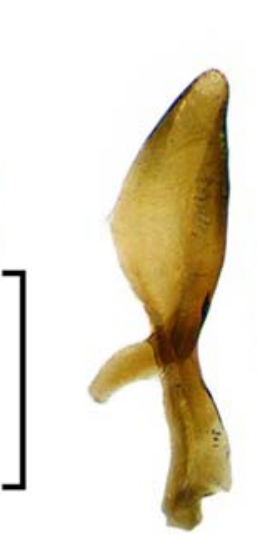

64

52
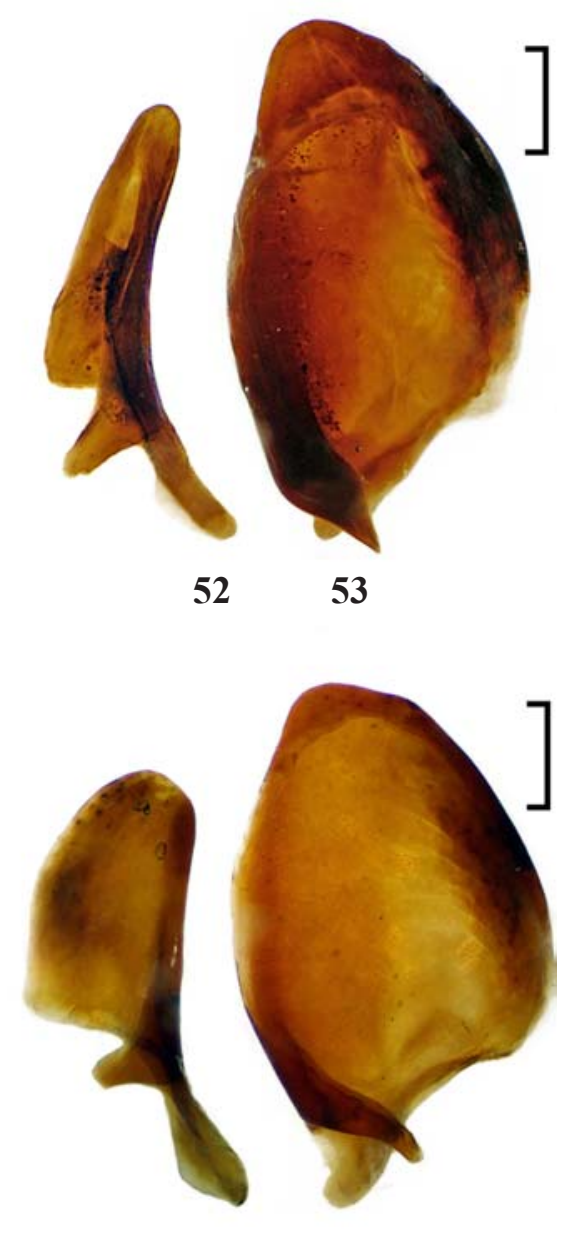

53

59

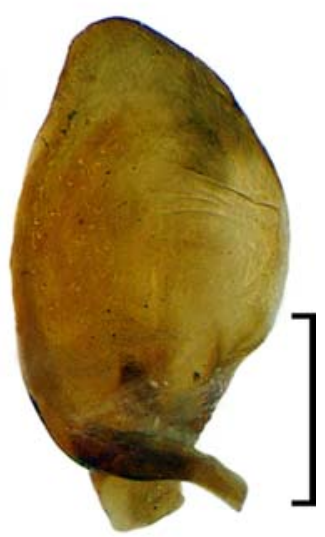

65

Figs 48-65. Parameres: 48-49 - Craspedophorus dalatensis sp.n.; 50-51 - C. breviceps sp.n.; 52-53 - C. sparsepunctatus sp.n.; 54$55-$ C. pallidicornis sp.n.; 56-57 - C. kabakovi sp.n.; 58-59 - C. expansicollis sp.n.; 60-61 - C. crebrepunctatus sp.n.; 62-63 C. alaticollis sp.n.; 64-65 - C. laticollis; 48, 50, 52, 54, 56, 58, 60, 62, 64 - right paramere; 49, 51, 53, 55, 57, 59, 61, 63, 65 -left paramere. Scale bars $-0.5 \mathrm{~mm}$.

Рис. 48-65. Парамеры: 48-49 - Craspedophorus dalatensis sp.n.; 50-51 - C. breviceps sp.n.; 52-53 - C. sparsepunctatus sp.n.; 54 $55-$ C. pallidicornis sp.n.; 56-57 - C. kabakovi sp.n.; 58-59-C. expansicollis sp.n.; 60-61 - C. crebrepunctatus sp.n.; 62-63 C. alaticollis sp.n.; 64-65 - C. laticollis; 48, 50, 52, 54, 56, 58, 60, 62, 64 - правая парамера; 49, 51, 53, 55, 57, 59, 61, 63, 65 - левая парамера. Масштаб - 0.5 мм. 
Tarsi longest in the group, metatarsomere 42.5 times as long as wide, with greater apical lobe very short, 0.15 times as long as tarsomere.
Aedeagus (Figs 42, 46, 60-61, 74-76): basal bulb of median lobe with a very small, short and narrow, dorsal slot. Apical lamella very short, in ventral view truncate, rounded
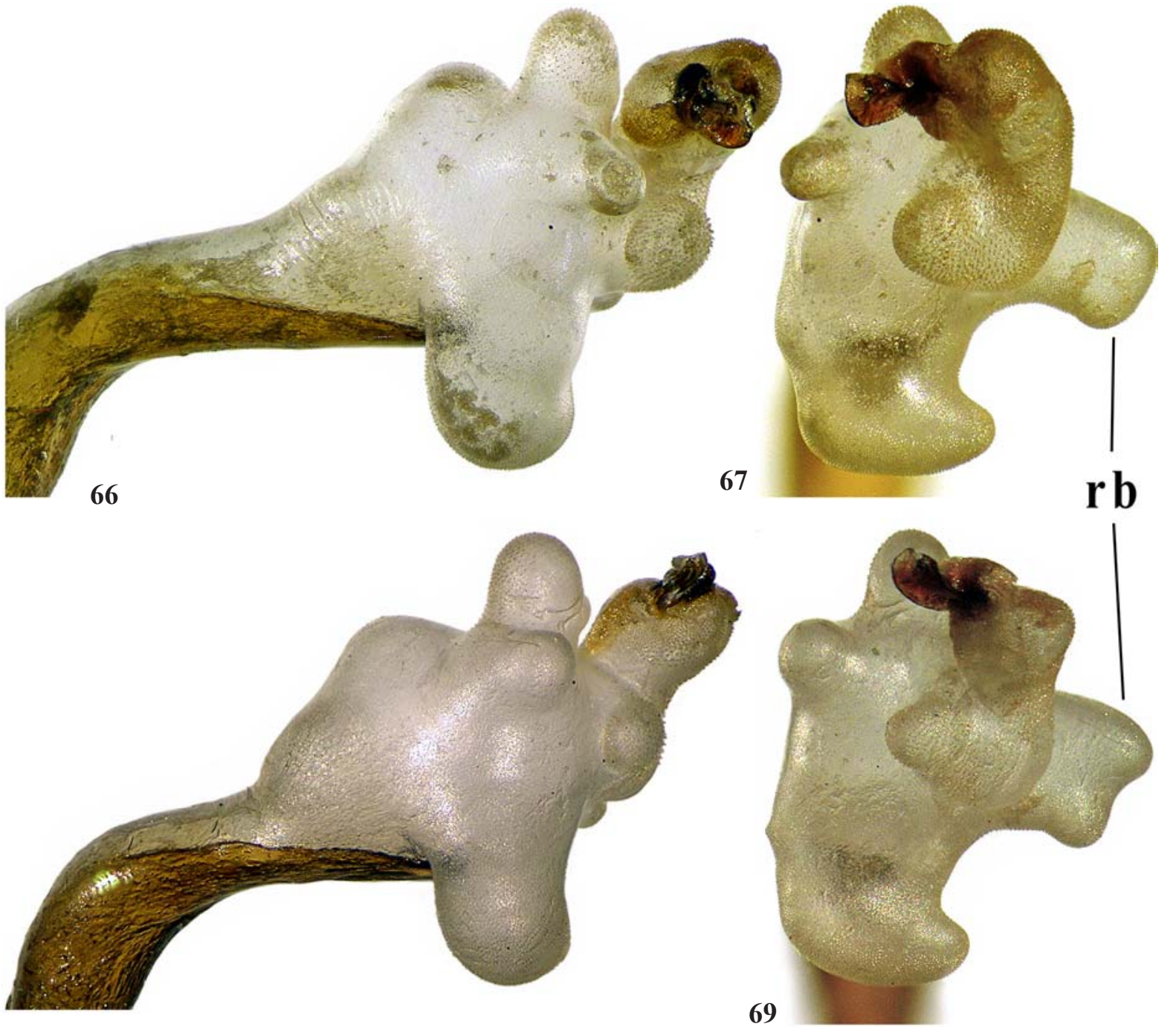

68

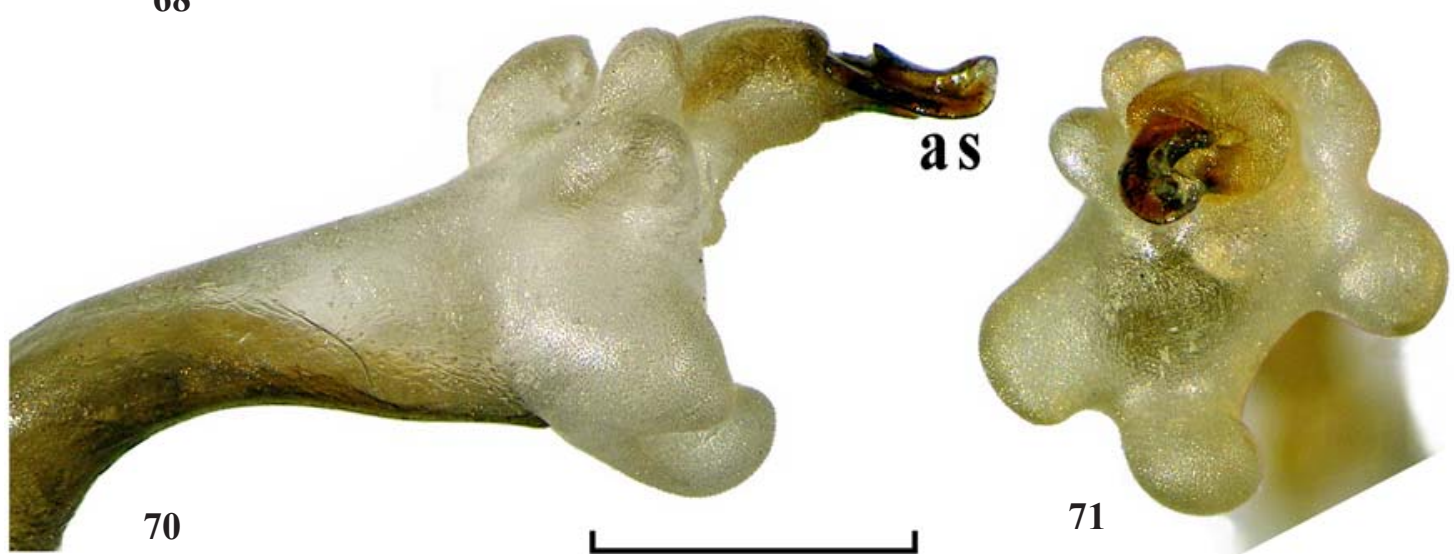

Figs 66-71. Craspedophorus, everted and inflated internal sac of aedeagus: 66-67 — C. dalatensis sp.n.; 68-69 - C. d. kruskopi ssp.n.; 70-71 - C. breviceps sp.n.; 66, 68, 70 - left lateral aspect; 67, 69, 71 — apical aspect; as — apical sclerites; rb — right lateral bulb. Scale bars $-1 \mathrm{~mm}$.

Рис. 66-71. Craspedophorus, вывернутый и наздутый внутренний мешок эдеагуса: 66-67 - C. dalatensis sp.n.; 68-69-C. d. kruskopi ssp.n.; 70-71 - C. breviceps sp.n.; 66, 68, 70 - слева; 67, 69, 71 - апикально; as - апикальные склериты; rb - правый боковой пузырь. Масштаб - 1 мм. 

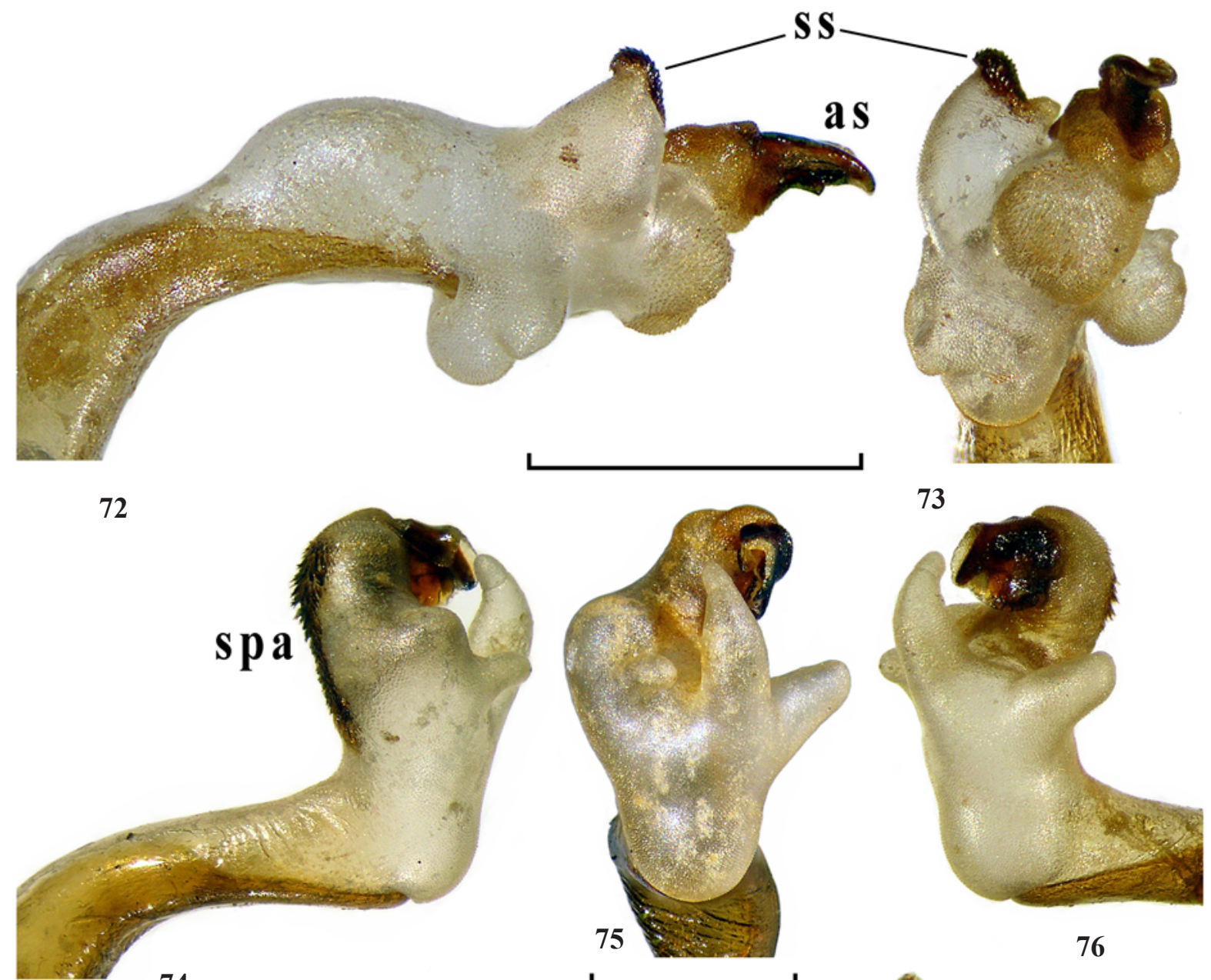

74

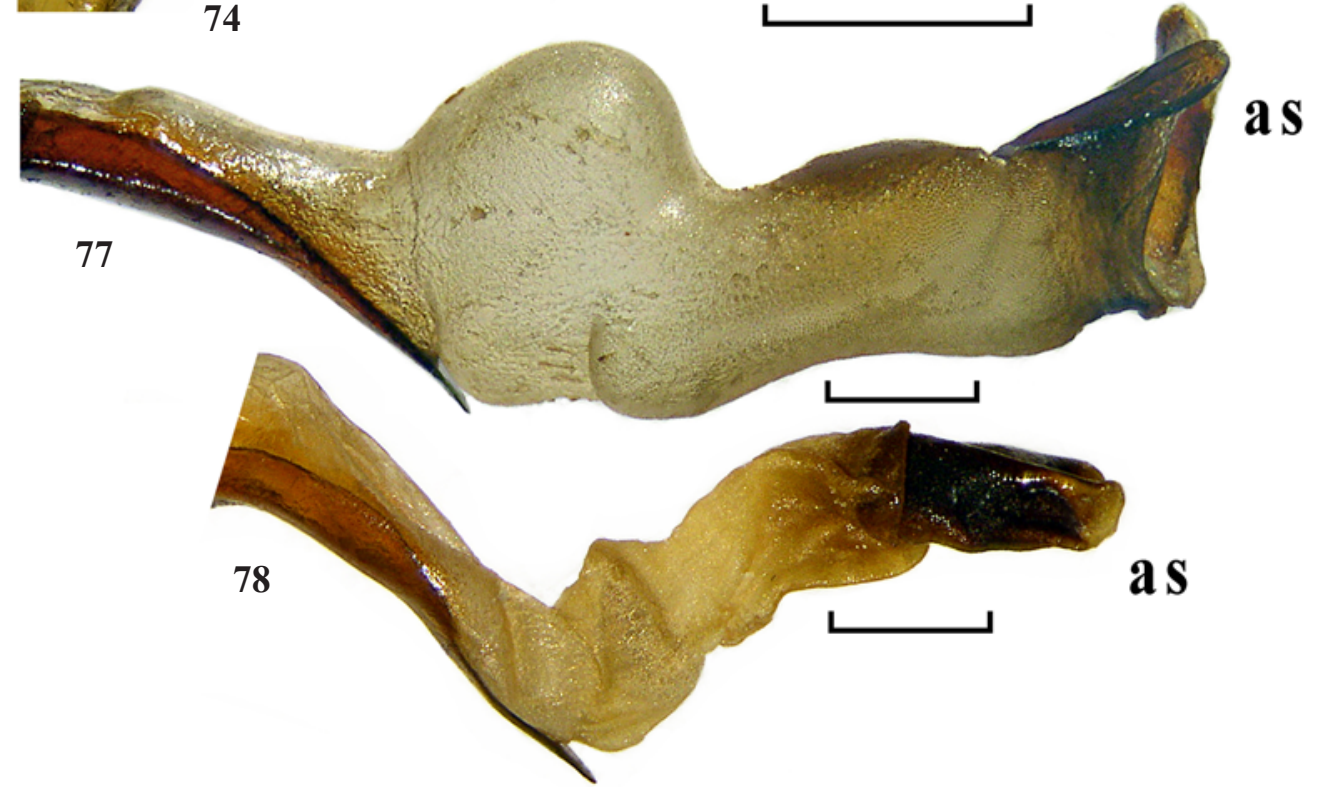

76

Figs 72-78. Craspedophorus, everted and inflated internal sac of aedeagus, left lateral (72, 74, 77-78) right lateral (76), and apical (73, 75) aspects: 72-73-C. pallidicornis sp.n.; 74-76-C. crebrepunctatus sp.n.; $77-$ C. sparsepunctatus sp.n.; $78-$ C. expansicollis sp.n.; as — apical sclerites; spa — spiculate area; ss — spiny sclerite. Scale bar $1 \mathrm{~mm}$.

Рис. 72-78. Craspedophorus, вывернутый и надутый внутренний мешок эдеагуса, слева (72, 74, 77-78), справа (76) и апикально (73, 75): 72-73 - C. pallidicornis sp.n.; 74-76 - C. crebrepunctatus sp.n.; $77-$ C. sparsepunctatus sp.n.; 78 - C. expansicollis sp.n.; as - апикальные склериты; spa - область спикул; ss - шипиконосный склерит. Масштаб 1 мм. 
on sides. Internal sac with a spiculate area on dorsal side (Figs 74, 77).

DIAGNOSIS. In addition to the features of the group, this species is distinctive in having the body very densely pubescent and pronotum strongly cordate.

DISTRIBUTION. Known from the type locality only.

NAME. Refers to very dense punctation of body.

HABITATS AND HABITS. The species inhabits semideciduous monsoon forests.

\section{The basifasciatus species group}

This group was originally diagnosed by the mediumsized body, the strongly convex ovoid elytra, and the wide anterior elytral macula reaching the shoulder [Häckel, Kirschenhofer, 2014]. The authors included there C. basifasciatus (Chaudoir, 1869), C. neglectus Kirschenhofer, 2000, C. yalaensis Kirschenhofer, 2010, and C. khaoyai Häckel et Kirschenhofer, 2014.

Quite recently Häckel [2016b] included C. saundersii in the basifasciatus-group and renamed it ' $C$. saundersii group nov.'. He also noted that Chaudoir [1879] did not describe its metepisterna. In fact, Chaudoir [1879, p. 120] placed both C. saundersii and C. basifasciatus in a formal species group defined (in a key) by short metepisterna.

COMMENTS. This group is defined by a peculiar combination of characters. Very flat mandibles and the subtruncate apex of labrum (indistinctly bisinuate due to a subtle median protrusion) are distinctive. A fairly large and wide head; flattened labrum; mandibles strongly rounded at outer margin; and the conspicuous microsculpture on the closed mandibles and often also on head, are features shared with the mouhotii-group. However, the basifasciatus-group shares most other characters with the microspilotus-group: penultimate labial palpomere parallel-sided and bisetose at inner margin; labrum abruptly deflexed apically, with medial pair of setae situated close to apex; pronotum bisetose on each side; and two setigerous pores on interval 3 in the middle third of elytron. This suggests close relationship between the two groups.

Both $C$. saundersii and C. basifasciatus were described from Laos and then excellently re-described [Chaudoir, 1879], with the original type localities replaced with 'Camboje'. Based on great similarity of the species, Chaudoir [1879] also hypothesized that $C$. basifasciatus might be just a male specimen of $C$. saundersii. Two more species, C. neglectus and $C$. yalaensis, were described much later and without reference to $C$. saundersii, C. basifasciatus, or C. breviformis (Bates, 1892). Because the photographed holotypes of $C$.

neglectus and $C$. yalaensis show great similarity and match well the description of $C$. basifasciatus, I consider the three to be synonymous. Another synonym is $C$. khaoyai, that only differs in smaller, mostly shorter, anterior elytral macula - a character that varies strongly between populations of C. saundersii - C. basifasciatus (see below).

Some characters in C. breviformis - C. basifasciatus C. saundersii have been found to show a considerable, albeit not quite consistent, geographic variability. First, the elytra are longer in westernmost populations (C. breviformis) and still more so in easternmost populations of $C$. saundersii (Tab. 1). Second, pronotal base-to-apex ratio is higher in C. breviformis than in C. saundersii, populations from Thailand (C. basifasciatus) being intermediate. Third, the scape is usually not longer than the eye, and is as long as or hardly longer than the eye in the extreme east. Also, body is generally larger and elytral pubescence somewhat denser in the westernmost and easternmost populations than in those in between. Finally, the microsculpture of the labrum, clypeus, and neck is faint in C. breviformis and C. basifasciatus, but prominent in $C$. saundersii.

The elytral maculae vary strongly between individuals, as well as between local populations, in both size and shape (Figs 79-86). This variation is more or less clinal, though somewhat oscillating Shorter and narrower maculae are observed in the easternmost populations (from Lam Dong, Dong Nai and Binh Phuoc provinces, Vietnam), where the anterior macula tends to be triangular, tapering inwards, spans from the lateral margin to stria 3, expanding onto the outer part of the epipleuron, and usually more or less dentate due to the component strips being longer on intervals 6 and 8 than on the adjacent ones; the black interval 9 separates the macula well from the shoulder. Individuals with the anterior macula reaching stria 3 or 4 prevail, but the maculae may be much reduced, the anterior one being restricted to intervals 7-9 and posterior one, to just interval 7.

Within the species range, both maculae tend to become larger westward, which culminates in the pattern described for $C$. basifasciatus. The anterior macula becomes wider and its inner component strips on intervals $2-5$ or $3-5$ subequally longer. This trend becomes apparent in Tay Ninh Province, Vietnam (Fig. 82), producing more rounded maculae. Among the four specimens examined from this locality, the anterior macula in the illustrated specimen reaches stria 2 rather than 3 , thus expanding towards suture. Yet the largest anterior macula is seen in some Thailand populations (Fig. 86), including those described as C. basifasciatus, C. neglectus or C. yalaensis. There the macula occupies the entire basal third

Table 4. Selected ratios in several Craspedophorus taxa. Таблица 1. Пропорции тела некоторых представителей Craspedophorus.

\begin{tabular}{l|c|c|c|c|c|c}
\hline \multicolumn{1}{c|}{ Species } & locality & $\mathbf{n}$ & PW/HW & PWb/PWa & EL/EW & A1L/OL \\
\hline saundersii & Vietnam & 8 & $1.54-1.63(1.59)$ & $1.24-1.40(1.32)$ & $1.45-1.50(1.47)$ & $1.0-1.02(1.01)$ \\
basifasciatus & $?$ & $\mathrm{HT}^{*}$ & 1.67 & $1.36 ?$ & 1.48 & \\
saundersii & Cambodia & $\mathrm{HT}^{*}$ & 1.64 & 1.32 & 1.46 & \\
basifasciatus: H\&K & Thailand & $1^{*}$ & 1.70 & 1.43 & 1.41 & \\
breviformis & Myanmar & 3 & $1.61-1.65(1.63)$ & $1.43-1.51(1.47)$ & $1.37-1.44(1.41)$ & $0.88-0.94(0.91)$ \\
khaoyai & Thailand & $\mathrm{HT}^{*}$ & 1.56 & 1.27 & 1.41 & \\
neglectus & Thailand & $\mathrm{HT}^{*}$ & 1.70 & 1.37 & 1.40 & \\
basifasciatus: H\&K & Laos & $1^{*}$ & 1.58 & 1.28 & 1.35 & \\
yalaensis & Thailand & $\mathrm{HT}^{*}$ & 1.54 & 1.33 & 1.32 & \\
basifasciatus & Thailand & 4 & $1.54-1.70(1.62)$ & $1.31-1.48(1.40)$ & $1.31-1.35(1.33)$ & $0.91-0.95(0.93)$ \\
\hline
\end{tabular}

\footnotetext{
* — measurements of photographed specimen; H\&K — Häckel \& Kirschenhofer [2014]; HT, holotype.
} 
of the elytra, except for the sutural interval, longer bases of intervals 2-5 and narrow bases of intervals 6 and 7. In some other populations from Thailand (Phetchaburi), the macula is slightly smaller and may or may not reach the humerus.

In C. breviformis (Figs 83-84), the elytral maculae are similar to those just described, but smaller, the anterior one spanning intervals $4-10$ or $5-9$, and the posterior, intervals $4-8$ or $5-8$. The anterior macula is thus separated from the lateral margin, leaving the epipleuron black.
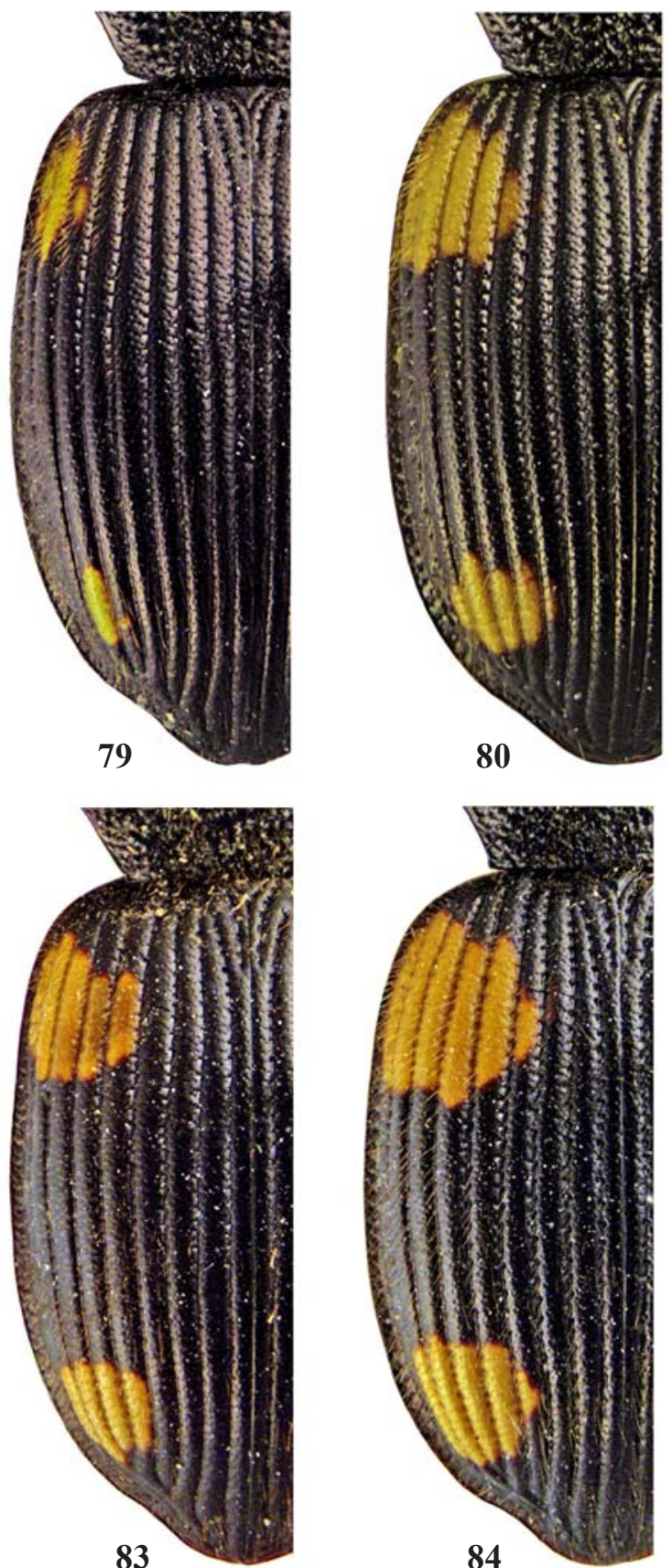

Figs 79-86. Craspedophorus, variation in elytral pale pattern: 79-82 - C. s. saundersii, specimens from Loc Bao (79, 81), Bu Gia Map (80) and Tay Ninh (82), Vietnam; 83-84-C. breviformis, lectotype (83) and paralectotype (84); 85-86-C. saundersii basifasciatus, specimens from Kaeng Krachan NP (85) and Nong Bun Nak (86), Thailand.

Рис. 79-86. Craspedophorus, изменчивость рисунка надкрылий: 79-82 - C. s. saundersii, экз. из Лок Бао (79, 81), Бу Зя Мап (80) и Тай Нин (82), Вьетнам; 83-84 - C. breviformis, лектотип (83) и паралектотип (84); 85-86 — C. saundersii basifasciatus, экз. из национального парка Кэнг Крачан (85) и Нонп Бун Нак (86), Таиланд.
Also, in eastern populations the eyes are slightly less prominent, with genae less transverse and meeting neck at right angle, $v s$. somewhat more prominent, with subacute angle between gena and neck, in western ones. However, both character states have been observed within the same population from southeastern Vietnam (Tay Ninh Prov.). One female from Savannakhet Province, Laos, shows the smallest and most protruding eyes, with slightly yet clearly acute angle between gena and neck and the highest scape/eye length ratio (A1L/OL 1.08).
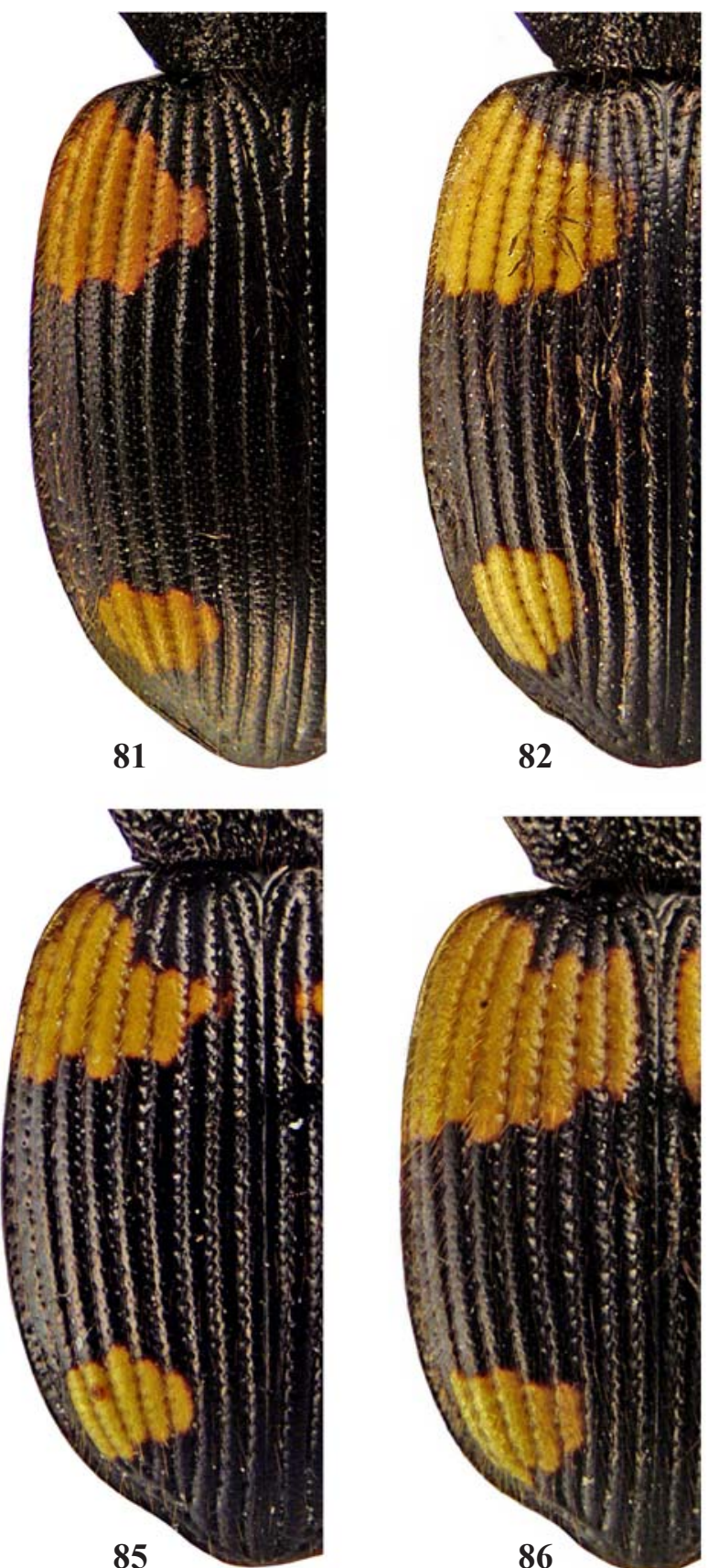
Aedeagi of examined six males are nearly identical in shape and structure, except in subtle detail. Everted and inflated internal sacs are not unlike in at least $C$. saundersii and C. basifasciatus (Figs 100-103).

Therefore it seems reasonable to recognize $C$. basifasciatus as a subspecies of $C$. saundersii, and C. breviformis as a very closely related yet distinct species, although there is a chance that the latter is the westernmost subspecies of $C$. saundersii. The name $C$. saundersii is conserved here as preferred to $C$. basifasciatus to honor Chaudoir's request [Chaudoir, 1879: 127].

Thus the basifasciatus-group is redefined here to include only $C$. saundersii and $C$. breviformis. This means that C. saundersi: Kirschenhofer, 2011a; Häckel, Kirschenhofer [2014] is a different species, a member of the microspilotusgroup.

\section{Craspedophorus saundersii saundersii}

(Chaudoir, 1869)

Figs 21, 30, 79-83, 87-88, 91-92, 96-97, 100, 102.

Chaudoir, 1869: 114 (Epicosmus; 'Laos'); 1879: 125 ('Cam- boje'). - saundersi Häckel, 2016: 6 (non Kirschenhofer, 2011a: 59; non Häckel et Kirschenhofer, 2014: 209).

MATERIAL. 21 ex.: $0^{\top}$, + (SIEE), South Vietnam, Dongnai Province, Nam Cat Tien National Park, $11^{\circ} 25^{\prime} 18^{\prime \prime} \mathrm{N} / 107^{\circ} 25^{\prime} 44^{\prime \prime}$ E, Expedition of the Joint Russian-Vietnamese Tropical Center, 2129.XI.2004, D. Fedorenko leg.; 9 (SIEE), $70 \mathrm{~km} \mathrm{NE}$ of Saigon, Ma Da, 18-19.VI.1990 (N. Belyaeva); ○7, 3 ㅇ (SIEE), Binh Phuoc Prov., Bu Gia Map Natn. Park, $12^{\circ} 11^{\prime} 37^{\prime \prime} \mathrm{N} / 107^{\circ} 12^{\prime} 21^{\prime \prime} \mathrm{E}, \mathrm{h}=350$ $540 \mathrm{~m}, 13-23 . I V .2009$ and 26.IV-4.V.2013, D. Fedorenko leg.; 우 (SIEE), Lam Dong Prov., 25 km NW of Bao Loc, Loc Bao env., $\mathrm{h}=800 \mathrm{~m}, 11^{\circ} 44^{\prime} 18^{\prime \prime} \mathrm{N} / 107^{\circ} 42^{\prime} 08^{\prime \prime} \mathrm{E}, 5-20 . I V .2013$, D. Fedorenko leg. $O^{7}, 9$ (SIEE), same locality, but $\mathrm{h}=800-1000 \mathrm{~m}, 11^{\circ} 43^{\prime} 27^{\prime \prime} \mathrm{N} /$ $107^{\circ} 42^{\prime} 44^{\prime \prime} \mathrm{E} ; 2 \mathrm{O}^{7} \mathrm{O}^{\top}, 2$, +9 (MPSU), Tay Ninh Prov., Tam Binh vill., wet Dipterocarpus-forest, 19.X and 9.XI.2001, A. Borisenko; 2 $O^{\top} O^{\top}, 2$ 우 (SIEE), Central Vietnam, Kon Tum Province, Chu Mom Ray National Park, $14^{\circ} 30^{\prime} \mathrm{N} / 107^{\circ} 43^{\prime} \mathrm{E}, \mathrm{h}=730 \mathrm{~m}$, 28.III-4.IV.2015, D. Fedorenko leg.; 2 우 (SIEE), Southern Laos, Prov. Champasak, env. Pakxong, $15^{\circ} 11^{\prime} 19^{\prime \prime} \mathrm{N} / 106^{\circ} 10^{\prime} 48^{\prime \prime} \mathrm{E}, \mathrm{h}=1180 \mathrm{~m}, 30 . \mathrm{XI} .2015$, leg. I.Melnik; + (BMNH), Laos, Tavieng, 25.I.1919, R.V.de Salvazae leg. - Aedeagus examined in $4 \mathrm{O}^{7} \mathrm{O}^{2}$.

REDESCRIPTION. Body (Fig. 21) 11-13.3 mm in length, black; antennae towards apices mostly (and often also tarsi) slightly paler; palps generally dark brown to nearly black,
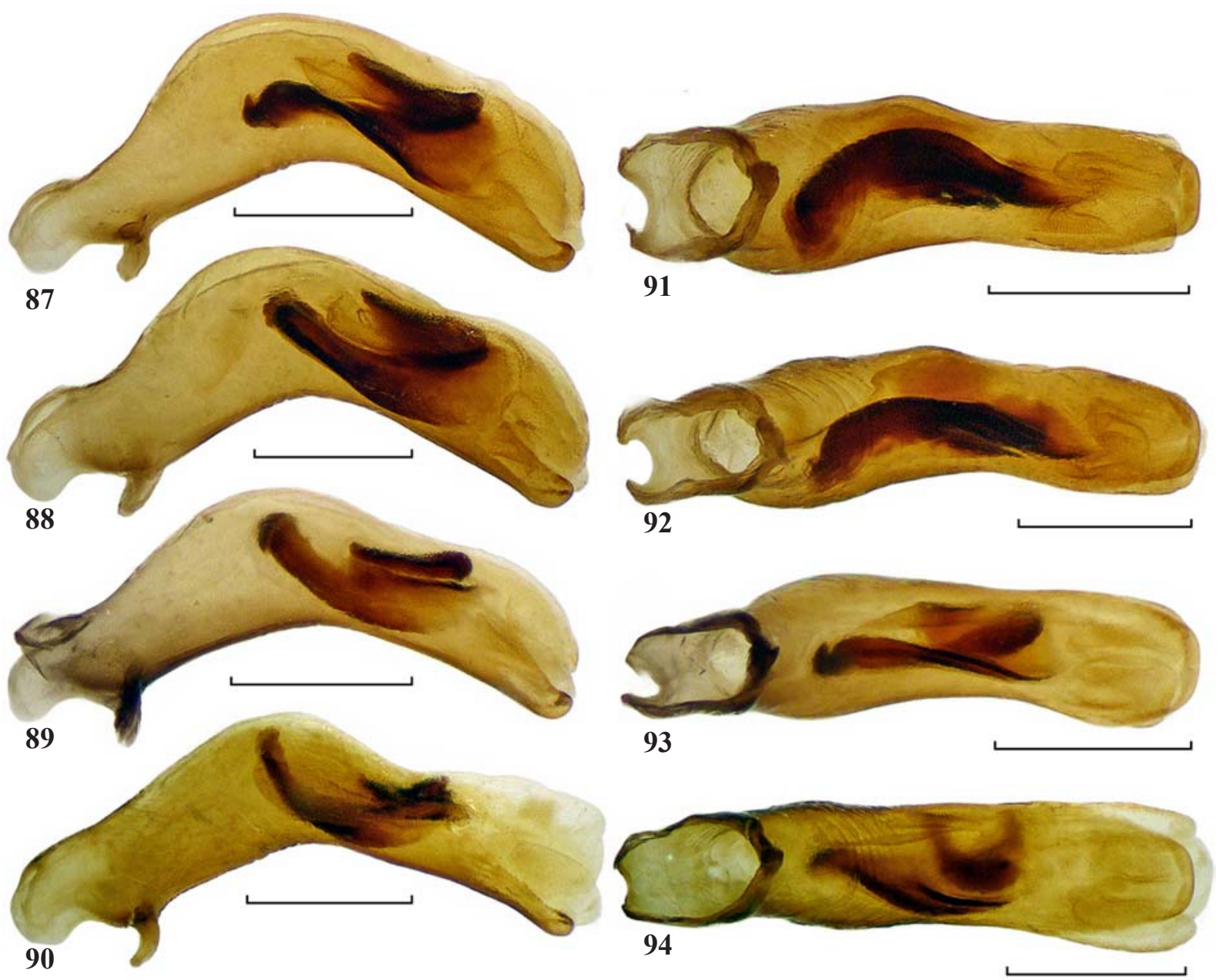

Figs 87-94. Craspedophorus, median lobe of aedeagus: 87-88, 91-92 - C. s. saundersii, males from Loc Bao (87, 91) and Bu Gia Map $(88,92) ; 89,93-$ C. s. basifasciatus; 90,94 - C. s. breviformis; 87-90 - left lateral aspect; 91-94 — ventral aspect. Scale bars - $0.5 \mathrm{~mm}$. Figs 87-88 show some variation of internal sclerites in shape resulting from their rotation on the longitudinal axis inside the median lobe.

Рис. 87-90. Craspedophorus, средняя доля эдеагуса: 87-88, 91-92 - C. s. saundersii, самцы из Лок Бао $(87,91)$ и Бу Зя Мап (88, 92); 89, 93 - C. s. basifasciatus; 90, 94 - C. s. breviformis; 87-90 — слева; 91-94 - вентрально. Масштаб — 0.5 мм. Различия в форме внутренних склеритов на рис. 74-75 обусловлены вращением склеритов внутри эдеагуса вокруг продольной оси. 
except for pale bases, articulations and apical margin of terminal segment, sometimes brown; knees (tibial condyles) and extreme apices of femora on each side of knee with a minute red spot. Elytral maculae vary in shape and size, mostly fairly small and narrow, anterior macula subtriangular, tapering inwards, between stria 3 or 4 and lateral margin, slightly extending onto epipleuron, posterior macula on intervals $4-8$. Less commonly, the anterior macula reaching stria 2 or both maculae strongly reduced, with the anterior macula isolated from lateral margin. Microsculpture meshed, strongly to moderately transverse on labrum, isodiametric on head, isodiametric to very slightly transverse on pronotum; this microsculpture sharp on labrum and clypeus, obsolete on vertex and frons, sharp to superficial on neck, mostly very distinct over pronotum.

Head (Fig. 30). Neck mostly irregularly rugulose to rugose before, rugulose to nearly smooth behind, rarely with one to three additional coarse punctures just behind neck constriction. Scape 1.0-1.01 times as long as eye tubercle, AR 0.86-0.91: 0.41-0.44: 0.71-0.74. Apical labial palpomere securiform, with inner margin two thirds as long as apex in male, much less securiform to subtriangular, with inner margin $11 / 5$ times as long as apex, in female; apex convex, inner margin straight, outer margin very concave in male and very gently so in female. Apical maxillary palpomere similar but slightly more slender.

Pronotum subhexagonal, $1.36-1.42(1.39, \mathrm{n}=8)$ times as wide as long, 1.54-1.63 (1.59) times as wide as head, broadest just behind middle (i.e., PLw/PL 0.49-0.56 (0.54)), with base 1.24-1.40 (1.32) times broader than apex. Sides very gently convex anteriorly, straight to indistinctly sinuate in front of basal angles. Base and apex truncate, apical angles rounded and adjoining or close to neck, basal angles obtuse, with a small, well-developed to nearly indistinct denticle. Lateral margin widely explanate yet slightly reflexed in basal half; lateral bead fine, obliterate at apical angles and in basal third.

Apterous. Elytra 1.45-1.50 (1.47) times as long as wide, 1.25-1.33 (1.30) times as wide as pronotum. Striae deep, moderately coarsely punctate; intervals convex, more so before apex, each with 4-5 irregular rows of fine setigerous punctures.

Aedeagus (Figs 87-88, 91-92, 100, 102): median lobe wide, in ventral (dorsal) view dilated just behind basal bulb and with a prominence at middle of left side; apical lamella truncate, short and wide in ventral view, rounded and clearly curved upwards at tip in lateral view. Internal sac with left sclerite fairly long and rounded basally in dorsal view. Right paramere mostly glabrous at apex, sometimes with sparse and fairly short setae same as in C. breviformis (Fig. 98), varying slightly in shape (Figs 96-97); left paramere as in Fig. 99.
VARIABILITY. Terminal labial and maxillary palpomeres vary considerably in shape between populations. In a male from $\mathrm{Bu}$ Gia Map, the inner margin is 0.84 times as long as apex, while in two of three females examined it is shorter, 1.03 and 1.16 times as long as apex.

DISTRIBUTION. Cambodia, southern Laos (Champasak and Savannakhet provinces), southern Vietnam. Given the apterous condition, we would expect the nominate subspecies to occupy the eastern part of the species range, east of the Mekong River.

HABITATS AND HABITS. Occurring in semideciduous monsoon broadleaf forests at the altitudes 50-1,000 m a.s.l. Many specimens have been taken by pitfall trapping as well as by handing from under logs.

COMMENTS. The above re-description is consistent with the original description, even though it is based on the limited material listed. This suggests that the holotype of C. saundersii might have originated from the eastern or northeastern parts of Cambodia adjacent to Vietnam.

\section{Craspedophorus saundersii}

basifasciatus (Chaudoir, 1869), stat.nov.

Figs 85-86, 89, 93, 95, 101, 103.

Chaudoir, 1869: 115 (Epicosmus; 'Laos'); 1879: 127 ('Camboje'); Häckel, 2016: 6. - neglectus Kirschenhofer, 2000: 351 (Tak, NW-Thailand), syn.n. - yalaensis Kirschenhofer, 2010: 173 (Yala Distr., S-Thailand), syn.n. — khaoyai Häckel et Kirschenhofer, 2014: 288 (Khao Yai NP, SE-Thailand), syn.n.

MATERIAL. $0^{7}, 9$ (ZISP), Thailand, $50 \mathrm{~km}$ SW Phetchaburi, env. Natn. Park Kaeng Krachan, 30.07.-5.08.[19]96, Gorochov leg.; $\bigcirc^{7}$, + (SIEE, SZMN), Nakhon Ratchasima (Korat), Nong Bun Nak, deciduous gallery forest, $\mathrm{h}=200 \mathrm{~m}, \mathrm{~N} 14^{\circ} 41^{\prime} 76^{\prime \prime} / \mathrm{E} 102^{\circ} 27^{\prime} 25^{\prime \prime}$, 28.07-2.08.2009, A.V. Korshunov leg. - Aedeagus examined in $0^{7} O^{7}$.

DESCRIPTION as compared to the nominate subspecies: Body generally smaller, BL 9.8-12 mm. Elytral maculae (Figs 85-86) generally larger, anterior macula reaching stria 1 or 2 , rarely 3 , posterior on intervals $4-8$. Palps rather pale brown. Dorsum shinier due to microsculpture finer, obliterate on frons, vertex and neck, superficial or faint on clypeus, very superficial to obliterate over pronotum. Neck anteriorly often coarsely and fairly densely punctate in addition to irregular wrinkles which are less distinct than in the nominate subspecies. Scape $0.91-0.95$ times as long as eye tubercle, AR 0.89-0.93: 0.43-0.47: 0.72-0.74. Apical labial palpomere less contrasting in shape between sexes, broader at apex, with outer margin less concave in male while barely convex in female; inner margin four fifths as long as apex in male and only $11 / 6$ as long as apex in female; outer margin concave in male while slightly convex in female.
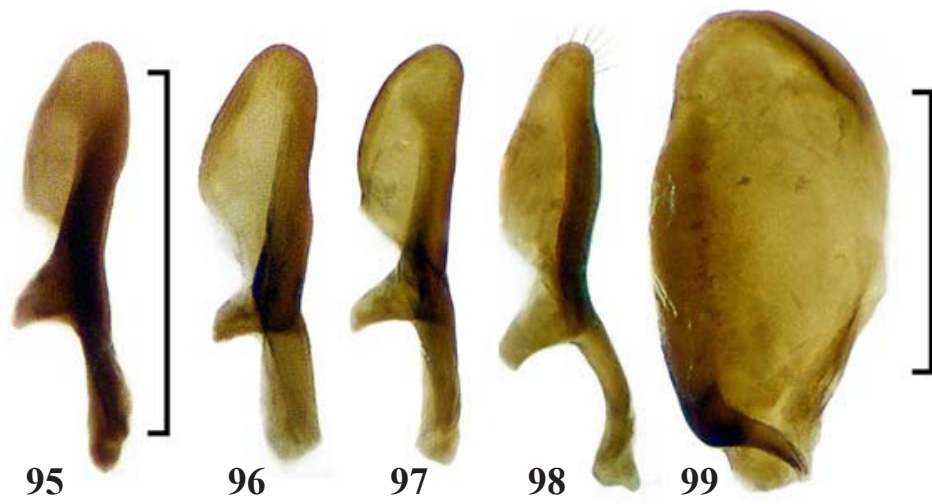

Figs 95-99. Craspedophorus, right (95-98) and left (99) parameres: $95-$ C. saundersii basifasciatus; 96-97 - C. s. saundersii; 98-99-C. breviformis. Scale bars $-0.5 \mathrm{~mm}$.

Рис. 95-99. Craspedophorus, правая (95-98) и левая (99) парамеры: 95 - C. saundersii basifasciatus; 96-97 - C. s. saundersii; 98-99-C. breviformis. Масштаб - 0.5 мм. 

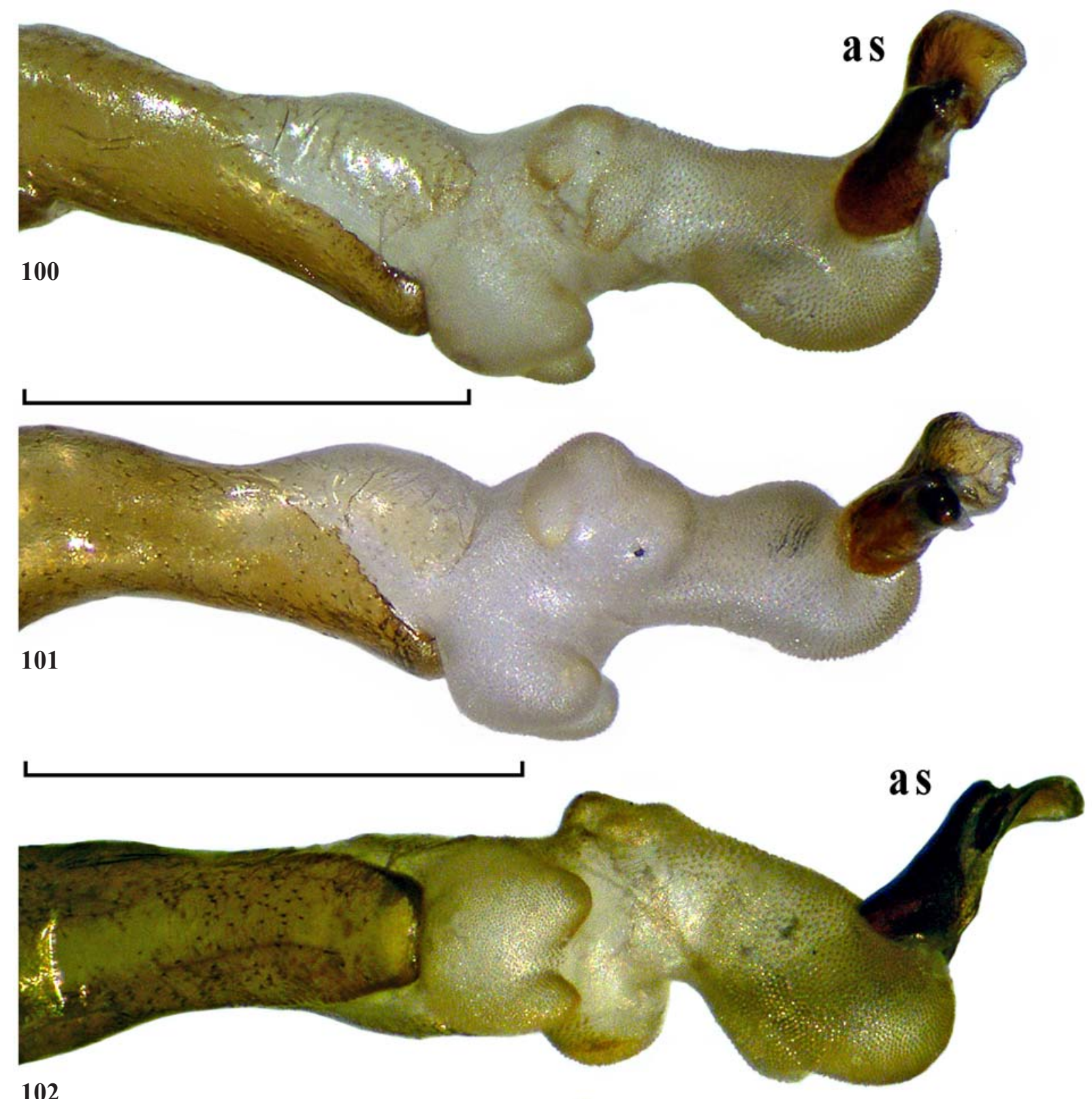

\section{2}

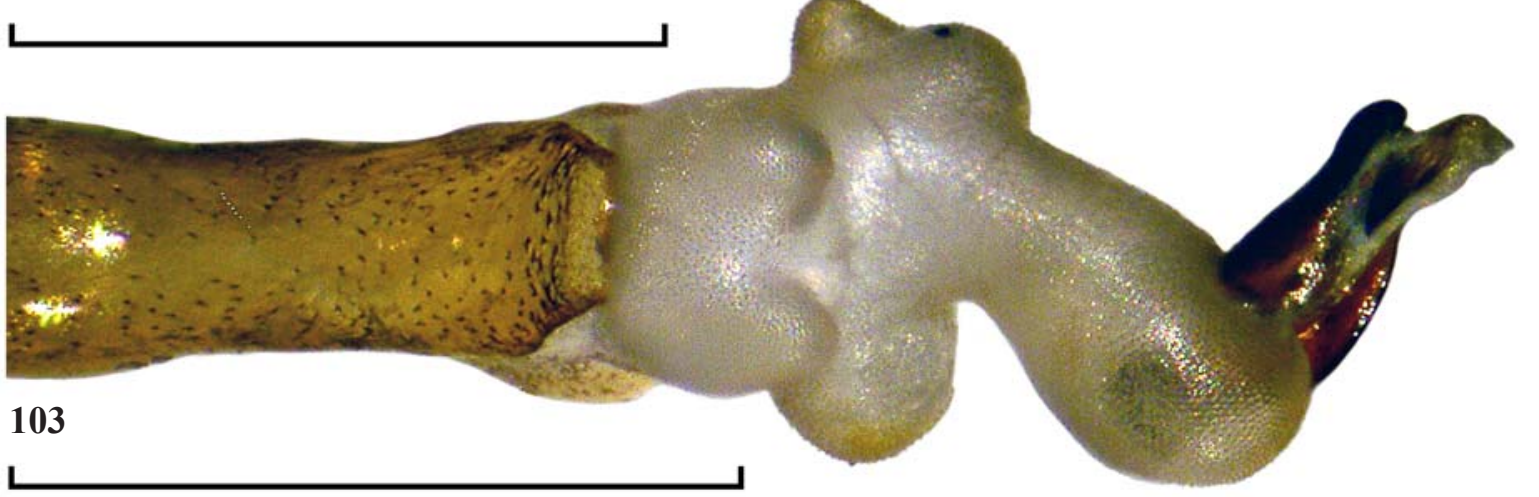

Figs 100-103. Craspedophorus, everted and inflated internal sac of aedeagus, left lateral (86-87) and ventral (88-89) aspects: 86, 88 C. s. saundersii; 87, 89 - C. s. basifasciatus; as - apical sclerites. Scale bars - $1 \mathrm{~mm}$.

Рис. 100-103. Craspedophorus, вывернутый и надутый внутренний мешок эдеагуса, слева (100-101) и снизу (102-103): 100, 102 - C. s. saundersii; 101, 103 - C. s. basifasciatus; as - апикальные склериты. Масштаб - 1 мм. 
Pronotum 1.38-1.46 $(1.41, \mathrm{n}=10)$ times as wide as long, $1.54-1.70$ (1.62) times as wide as head, broadest $0.50-0.53$ (0.51) times from apex, with base 1.28-1.48 (1.36) times broader than apex.

Elytra shorter and wider, 1.31-1.41 (1.35) times as long as wide, 1.26-1.37 (1.32) times as wide as pronotum, each interval with 3-4 irregular rows of fine setigerous punctures.

Aedeagus (Figs 89, 93, 101, 103) in ventral view (Fig. 93) without bulge on left side. Internal sac with left sclerite barely shorter. Right paramere (Fig. 95) suboval, with inner margin gently convex (vs subtriangular with inner margin straight).

DISTRIBUTION. Thailand and probably Cambodia.

COMMENTS. All the nominal species synonymized here under $C$. s. basifasciatus are quite similar to each other, except for the anterior elytral maculae being different in shape and/or size. Given high individual and geographic variability of these characters in C. s. saundersii, and the fact that only holotypes of $C$. neglectus, C. yalaensis, and C. khaoyai are known, the differences seem insufficient for keeping the latter three even as subspecies.

The holotype photographed in Häckel [2016] is distinctive in having the longest elytra (EL/EW 1.48), as long as in C. saundersii saundersii.

\section{Craspedophorus breviformis (Bates, 1892)} Figs 83-84, 90, 94, 98-99.

Bates, 1892: 299 (Epicosmus; Burma [= Myanmar]). MATERIAL. Three syntypes (MSNG): $\sigma^{7}$, labelled: 'Palon (Pegù)/ L.Fea.VIII.IX.87', 'TYPUS', 'breviformis/ Bates' [hw], 'Epicosmus/ breviformis/ Bates' [hw], 'Epic./ breviformis/ (es tip.) Bates' [hw], 'SYNTYPUS/ Epicosmus/ breviformis/ Bates, 1892'

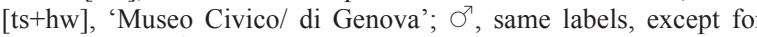
those 2 to 5; ㅇ, 'Carin Chebà/ 900-1100.m./ L.Fea V XII-88, 'SYNTYPUS/ Epicosmus/ breviformis/ Bates, 1892' [ts+hw], 'Museo Civico/ di Genova', designated here as lectotype.

DESCRIPTION. Like C. s. saundersii, except as follows: BL 11.8-12.7 mm. Anterior elytral macula (Figs 83-84) on intervals 4-9 or 5-9 (lectotype), or also extended onto both reflexed lateral margin and outer half of interval 3, leaving extreme lateral edge and epipleuron black; posterior macula subtriangular, on intervals $4-8$ or $5-8$, tapering inwards. Microsculpture obliterate over head to very superficial on clypeus only. Head: Frontal foveae somewhat deeper. Neck but slightly rugulose behind neck constriction. Scape 0.88 0.94 times as long as eye tubercle, AR 0.77-0.82: 0.36-0.47: 0.63-0.72. Apical labial palpomere with inner margin 0.62 times $\left(O^{7}\right)$ or 1.23 times $\left(\begin{array}{l}(+) \\ )\end{array}\right)$ as long as apex, but outer margin less concave in male while very gently convex in female. Pronotum broadest at mid-length, PLw/PL 0.50-0.52 (0.51), with base slightly broader, 1.43-1.51 (1.47) times broader than apex. PW/PL 1.37-1.45 (1.41, n=3), PW/HW 1.61-1.65 (1.63). Elytra slightly shorter, EL/EW 1.37-1.44 (1.41), EW/ PW 1.26-1.36 (1.31).

Aedeagus (examined in lectotype; Figs 90, 98-99) rather narrow, in ventral view (Fig. 94) without bulge on left side; apical lamella nearly straight in lateral view. Internal sac with left sclerite short and truncate basally. Right paramere (Figs 98-99) sparsely pubescent apically, convex at inner margin, with a slight preapical sinuation and a narrowly rounded apex.

COMMENTS. According to the original description, the anterior elytral macula extends over intervals $6-9$ or $6-10$ However, all the three syntypes examined show this macula reaching stria 4 or 3 , or just beyond. The female from 'Carin Chebà' is selected here as lectotype because it fits the original description best, having the narrowest macula.

\section{The microspilotus species group}

DIAGNOSIS. Usually macropterous, small to mediumsized Panagaeini, all black, except for pale quadrimaculate elytral pattern and sometimes also rather pale brown labial palps, as well as antennae toward apices, tibiae, and tarsi. Labrum, clypeus, exposed parts of mandibles, and neck smooth and glossy because of the microsculpture lacking or being very superficial; rarely neck coarsely and sparsely punctate. Head rather narrow; labrum conspicuously emarginate, abruptly deflexed in the emargination, with medial setae inserted close to apical margin. Mandibles, especially the right one, straight to concave at outer margin, except at the very bases and apices. Penultimate labial palpomere subcylindrical, bisetose at inner margin (a very short additional seta may be present laterad of normal setae); both maxillaries and labials with apical palpomere triangular rather than securiform, and two terminal maxillary palpomeres pubescent. Pronotal lateral margin generally bisetose on each side. Metepisterna mostly clearly longer than wide following macropterous condition. Movable abdominal sterna each with a row of coarse and close punctures along bases. Elytra usually with two, clearly defined, discal setigerous pores in middle two quarters of interval 3 , serial setae in intervals 5 and 7 imperceptible.

COMMENTS. This large group was established by Kirschenhofer [2000]. Many species placed there need clarification of their relationship and/or status.

We recognize two subgroups within this group: the microspilotus-subgroup and the sapaensis-subgroup. The latter also includes all the members of the former Dischissus guttiferus-group [Fedorenko, 2015].

Based on my study of several types, the following new synonymy is proposed:

\section{The microspilotus-subgroup}

\section{Craspedophorus mandarinellus (Bates, 1892)}

Bates, 1892: 299 (Epicosmus; Bhamo, Burma); Häckel, Farkač, 2012: 77. - vietnamensis Kirschenhofer, 2000: 339 (Sapa, NVietnam); Häckel, Farkač, 2012: 77, syn.n. — freudeellus Häckel et Kirschenhofer, 2014: (Cat Tien NP, S-Vietnam), syn.n.

MATERIAL. Holotype $O^{7}$ (MSNG) labelled: 'Bhamò/ Birmania/ Fea VII 1886', 'TYPUS', 'mandarinellus/ Bates' [hw], 'Epicosmus/ mandarinellus/ Bates' [hw], 'Epic./ mandarinellus/ typus! Bates'[hw], 'HOLOTYPUS $\sigma^{7} /$ Epicosmus/ mandarinellus/ Bates, 1892 ' [ts+hw], 'Museo Civico/ di Genova').

Additional material: $5 \sigma^{7} \sigma^{\top}$, (SIEE), South Vietnam, Dongnai Province, Nam Cat Tien National Park, $11^{\circ} 25^{\prime} 18^{\prime \prime}$ N/ $107^{\circ} 25^{\prime} 44^{\prime \prime}$ E, Expedition of the Joint Russian-Vietnamese Tropical Center, 1618.XI.2004 and 5-11.VI.2005, D. Fedorenko leg.; ○’ , (SIEE), SIndia, Karnataka, Western Ghats, Shimoga Distr., Jog Falls, $14^{\wedge} 13.242 \mathrm{~N} / 74^{\wedge} 43.472 \mathrm{E}, \mathrm{h}=530 \mathrm{~m}$, at light, 1-3.XI.2003, S. Saluk leg.; + (SIEE), same data, but ZARS, Mudigere env., $15^{\circ} 07.152^{\prime} \mathrm{N} / 75^{\circ} 37.62^{\prime} \mathrm{E}, \mathrm{h}=990 \mathrm{~m}$, at light, 15.XI.2003. Aedeagus examined in five $\sigma^{7} \sigma^{7}$.

COMMENTS. C. mandarinellus is distinctive within the subgroup based on the following: body winged, fairly small and slender; elytra fairly long (EL/EW 1.55-1.62); pronotum rather narrow (PW/PL 1.40 at most), with lateral margins very gently explanate-reflexed; right mandible straight at outer margin; head and pronotum without microsculpture; pale elytral maculae with more or less even margins, anterior macula usually spanning from interval 4 to lateral margin, posterior one, intervals 4-8; intervals each with 4-5 irregular longitudinal rows of fine punctures; appendages black.

The species is widespread from southern India to southern China, yet shows surprisingly little variation, except in two aspects: (1) the body length ( $9.2 \mathrm{~mm}$ in the holotype) 
varies from $9.8-10 \mathrm{~mm}$ in western populations (India) to 8.5$9.6 \mathrm{~mm}$ in southeastern ones (southern Vietnam); (2) the anterior macula reaches stria 4 in the holotype.

Two other species, C. freudeellus and C. vietnamensis, recently described from Vietnam, differ from each other and from $C$. mandarinellus in nothing but BL: $8.2-8.5 \mathrm{~mm}$ in C. freudeellus, $9.5-9.9 \mathrm{~mm}$ in C. vietnamensis, according to [Häckel, Kirschenhofer, 2014b]. Actually, though, the size ranges are much closer, if not overlapping: the $\mathrm{BL}$ of the specimens illustrated in Häckel \& Kirschenhofer [2014b, Figs $13 \mathrm{a}-\mathrm{b}$ and $14 \mathrm{a}-\mathrm{b}$ ] measured using the scale bar is 8.6 $8.7 \mathrm{~mm}$ in the holotype and the paratype of $C$. freudeellus and just $8.9-9.6 \mathrm{~mm}$ in C. vietnamensis. The authors [ibid., $\mathrm{p}$. 323 ] add that they 'find distinct differences in the colouration of both sexes' in C. vietnamensis - a mere guess, in fact, based on just one male and two female specimens. Finally, C. vietnamensis was said [ibid., p. 313] to be closest to C. austronesiensis Häckel et Kirschenhofer, 2014 and C. mannae Andrewes, 1930 with its subspecies C. m. sulawesiensis Häckel et Kirschenhofer, 2014. In my opinion, C. mannae (paratype examined) doesn't belong in this list as having clearly reflexed lateral pronotal margins, unlike the other three. Thus, C. sulawesiensis stat.n. is distinct from C. mannae and likely conspecific with $C$. austronesiensis.

C. mandarinellus was described by H.W. Bates from a single specimen, that has survived and is thus the holotype. Häckel [2016] erroneously designated a neotype (BMNH) and a number of 'paralectotypes'; no re-description of the 'neotype' was provided other than a lengthy discussion of relationships between many species, mostly members of the microspilotus-group.

The neotype designation is invalid. As for C. mandarinellus sensu Häckel [2016], it's probably conspecific with C. dembickyi Kirschenhofer, 2000 or C. lesnei Andrewes, 1926 , or both; a study of types of the latter two is necessary to clarify the matter.

\section{Craspedophorus cereus (MacLeay, 1825)}

MacLeay, 1825: 12 (Panagaeus; Java); Andrewes, 1919: 135; Häckel, 2015: 238 - buruensis Häckel et Kirschenhofer, 2014 295 (Buru Island), syn.n. - ? ssp. formosanus Jedlička, 1939: 1 (Formosa [= Taiwan]); 1965: 5; Habu, 1978: 71; Kirschenhofer, 2000: 330; Häckel, Farkač, 2012: 77; Häckel, Kirschenhofer, 2014b: 298. - chinensis Jedlička, 1965: 5 (Prov. Fukien, China); Kirschenhofer, 2000: 331; Häckel \& Kirschenhofer, 2014b: 297, syn.n. — saddlepeakensis Kirschenhofer, 2011: 45 (Andaman Is.); Häckel \& Kirschenhofer, 2014b: 319, syn.n. - laosensis Kirschenhofer, 2012: 231 (Luangphabang prov., Laos); Häckel, Kirschenhofer, 2014b: 305, syn.n. — punensis Häckel et Kirschenhofer, 2014: 318 (Maharashtra, W-India), syn.n. - batesi Häckel, 2014: 3 (Bombay [=Mumbai], W-India), syn.n. — maculatus: Häckel et Kirschenhofer, 2014: 307 (non maculatus Kirschenhofer, 2000). - ? philippinus Jedlička, 1939: 1 (Luzon, Philippines).

MATERIAL. $2 O^{7} O^{7}, 4$ 우오 (SIEE), Vietnam, Dongnai Province, Nam Cat Tien National Park, $11^{\circ} 25^{\prime} 18^{\prime \prime}$ N/ $107^{\circ} 25^{\prime} 44^{\prime \prime}$ E, Expedition of the Joint Russian-Vietnamese Tropical Center, at light, 2325.X and 24.XI.2004, as well as 29.V-7.VI.2005, D. Fedorenko leg.; O $^{7}$ (SIEE), Ninh Binh Prov., $10 \mathrm{~km} \mathrm{SSW}$ of Ninh Binh, Cuc Phuong National Park, $20^{\circ} 14^{\prime} 37^{\prime \prime} \mathrm{N} / 105^{\circ} 42^{\prime} 55^{\prime \prime} \mathrm{E}$, at light, 13 15.IV.2012, M.A. Dzhus leg.; $\sigma^{7}$ (SIEE), Cambodia, Mondulkiri Prov., env. Sen Monorom, $19^{\circ} 29^{\prime} 02^{\prime \prime} \mathrm{N} / 107^{\circ} 10^{\prime} 51^{\prime \prime} \mathrm{E}, \mathrm{h}=780 \mathrm{~m}$, at light, 1-5.VI.2014, I. Melnik leg.; $\mathrm{O}^{7}$ (BMNH), '[Bangladesh,] Dacca', 'Bowring, 63.47*'. - Aedeagus examined in three males.

COMMENTS. Among the nominal species listed above, only $C$. chinensis and $C$. formosanus have wider geographic ranges. The former was described from southern China and later recorded in Vietnam; the latter, described from Taiwan and later reported from the Ryukyu Islands, southern Japan.
In contrast, the other 'species' are allopatric and local, and their combined distribution suggests that they are hardly more than local populations of a single widespread species.

Moreover, these beetles are good fliers: the vast majority of the specimens have been collected at light — another piece of evidence supporting the wider range of the species and the proposed synonymy. Photos of the type specimens of the taxa synonymized above show no significant difference in size, shape, gestalt, or any other character - but a rather consistent elytral pattern, also linked by intermediate forms. Finally, the aedeagi are identical in shape and structure, including in C. formosanus, well illustrated in Habu [1978], and of males from Cat Tien NP in southern Vietnam, one of the recent records of C. chinensis [Häckel, Kirschenhofer, 2014b].

C. punensis $(=C$. batesi $)$ is defined by the combination of barely shorter elytra (EL/EW 1.53-1.57) and slightly dentate anterior and posterior margins of the anterior macula. A specimen from northwestern Thailand, determined as C. maculatus in Häckel \& Kirschenhofer [2014b], differs from $C$. punensis in nothing else but longer elytra (EL/EW 1.62), transitional between the westernmost and eastern populations of the species.

Häckel [2015] illustrated the lectotype of C. cereus (erroneously called 'HT' [holotype] in the caption) [ibid., Fig. 1]. He downgraded C. austronesiensis Häckel et Kirschenhofer, 2014 to a subspecies of $C$. cereus without comment, perhaps based on the similarity between the two species in body proportions and elytral pattern. However, according to the original description and re-description [Andrewes, 1919] of C. cereus, its BL is ca. $12 \mathrm{~mm}$, vs. $8.8-9.1 \mathrm{~mm}$ in C. austronesiensis - a significant difference for species of the microspilotus-group. I therefore treat C. austronesiensis and C. cereus as separate species until evidence to the contrary has been obtained.

On the other hand, the lectotype of $C$. cereus is quite similar to the holotype ( $(+)$ of $C$. buruensis. The latter was said in the description to be similar to $C$. chinensis and $C$. formosanus while differing in having the elytra clearly shorter, with EL/EW 1.47 vs. 1.58 in C. formosanus. My measurements give EL/EW values 1.51 for $C$. buruensis vs. 1.561.66 for the populations of $C$. chinensis $-C$. formosanus from mainland Southeast Asia; EL/EW ca. 1.53-1.55 is what has been roughly estimated for the unlocked elytra of the lectotype of C. cereus. These differences do not seem sufficient to maintain species status of $C$. cereus s.str. or C. buruensis, unless supported by additional characters. These subtle differences in addition to insular distributions of the two taxa imply hardly more than subspecies status of $C$. cereus s.str. (= C. buruensis).

The status of C. philippinus has to be clarified, but it does not seem to be a distinct species.

DISTRIBUTION. India to Vietnam, South China, South Japan, Java, Buru; probably also the Philippines. Louwerens [1953] reported C. philippinus also from West Flores.

\section{The sapaensis-subgroup (= guttiferus-group) \\ Craspedophorus chaudoiri (Andrewes, 1919), comb.n.}

Andrewes, 1919: 135 (Dischissus), replacement name for Dischissus cereus Chaudoir, 1879: 150 = Panagaeus cereus: Chaudoir, 1869: 116 (Java), non Craspedophorus cereus MacLeay, 1825: 12 (Panagaeus; Java); Andrewes, 1919: 135; Häckel, Farkač, 2012: 84; Häckel, Kirschenhofer, 2014a: 68; Häckel, 2015: 239. — formaster Andrewes, 1936: 216 (Java), syn.n.

MATERIAL. Holotype of Dischissus formaster, ơ (BMNH) labelled: 'W. Java. 6-800 m./ Djampang Tengah/ G. Tjisoeroe 
1933/ IX/ M. E. Walsh misit.' [ts], 'Type' [ts, red], 'Dischissus/ formaster/ Type Andr. [hw]/ H.E. Andrewes det. [ts]', 'H.E. Andrewes Coll./ B.M. 1945-97.' [ts].

Additional material. o (BMNH): 'Lahago/ Central Nias/ 4 II 10 III 1896/ I.Z. Kannegieter'[ts], 'Ex coll. T. Sloane'[ts], 'H.E. Andrewes Coll./ B.M. 1945-97.' [ts]; \& (BMNH): 'Hili Madjedja/ Nord Nias/ Mitschke 4 ${ }^{\text {de }}$-trim.' 95 ' [ts], 'Ex coll. T. Sloane'[ts], 'H.E. Andrewes Coll./ B.M. 1945-97.' [ts]. + (BMNH): 'T. F./ 8.2.85', 'Coll. Kraatz', 'Sumatra', 'Ex Deutsch./Ent. Mus.', 'Dischissus/ Chaudoiri Andr. (from description) [hw]/ H.E. Andrewes det. [ts]', 'Dischissus/ cereus Chd./ nec Macl.' [hw], 'H.E. Andrewes Coll./ B.M. 1945-97.' [ts]; of (BMNH): 'Bihdjei-Medan/ Sumatra/ Dr.C.R.Pfister'[ts], 'Ex coll./ B.H.Klynstra'[ts], 'This might be Dischissus Chaudoiri Andr.' [hw]. 9 (BMNH): deep blue rectangle, 'Brunei/ N.Borneo/ v.d. Poll'[hw], 'Ex coll./ T. Sloane'[ts], 'not Dischissus cereus Chaud.' [hw], 'seems Dischissus/ cereus Chaud. 18.10.71'[hw], 'H.E. Andrewes Coll./ B.M. 1945-97.' [ts].

COMMENTS. The specimen misidentified by Chaudoir [1869] as MacLeay's Panagaeus cereus was the one from Jeakes collection. This specimen is the holotype of $P$. cereus Chaudoir, 1869 and thus of Craspedophorus chaudoiri, photograped in Häckel [2015].

C. chaudoiri is closest to C. alaticollis (Bates, 1892), comb.n., and C. sapaensis (Häckel \& Kirschenhofer, 2014), comb.n. The three have similar body proportions and elytral pattern of rather uneven, oblique narrow bands, with at least some components (strips in each interval) more or less expanded. A distinct yet shallow impressed line between pronotal disc and explanate margins easily separates $C$. chaudoiri from the other two species with their deep grooves.

Based on my examination of the three female specimens determined by H.E. Andrewes as either 'Dischissus chaudoiri' or 'D. cereus Chaudoir', all of them are in fact Craspedophorus hajeki (Häckel et Kirschenhofer, 2014), comb.n., and none fits the description or re-description of the Chaudoir's species. It looks like Andrewes [1919] misinterpreted D. cereus Chaudoir, 1879 and re-described it subsequently under the name $D$. formaster.

DISTRIBUTION. Known from Java, reported here from Sumatra. All the Sumatran records in Andrewes [1933] refer to Craspedophorus hajeki.

Craspedophorus sapaensis (Kirschenhofer, 1994), comb.n.

Kirschenhofer, 1994: 1044 (Dischissus; N-Vietnam: Sapa); 2000: 325, 354; Häckel, Farkač, 2012: 84; Häckel, Kirschenhofer, 2014a: 66 (Craspedophorus); 2014b: 281. — ssp. guangdongensis Häckel et Kirschenhofer, 2014b: 282 (Guangdong prov., China).

MATERIAL. + (SIEE), Vietnam, Binh Phuoc Province, Bu Gia Map National Park, $12^{\circ} 11^{\prime} 37^{\prime \prime} \mathrm{N} / 107^{\circ} 12^{\prime} 21^{\prime \prime} \mathrm{E}, \mathrm{h}=350-540 \mathrm{~m}$, at light, 17.IV.2009, D. Fedorenko leg.; $\sigma^{7}$ (SIEE), Dak Lak Province, Chu Yang Sin Natn. Park, 12 $25^{\prime} 25^{\prime \prime}$ N/ 108 $21^{\prime} 53^{\prime \prime}$ E, Krong Kmar river, upper flow, h=970 m, at light, 15-30.V.2014, D. Fedorenko leg.; $\sigma^{7}$ (SIEE), Phu Tho Province, $\sim 90 \mathrm{~km}$ W of Hanoi, Xuan Son National Park, $21^{\circ} 07^{\prime} 29^{\prime \prime} \mathrm{N} / 104^{\circ} 57^{\prime} 28^{\prime \prime} \mathrm{E}, \mathrm{h}=400 \mathrm{~m}$, at light, 615.VI.2014, D. Fedorenko leg.; 9 (ZISP), mountains $50 \mathrm{~km}$ NE of Thai Nguen, h=300 m, 10.IV.1963, O.N. Kabakov leg. [in Russian]; + (ZISP), Cao Bang Province, Nguen Binh Distr., Quang Thanh vill., 4-13.V.[19]98, N. Orlov leg.; O' (BMNH), Laos, Xieng Khouang [Xiangkhoang], Ban Sai, II.1919, R.V.de Salvazae leg.

COMMENTS. The species was illustrated and defined by sides of the pronotum evenly rounded (more so in the front, less so towards base), with the basal angles projecting as small denticles. Later [Kirschenhofer, 2000], the pronotum was said (in the key to species and in Fig. 46) to be gently sinuate behind. All the six specimens of $C$. sapaensis examined by me from Vietnam and Laos match well the description of this species, but not the redescription. This is true of all characters, including aedeagi and their apical lamellae of two males.

I also failed to find any significant difference between the photographed specimens [Häckel \& Kirschenhofer, 2014] of C. s. sapaensis [ibid., Figs $1 \mathrm{a}-\mathrm{f}$ ] and C. s. guangdongensis [ibid., Figs $1 \mathrm{~g}-\mathrm{h}$ ] in body size or proportions (Tab. 2). When measured using the scale bars, the two photographed specimens of $C$. s. guangdongensis show the same size as the four C. s. sapaensis specimens from Vietnam and Laos [ibid., Figs la-d], contrary to the description. Table 2 also shows that in C. $s$. guangdongensis the pronotum is much less transverse than the description indicates. Finally, EL/EW data (Tab. 2) do not support the claim that $C$. s. guangdongensis is more slender than C. s. sapaensis. Moreover, in the five specimens from Vietnam examined by me the elytra are even slightly longer. This reduces the diagnosis of C. s. guangdongensis to a few quantitative characters that seem questionable, too.

\section{Craspedophorus alaticollis (Bates, 1892), comb. n.} Figs 43, 47, 62-63.

Bates, 1892: 302 (Dischissus; Thagata, Tenasserim, Burma); Häckel, Farkač, 2012: 84. - baehri Kirschenhofer, 2000: 356 (Dischissus; Dawna, Burma); Häckel, Farkač, 2012: 84; Häckel, Kirschenhofer, 2014a: 66, syn.n.

MATERIAL. Holotype $\sigma^{7}$ (MSNG) labelled: 'Tenasserim/ Thagatà/ Fea. Apr. 1887', 'TYPUS', 'alaticollis/ Bates' [hw], 'Dischissus/ alaticollis/ (typus!) Bates' [hw], 'HOLOTYPUS/ Dischissus/ alaticollis/ Bates, 1892' [ts+hw], 'Museo Civico/ di Genova'.

COMMENTS. The description of Dischissus baehri agrees well with the holotype of $D$. alaticollis, therefore we synonymize the two. Redescription is not necessary. Aedeagus as in Figs 43, 47, 62-63.

Table 2. Selected metrics in Craspedophorus s. sapaensis (s) and C. s. guangdongensis (sg). Таблица 2. Некоторые промеры и пропорции у подвидов Craspedophorus s. sapaensis и C. s. guangdongensis (sg).

\begin{tabular}{|c|c|c|c|c|c|c|}
\hline Subspecies & $\mathbf{n}$ & BL, mm & PW/HW & PW/PL & $\mathbf{E W} / \mathbf{P W}$ & EL/EW \\
\hline$S$, original data & 5 & $13.2-14.4$ & $1.60-1.69(1.64)$ & $1.40-1.52(1.45)$ & $1.28-1.39(1.34)$ & $1.55-1.62(1.58)$ \\
\hline$s: \mathrm{H} \& \mathrm{~K}: 282$ & & $13.3-14.5$ & & & & \\
\hline sg: H \& K: 282 & & $12-13$ & 1.61 & 1.62 & 1.43 & \\
\hline$s: \mathrm{H} \& \mathrm{~K}:$ Figs $1 \mathrm{a}-\mathrm{f}$ & 6 & $11.7-13.2$ & $1.60-1.70(1.65)$ & $1.52-1.57(1.54)$ & $1.29-1.36(1.33)$ & $1.52-1.59(1.55)$ \\
\hline$s: \mathrm{H} \& \mathrm{~K}$ : Figs $1 \mathrm{f}-\mathrm{e}$ & 2 & $12.4-13.2$ & 1.70 & $1.52-1.57(1.55)$ & $1.29-1.36(1.33)$ & $1.52-1.59(1.56)$ \\
\hline$s: \mathrm{H} \& \mathrm{~K}$ : Figs $1 \mathrm{a}-\mathrm{d}$ & 4 & $11.7-12.2$ & $1.60-1.67(1.63)$ & $1.52-1.56(1.53)$ & $1.32-1.35(1.34)$ & $1.53-1.57(1.55)$ \\
\hline$s g:$ H \& K: Figs $1 \mathrm{~g}-\mathrm{h}$ & 2 & $11.9-12.3$ & $1.66-1.71(1.69)$ & $1.53-1.55(1.54)$ & $1.33-1.37(1.35)$ & $1.50-1.56(1.53)$ \\
\hline
\end{tabular}

BL is slightly greater in lines 1-3 than in lines 4-7 due to different measurement techniques (direct vs scale bar, respectively); the same is true of PW/PL data in line 1 as compared to the remainder, because of somewhat different orientation of the pronota. $\mathrm{H} \& \mathrm{~K}-\mathrm{Häckel}$ \& Kirschenhofer [2014b]. 
This synonymy means that $D$. alaticollis : Häckel et Kirschenhofer, 2014 (non Bates, 1892) is a different and likely unnamed taxon.

Finally, a brief note on the recently described C. begdugulensis Kirschenhofer, 2011, comb.n. According to the description, it resembles C. guttiferus (Schaum, 1853), comb.n., in most aspects, with BL at 13.9-14.1 and $13.8 \mathrm{~mm}$, respectively, and small elytral maculae in both, the anterior one spanning from lateral margin to interval 7 , the posterior one, just the intervals 6 and 7. The two show similar distribution, C. guttiferus being known from Java and Sumatra [Andrewes, 1933a] and C. begdugulensis, from Bali, just east of Java. It's hard to tell why neither Kirschenhofer [2011a] nor Häckel \& Kirschenhofer [2014a] compared the two species, all the more surprising that Java is indicated as the provenance of two photographed $C$. begdugulensis specimens in the latter paper [ibid., Figs 8a and 8b].

ACKNOWLEDGEMENTS. I am indebted to Dr. Roman Yu. Dudko (SZMN), Dr. Boris M. Kataev (ZISP), Dr. Kirill V. Makarov (MPSU), Dr. Roberto Poggi and Dr. Maria Tavano (MSNG), Dr. Maxwell Barclay and Dr. Beulah Gardner (both BMNH) for the loan of material under their care. I am also very grateful to Dr. Alexei V. Abramov (ZISP), Dr. Alexander E. Anichkin (Yoshkar-Ola), Dr. Sergei V. Saluk (Minsk) and Igor V. Melnik (Moscow) for donating specimens. I also thank Vassili Belov (College Station, TX, USA) for suggestions that have improved the manuscript.

\section{References}

Andrewes H.E. 1919. Notes on the types of Oriental Carabidae in the British Museum, and in the Hope Department of the Oxford University Museum // Trans. Ent. Soc. Lond. P.119-217.

Andrewes H.E. 1921. Notes on synonymy and on some types of Oriental Carabidae in various foreign collections // Trans. Ent. Soc. Lond. P.145-195.

Andrewes H.E. 1922. Notes on the types of Oriental Carabidae in the Stettin Museum // Trans. Ent. Soc. Lond. P.245-250.

Andrewes H.E. 1924. Papers on Oriental Carabidæ.-XIV // Annals and Magazine of Natural History. Ser.9. Vol.14. No.84. P.585593.

Andrewes H.E. 1926. A catalogue of Philippine Carabidae // Philipp. J. Sci. Vol.31. No.3. P.345-361.

Andrewes H.E. 1927. Papers on Oriental Carabidae. - XIX // Ann. Mag. Nat. Hist. Ser.9. Vol.19. P.97-111.

Andrewes H.E. 1933a. A Catalogue of the Carabidae of Sumatra // Tidschr. Entomol. Jg.76. S.319-382.

Andrewes H.E. 1933b. On the types of Oriental Carabidae described by V. de Motchulsky. Pt.2. // Trans. Ent. Soc. Lond. T.81. P.119.

Andrewes H.E. 1946. Entomological results from the Swedish Expedition 1934 to Burma and British India // Arkiv zool. Bd.38A. No.20. P.1-49. Pl.1-6.

Bates H.W. 1873. On the Geodephagous Coleoptera of Japan // Trans. Ent. Soc. Lond. P.219-322.

Bates H.W. 1889. Contributions a la faune Indo-Chinoise. $3^{\mathrm{e}}$ Mémoire. Carabidae // Ann. Soc. Ent. France. $6^{e}$ sér. T.9. P.261-286

Bates H.W. 1890. Viaggio di Leonardo Fea in Birmania e regione vicine. XVI. On some Carabidae from Burma collected by $\mathrm{Mr}$. L. Fea // Ann. Mus. Stor. Nat. Genova. Ser.2. Vol.7. No.27. P. $100-111$.

Bates H.W. 1892. Viaggio di Leonardo Fea in Birmania e regione vicine. XLIV. List of the Carabidae // Ann. Mus. Stor. Nat. Genova. Ser.2. Vol.12. No.32. P.267-428.

Chaudoir M. 1869. Descriptions de Cicindélètes et de Carabiques nouveaux // Rev. Mag. Zool. 2e sér. T.21. P.64-70, 114-122.

Chaudoir M. (1878) 1879. Essai monographique sur les Panagéides // Ann. Soc. Ent. Belg. T.21. P.83-185
Csiki E. 1929. Carabidae. Harpalinae III. Coleopterorum Catalogus. Vol.2. Pt.104. Berlin: W. Junk. P.347-528.

Darlington P.J. 1952. Notes on Brachyonychus Chd. (Coleoptera, Carabidae, Panagaeini) // Psyche. Vol.59. P.126-128.

Fedorenko D.N. 2015. Notes on the genera Dischissus and Microcosmodes (Coleoptera, Carabidae, Panagaeini) from the Oriental Region, with description of a new genus and a new species // Russian Ent. J. Vol.24. No.4. P.271-279.

Gestro R. 1883. Sopra alcuni Coleotteri di Birmania raccolti dal Capitano G.B.Comotto // Ann. Mus. Stor. Nat. Genova. Vol.18. P.297-317.

Habu A. 1961. 1. Family Carabidae. In: Chûjô, M. Coleoptera from Southeast Asia. Nature and life in Southeast Asia, 1. P. 265-300.

Habu A. 1978. On some species of ground beetles from the Ryukyus hitherto unknown or poorlly known to Japan // Ent. Rev. Japan. Vol.32. Nos1/2. P.31-37.

Häckel M. 2015. Notes on Oriental Panagaeini. Craspedophorus cereus (MacLeay, 1825) and Dischissus chaudoiri Andrewes, 1919, and new status of Craspedophorus austronesiensis Häckel et Kirschenhofer, 2014 (Coleoptera: Carabidae) // Studies and Reports. Taxonomical series. Vol.11. No.2. P.237-245.

Häckel M. 2016. Notes on Oriental Panagaeini 2. Craspedophorus saundersi (Chaudoir, 1869) and C. sundaicus (Oberthür, 1883), C. mandarinellus (Bates, 1892), and description of a new species (Coleoptera: Carabidae) // Studies and Reports. Taxonomical series. Vol.12. No.1. P.1-39.

Häckel M., Farkač J. 2012. A check-list of the subfamily Panagaeinae Hope, 1838 of the World (Coleoptera: Carabidae) // Studies and Reports. Taxonomical series. Vol.8. Nos1-2. P.67-116.

Häckel M., Anichtchenko A. 2015. Two new species (Coleoptera: Carabidae: Panagaeini) from the Philippines // Zootaxa. Vol.3955. No.3. P.427-434.

Häckel M., Kirschenhofer E. 2014a. A contribution to knowledge of the subfamily Panagaeinae Hope, 1838 from Asia and Australia. Part 1. Revision of the genus Dischissus Bates, 1873 (Coleoptera: Carabidae) // Studies and Reports. Taxonomical series. Vol.10. No.1. P.51-81

Häckel M., Kirschenhofer E. 2014b. A Contribution to knowledge of the subfamily Panagaeinae Hope, 1838 from Asia. Part 2. East Palearctic and Oriental Species of the genus Craspedophorus Hope, 1838, and the genus Tinoderus Chaudoir, 1879 (Coleoptera: Carabidae)// Studies and Reports. Taxonomical series. Vol.10. No.2. P.275-392.

Jedlička A. 1965. Monographie des tribus Panagaeini aus Ostasien (Coleoptera, Carabidae) // Ann. Zool. Bot. No.12. P.1-15.

Kirschenhofer E. 1996. Weitere neue und wenig bekannte Carabidae aus Süd- und Südostasien (Coleoptera: Carabidae: Lebiinae, Colliurinae, Callistinae, Hexagoninae, Brachininae, Panagaeinae). II. Teil. // Linzer biol. Beitr. Bd.28. H.2. S.757-799.

Kirschenhofer E. 2000. Neue und wenig bekannte Panagaeini der östlichen Paläarktis sowie der Orientalis (Coleoptera, Carabidae) // Entomofauna. Bd.21. H.29. S.321-372.

Kirschenhofer E. 2004. Uber neue Arten und wenig bekannte Carabidae aus der athiopische und orientalische Region (Coleoptera, Carabidae, Chlaenini, Panagaeini) // Entomofauna. Bd.25. H.16. S.261-272.

Kirschenhofer E. 2010. Neue Arten der Gattung Lebia Latreille, 1802, Lachnolebia Maindron, 1905 und Craspedophorus Hope, 1838 aus Asien (Coleoptera: Carabidae) // Mitt. internat. entomol. Ver. Bd.35. H.3/4. S.165-175.

Kirschenhofer E. 2011a. Neue Arten der Gattungen Craspedophorus Hope, 1838, Brachinus Weber, 1801, Trigonotoma Dejean, 1828, faunistische Meldungen der Gattung Chlaenius Bonelli, 1810 aus der Orientalis (Coleoptera, Carabidae) // Acta Coleopterologica. Vol.27. No.1. P.38-60.

Kirschenhofer E. 2011b. Beschreibungen neuer truncatipenner Carabiden aus Ost- und Südostasien; eine neue Art der Gattung Craspedophorus Hope, 1838 (Panagaeini) aus Südostasien; Bemerkungen zu zwei japanischen Arten der Gattung Parena Mostschulsky, 1859 (Coleoptera, Carabidae) // Acta Coleopterologica. Vol.27. No.1. P.61-75.

Kirschenhofer E. 2012a. Neue afrotropische and orientalische Carabiden-Arten der Gattungen Chlaenius Bonelli, 1810, Brachinus 
Weber, 1801, Craspedophorus Hope, 1838, Paracallistoides Basilewsky, 1965 und Setolebia Jedlička, 1941 (Coleoptera: Carabidae) // Mitt. internat. entomol. Ver. Bd.37. H.1/2. S.1-19.

Kirschenhofer E. 2012b. Neue Arten der Gattungen Brachinus Weber, 1801, Coptodera Dejean, 1825, Dolichoctis SchmidtGöbel, 1846, Lebia Latreille, 1802, Formosiella Jedlička, 1951 , Scalidion Schmidt-Göbel, 1846 und Craspedophorus Hope, 1838 aus Asien (Coleoptera: Carabidae) // Mitt. internat. entomol. Ver. Bd.37. H.4. S.199-234.

Lorenz W. 1998. Systematic list of extant ground beetles of the world (Insecta Coleoptera "Geadephaga": Trachypachidae and Carabidae incl. Paussinae, Cicindelinae, Rhysodinae). 1st ed. Tutzing. $502 \mathrm{pp}$.
Louwerens C.J. 1953. Carabidae (Col.) from the Sunda Islands // Verhandl. Naturf. Ges. Basel. Bd.64. No.2. S.305-325.

MacLeay W.S. 1825. Annulosa Javanica, or, An attempt ... London. P. I-XII, $1-50$.

Pang Jian-mei, Tian Ming-yi. 2012. One new species of the genus Craspedophorus Hope, 1838 (Coleoptera: Carabidae: Panagaeini) from Jianfengling Nature Reserve of Hainan Province // J. South China Agric. Univ. Vol.33. No.2. P.264-265, 269.

Schaum 1853. Quelques observations sur le groupe des Panagéites, et description de sept nouvelles espèces // Ann. Soc. Ent. France. $3^{\text {e }}$ sér. T. 1. P. 429-441.

Schaum 1863. Beitträge zur Kenntniss einiger Carabicinen-Gattungen // Berlin. Ent. Zeitschr. Jg.7. S.61-92. 